\title{
Solid-State Synthesis, Characterization, UV-Induced Coloration and Photocatalytic Activity - The Sr6Bi2O11, Sr3Bi2O6 and Sr2Bi2O5 Bismuthates
}

D.S. Shtarev, ${ }^{1,2, a}$ A.V. Shtareva, ${ }^{1, b}$ V.K. Ryabchuk, ${ }^{3, c}$ A.V. Rudakova, ${ }^{3, d}$ P.D. Murzin, ${ }^{3, e}$ M.S. Molokeev, ${ }^{2,4,5, f}$ A.V. Koroleva, ${ }^{3, g}$ A.I. Blokh, ${ }^{2, h}$ and Nick Serpone ${ }^{6, i} *$

${ }^{1}$ Yu. A. Kosygin Institute of Tectonics and Geophysics, Far Eastern branch of the Russian Academy of Sciences, 65 Kim Yu Chen Street, Khabarovsk, 680063 Russian Federation; emails: shtarev@ mail.ru, and avshtareva@mail.ru

2 Far Eastern State Transport University, 47 Seryshev Street, Khabarovsk, 680021 Russian Federation; emails: msmolokeev@mail.ru and blokh@ rambler.ru

3 St. Petersburg State University, Ulianovskaya 2, Petergof, Saint-Petersburg, 198904 Russian Federation; emails: v.ryabchuk@spbu.ru ; arudakova@mail.ru ; p.d.murzin@gmail.com and $^{\mathrm{g}}$-dalika@inbox.ru

4 Kirensky Institute of Physics, Akademgorodok 50, bld. 38, Krasnoyarsk, 660036 Russian Federation.

5 Siberian Federal University, 79 Svobodny pr., 660041 Krasnoyarsk, Russian Federation.

${ }^{6}$ PhotoGreen Laboratory, Dipartimento di Chimica, Universita di Pavia, via Taramelli 12, Pavia 27100, Italia; email: nick.serpone@unipv.it

\begin{abstract}
This article reports on two novel visible-light-active strontium bismuthate photocatalysts $\left(\mathrm{Sr}_{6} \mathrm{Bi}_{2} \mathrm{O}_{11}\right.$ and $\left.\mathrm{Sr}_{3} \mathrm{Bi}_{2} \mathrm{O}_{6}\right)$ prepared by solid-state synthesis for which the number of strontium atoms exceeded the number of bismuth atoms in the cation sublattice; for comparison, the bismuthate $\mathrm{Sr}_{2} \mathrm{Bi}_{2} \mathrm{O}_{5}$ was also re-examined. All three bismuthates were characterized by a variety of spectroscopic techniques (XRD, XPS, EDX, DR, Raman, SEM, and EIS). Both newly as-synthesized bismuthates displayed photocatalytic activity toward the photodegradation of substrates in the gas phase (acetaldehyde) and in aqueous media (phenol), with the $\mathrm{Sr}_{6} \mathrm{Bi}_{2} \mathrm{O}_{11}$ phase exhibiting a significantly greater photoactivity than the $\mathrm{Sr}_{3} \mathrm{Bi}_{2} \mathrm{O}_{6}$ phase; by comparison, the bismuthate $\mathrm{Sr}_{2} \mathrm{Bi}_{2} \mathrm{O}_{5}$ was photocatalytically inactive. Detailed photocatalytic mechanisms have been proposed to explain how composition and structure of the three bismuthates affect their photocatalytic activity. The role of point defects in their crystal lattice is described for processes in which the photocatalytic activity was inhibited. Inferences made were aided by examining the UV-induced coloration of these ternary metal oxides that provided information regarding defect levels within their respective bandgaps; such defects acted as electron traps and thus affected the photocatalytic performance of the bismuthates.
\end{abstract}

Keywords: visible-light-active photocatalysts; strontium bismuthates; photocatalytic activity; UVinduced photocoloration;

* Corresponding author: nick.serpone@unipv.it 


\section{Introduction}

Development of new solid-state visible-light-active (VLA) photocatalytic materials has been one of the main streams in the field of Heterogeneous Photocatalysis in the last two decades [1, 2]. Two basic approaches have been followed in producing VLA photocatalysts: (i) modification of well-known photocatalysts such as $\mathrm{TiO}_{2}$ and $\mathrm{ZnO}$, among others, by dye sensitization, metal and nonmetal doping, creation of heterostructural composites, containing titania and zinc components including prompting of using Z-schemes [3-5]; and (ii) search for novel semiconductor materials including complex metal oxides and non-oxide solids together with their composites [6-10]. The group of novel photoactive materials includes Bi-containing photocatalysts and photocatalytic composites $[1,11]$.

The bandgap energies $\left(\mathrm{E}_{\mathrm{g}}\right)$ of various bismuthates range from 2 to $3 \mathrm{eV}$; as such, band-to-band photoexcitation of these solids corresponds to the considerable involvement of part of the visible light spectral region. For instance, $\mathrm{E}_{\mathrm{g}} \mathrm{s}$ are practically equal $(2.5-2.7 \mathrm{eV})$ for the complex ternary metal oxides $\mathrm{Bi}_{4} \mathrm{Ti}_{3} \mathrm{O}_{12}, \mathrm{Bi}_{2} \mathrm{WO}_{6}, \mathrm{BiVO}_{4}$, and $\mathrm{Bi}_{2} \mathrm{MoO}_{6}$, and reduces from 3.6 to $1.8 \mathrm{eV}$ in the precursor systems $\mathrm{BiOX}(\mathrm{X}=\mathrm{F}, \mathrm{Cl}, \mathrm{Br}, \mathrm{I})$ and changes irregularly (range, $2.6-1.8 \mathrm{eV}$ ) for the $\mathrm{MBiO}_{3}(\mathrm{M}=\mathrm{Li}$, $\mathrm{K}, \mathrm{Na}, \mathrm{Ag}$ ) ternary systems. Accordingly, the positions of the conduction and valence bands for many bismuthates are favorable for an exothermic redox reaction behavior ([11] and refs. therein). Thus, it is evident that the basic parameters (bandgap energy $2.0<\mathrm{E}_{\mathrm{g}}<3.0 \mathrm{eV}$ ) and positions of the conduction and valence bands for good photocatalysts can be satisfied for a wide variety of Bi-based compounds with different chemical formulas, crystalline structures and other different physical and chemical properties. In turn, this solicits for the search of novel Bi-based photocatalysts.

The aim of this article was the synthesis of $\mathrm{Sr}_{2} \mathrm{Bi}_{2} \mathrm{O}_{5}, \mathrm{Sr}_{3} \mathrm{Bi}_{2} \mathrm{O}_{6}$, and $\mathrm{Sr}_{6} \mathrm{Bi}_{2} \mathrm{O}_{11}$ and concomitant studies of their optical, structural, and photocatalytic properties. Calcium and strontium containing bismuthates may be considered a priori as promising photocatalysts, particularly for both Cacontaining [12-16] and Sr-containing [17-22] bismuthates. The ternary systems $\mathrm{Sr}_{2} \mathrm{Bi}_{2} \mathrm{O}_{5}, \mathrm{Sr}_{3} \mathrm{Bi}_{2} \mathrm{O}_{6}$, and $\mathrm{Sr}_{6} \mathrm{Bi}_{2} \mathrm{O}_{11}$ were chosen for detailed studies for several reasons. Shtarev and coworkers [23] showed earlier that the potential of the bottom of the conduction band of strontium bismuthates can be determined from the ratio between the number of bismuth and strontium atoms in the cation sublattice. In that case, the most promising compositions were those in which the number of strontium atoms in the cationic sublattices is equal to or exceeds the number of bismuth atoms. Judging from the phase diagram of Figure 1 [24] below, such compositions include the strontium bismuthates $\mathrm{Sr}_{2} \mathrm{Bi}_{2} \mathrm{O}_{5}$, $\mathrm{Sr}_{3} \mathrm{Bi}_{2} \mathrm{O}_{6}$, and $\mathrm{Sr}_{6} \mathrm{Bi}_{2} \mathrm{O}_{11}$. However, only one of these (namely, $\mathrm{Sr}_{2} \mathrm{Bi}_{2} \mathrm{O}_{5}$ ) has been investigated earlier as a photocatalyst $[19,20]$. Consequently, it was relevant to also investigate the nature and 
photocatalytic properties of the two ternary systems $\mathrm{Sr}_{3} \mathrm{Bi}_{2} \mathrm{O}_{6}$, and $\mathrm{Sr}_{6} \mathrm{Bi}_{2} \mathrm{O}_{11}$, heretofore not studied earlier as possible photocatalysts.

\section{Experimental}

\subsection{Synthesis of strontium bismuthates}

As result of synthesis, the strontium bismuthate phases are expected to be $\mathrm{Sr}_{2} \mathrm{Bi}_{2} \mathrm{O}_{5}, \mathrm{Sr}_{3} \mathrm{Bi}_{2} \mathrm{O}_{6}$ and $\mathrm{Sr}_{6} \mathrm{Bi}_{2} \mathrm{O}_{11}$, that corresponds to $\mathrm{SrO}$ content of 50,60 and 75 at.\% in the cation sublattice of obtained samples, respectively (red solid circles in Figure 1). Polycrystalline strontium bismuthate samples $\left(\mathrm{Sr}_{2} \mathrm{Bi}_{2} \mathrm{O}_{5}, \mathrm{Sr}_{3} \mathrm{Bi}_{2} \mathrm{O}_{6}\right.$, and $\left.\mathrm{Sr}_{6} \mathrm{Bi}_{2} \mathrm{O}_{11}\right)$ were prepared by a thorough mixing of starting materials, strontium nitrate $\mathrm{Sr}\left(\mathrm{NO}_{3}\right)_{2}\left(99.5 \%\right.$ or better; ACROS Chemicals) and bismuth oxide $\mathrm{Bi}_{2} \mathrm{O}_{3}(99.5 \%$ or better; ACROS Chemicals) in stoichiometric proportions in an agate mortar for $40 \mathrm{~min}$. in the presence of ethanol (puriss. p.a., absolute, $\geq 99.8 \%$ (GC), Vekton). Subsequently, the resulting mixtures were subjected to a two-stage heating procedure. In the first stage $\left(650{ }^{\circ} \mathrm{C}\right.$ for $24 \mathrm{hrs}$ in air), strontium nitrate was converted into strontium oxide, whereas in the second stage (higher temperature for 72 hrs in air), a solid-state reaction occurred that led to the formation of the strontium bismuthates. Synthesis conditions are detailed in Table 1.

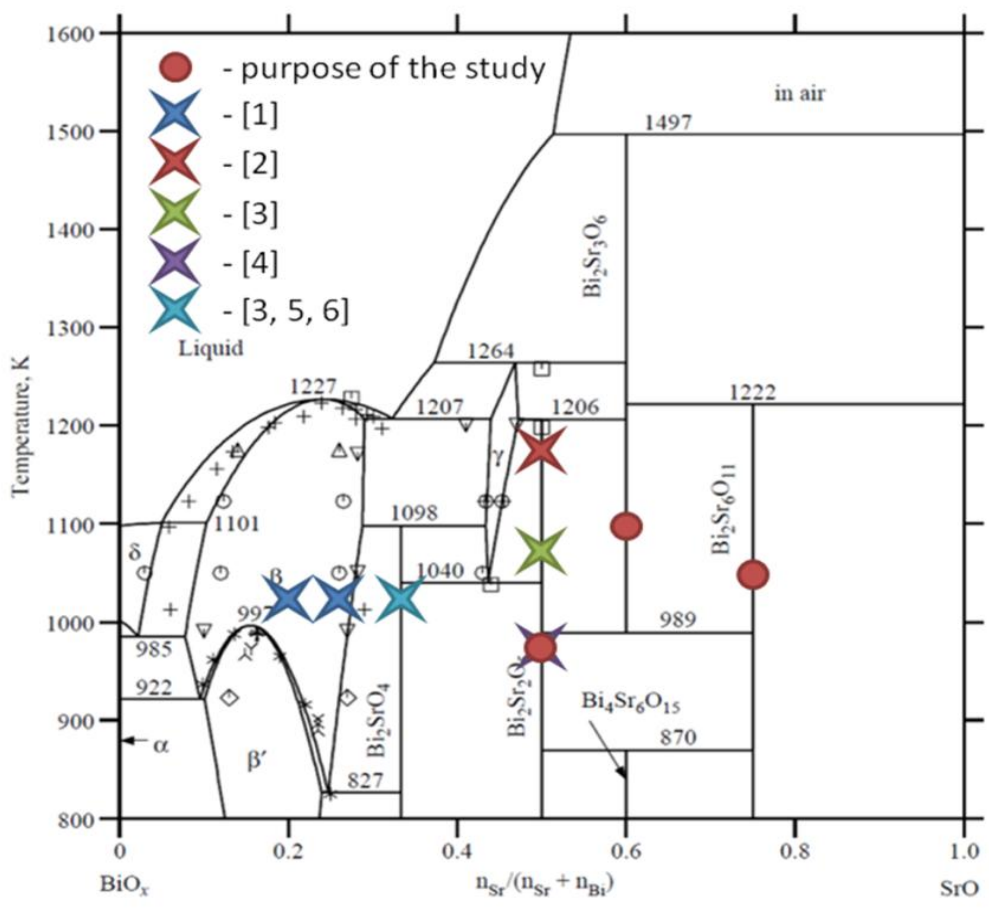

Figure 1. Phase diagram of strontium bismuthates [24]. Colored markers represent the strontium bismuthates that are known photocatalysts. Red solid circles denote the bismuthates examined in this study. 
Interestingly, the as-prepared strontium bismuthate samples of different composition display different colors: dirty-yellow for $\mathrm{Sr}_{2} \mathrm{Bi}_{2} \mathrm{O}_{5}$, beige for $\mathrm{Sr}_{3} \mathrm{Bi}_{2} \mathrm{O}_{6}$, and khaki-colored for $\mathrm{Sr}_{6} \mathrm{Bi}_{2} \mathrm{O}_{11}$ as illustrated in Figure S1 (see Supplementary Information).

Table 1. Synthesis conditions in the preparation of the strontium bismuthates

\begin{tabular}{|c|c|c|c|c|}
\hline \multirow{2}{*}{$\begin{array}{c}\text { Expected strontium } \\
\text { bismuthate phase } \\
\text { (SrO content, \%) }\end{array}$} & \multicolumn{2}{|c|}{$\begin{array}{c}\text { Content of starting materials, } \\
\text { (mols) }\end{array}$} & \multicolumn{2}{|c|}{$\begin{array}{c}\text { Synthesis temperature, } \\
\left({ }^{\mathbf{0}} \mathrm{C}\right)\end{array}$} \\
\cline { 2 - 5 } & $\mathrm{Sr}\left(\mathrm{NO}_{3}\right)_{2}$ & $\mathrm{Bi}_{2} \mathrm{O}_{3}$ & $\begin{array}{c}\mathbf{1}^{\text {st }} \text { stage } \\
(2 \mathrm{hrs})\end{array}$ & $\begin{array}{c}2^{\text {nd }} \text { stage } \\
(72 \mathrm{hrs})\end{array}$ \\
\hline $\mathrm{Sr}_{2} \mathrm{Bi}_{2} \mathrm{O}_{5}(50)$ & 1.50 & 0.75 & 650 & 700 \\
\hline $\mathrm{Sr}_{3} \mathrm{Bi}_{2} \mathrm{O}_{6}(60)$ & 1.50 & 0.50 & 650 & 825 \\
\hline $\mathrm{Sr}_{6} \mathrm{Bi}_{2} \mathrm{O}_{11}(75)$ & 1.50 & 0.25 & 650 & 775 \\
\hline
\end{tabular}

\subsection{Material characterization}

The X-Ray Diffraction (XRD) method was used to analyze which strontium bismuthate phase formed in the solid-state synthesis employing a Rigaku Ultima IV diffractometer (Japan) with CuKa radiation $(\lambda=1.5406 \AA)$ in the range of $10 \mathrm{deg} . \leq 2 \theta \leq 80 \mathrm{deg}$. at a scanning speed of $2 \mathrm{deg} \cdot \mathrm{min}^{-1}$. Structural data of the strontium bismuthate phases were obtained from the PDF-2 database, whereas the phase identification of the as-synthesized samples was carried out using the «Search Match!» software package.

The morphologies of the samples were ascertained by scanning electron microscopy (SEM, TESCAN, Czech Republic; acceleration voltage was $20 \mathrm{kV}$ ). The distribution and mapping of the elements in the samples were established by Energy Dispersive X-Ray Spectroscopy (EDX, X-Max ${ }^{\mathrm{N}}$, Oxford Instruments, UK).

Raman spectra of the samples under examination were recorded in the $80-1500 \mathrm{~cm}^{-1}$ spectral region at ambient temperature using a SENTERRA Raman spectrometer (Bruker) with a resolution of 2 $\mathrm{cm}^{-1}$ (excitation laser wavelength was $785 \mathrm{~nm}$; laser beam power was $1 \mathrm{~mW}$ ).

The specific surface area of all strontium bismuthate samples pretreated at $350{ }^{\circ} \mathrm{C}$ for $6 \mathrm{hrs}$ was measured by the BET method using the Quadrasorb SI surface area analyzer.

Electrochemical impedance spectroscopy (EIS) was applied to study the electrophysical properties of the as-synthesized samples. A NOVOCONTROL BDS dielectric spectrometer was used for precision measurements of the complex conductivity over a wide frequency range $(0.01 \mathrm{~Hz}$ to 40 
$\mathrm{MHz})$ and temperature $\left(-100{ }^{\circ} \mathrm{C}\right.$ to $\left.+300{ }^{\circ} \mathrm{C}\right)$. The powdered samples were pressed into self-supported pellets of $8.9 \mathrm{~mm}$ diameter and $1.2 \mathrm{~mm}$ thickness.

The elemental composition and the valence band position for all the studied samples were determined by means of X-ray photoelectron spectroscopy (XPS); XPS spectra were recorded using a Thermo Fisher Scientific Escalab 250Xi spectrometer with Al Ka radiation (1486.6 eV) and spectral resolution of $0.5 \mathrm{eV}$. The reference carbon line $\mathrm{C}_{\mathrm{ls}}(\mathrm{C}-\mathrm{C}$ bond) had an energy position of $284.8 \mathrm{eV}$ [25].

Diffuse reflectance spectra $\mathrm{R}(\lambda)$ and absorbance spectra $\{\mathrm{A}(\lambda)=1-\mathrm{R}(\lambda)\}$ were recorded in the 250-1200 nm spectral range at ambient conditions using a Cary $5000 \mathrm{UV} / \mathrm{vis} / \mathrm{NIR}$ spectrophotometer equipped with a DRA 2500 external diffuse reflectance accessory. Optical-grade $\mathrm{BaSO}_{4}$ was the reference standard. To investigate the UV-induced photocoloration, the solid samples were placed into home-made aluminum sample holders (diameter, $15 \mathrm{~mm}$; depth, $3 \mathrm{~mm}$ ) covered with a quartz window and irradiated in the spectral region 250-400 nm with a 120-W high-pressure Hg lamp (DRK-120; MELZ, Russia) and a UFS-2 bandpath filter (LOMO, Russia). In the spectral region of 250-400 nm, most of the light irradiance $\left(15 \mathrm{~mW} \mathrm{~cm}{ }^{-2}\right.$; NOVA 2 radiometer) originated with the $365-\mathrm{nm}$ mercury line.

\subsection{Photocatalytic activity of the as-prepared strontium bismuthates}

\subsubsection{Gas-phase photocatalytic test}

The photocatalytic activity of the as-synthesized materials was evaluated in the gaseous phase using the decomposition of acetaldehyde as the test process and test substrate when the photocatalyst/ $\mathrm{CH}_{3} \mathrm{CHO}$ mixture was exposed to irradiation. The basis for gas-phase testing was the ISO 22197-2 standard "Test method for air-purification performance of semiconducting photocatalytic materials, removal of acetaldehyde" [26]. Samples were pressed into self-supported pellets of $46 \times 70 \mathrm{~mm}$ size and of $0.5 \mathrm{~mm}$ thickness and placed into a special compartment. Samples in this compartment were pre-activated at $150{ }^{\circ} \mathrm{C}$ for $16 \mathrm{hrs}$ and then placed in the flow reactor. According to test conditions, the total gas flow rate was set at $0.18 \mathrm{~L} \mathrm{~min}^{-1}$ (normal conditions) with the acetaldehyde concentration and the moisture content in the gas flow being $5 \mathrm{ppm}$ and $50 \%$, respectively. The gas mixture of acetaldehyde in nitrogen (Linde Gas Rus, JSC) had an initial concentration of $1536 \mathrm{ppm}$.

Initial (before irradiation of the sample) and operating (during and after irradiation of the sample) acetaldehyde concentrations in the flow were determined by GC analysis using a Model 8610C gas chromatograph with flame ionization detector (SRI Instruments); pre-irradiation period and irradiation period were $1 \mathrm{hr}$ and $2 \mathrm{hrs}$, respectively. The light source for irradiating the sample was a 150-W Xe 
lamp (OSRAM); a cutoff optical filter was installed to remove wavelengths below $300 \mathrm{~nm}$; light irradiance was $3 \mathrm{~mW} \mathrm{~cm} \mathrm{~cm}^{-2}$.

According to the ISO test, the value of the photocatalytic activity $(r)$ was taken as a relative alteration of the acetaldehyde concentration during and after the reaction (in $\mu \mathrm{mol})$ - eqn (1):

$$
r=\frac{C_{h v}-C_{\text {dark }}}{C_{\text {dark }}} \cdot f \cdot C_{\text {dark }} \cdot \frac{1.016 \cdot 60}{22.4}
$$

where $C_{h v}$ is the average acetaldehyde concentration during the last hour of the photodegradation reaction in $\mu \mathrm{L} \mathrm{L}^{-1} ; C_{d a r k}$ denotes the average acetaldehyde concentration in the dark after termination of the photodegradation reaction (in $\mu \mathrm{L} \mathrm{L}^{-1}$ ); and $f$ represents the flow rate in $\mathrm{L} \mathrm{min}^{-1}$ (normal conditions).

\subsubsection{Liquid-phase photocatalytic test}

The photocatalytic activity of the as-synthesized materials was evaluated in liquid phase by the decomposition of phenol in a batch reactor with lateral quartz window subjected to UV irradiation under ambient conditions. Prior to irradiation, the aqueous suspension of strontium bismuthates $(1.0 \mathrm{~g}$ $\left.\mathrm{L}^{-1} ; \mathrm{pH}, 7.0 ; 300 \mathrm{~mL}\right)$ was pretreated in an ultrasonic processor for $10 \mathrm{~min}$, after which the phenol (100 ppm; purity, $99.5 \%$; Aldrich) was added to the suspension and then magnetically stirred for $1 \mathrm{hr}$ in the dark to reach adsorption/desorption equilibrium. The initial phenol concentration used corresponded to the concentration range where the photoreaction rate is concentration-independent at certain light irradiances. The light source for sample irradiation was a 150-W Xe lamp (OSRAM); an optical cutoff filter was installed to remove wavelengths below $300 \mathrm{~nm}$; light irradiance was $7 \mathrm{~mW} \mathrm{~cm}{ }^{-2}$.

At given intervals, aliquot samples were collected and filtered through a $0.2 \mu \mathrm{m}$ Minisart filter to remove solid particles before the HPLC analysis of the phenol concentration using a 1260 Infinity chromatograph with a UV-Vis detector and a C18 column (Agilent Technologies). The mobile phase was a mixture of methanol/water at a volume ratio of 50:50; the detection wavelength was $210 \mathrm{~nm}$ with a bandwidth of $4 \mathrm{~nm}$. Evaluation of the photocatalytic activity of the samples was determined by estimating the rate of phenol photodegradation using the kinetic approximation (eqns (2) and (3)):

$$
C(t)=C_{0} \cdot \exp (-k t)
$$

and

$$
d C / d C_{(t \rightarrow 0)}=-k C_{0}
$$


where $k$ is an apparent quasi-first-order rate constant.

To clarify the mechanism of the phenol photodegradation reaction, we examined the effect of selected radical scavengers on the reaction rate. The following scavengers were chosen: isopropanol (IPA, HPLC grade, > $99.9 \%$, Panreac) as a hydroxyl radical ( $\left.{ }^{\circ} \mathrm{OH}\right)$ scavenger, p-benzoquinone (p-BQ, $>98 \%$, Sigma-Aldrich) as a superoxide radical anion $\left(\mathrm{O}_{2}^{-{ }^{-}}\right)$scavenger and ammonium oxalate (AO, synthesized from oxalic acid and ammonium hydroxide) as a hole $\left(\mathrm{h}^{+}\right)$scavenger. Initial phenol concentration and catalyst loading were $100 \mathrm{ppm}$ and $1.0 \mathrm{~g} \mathrm{~L}^{-1}$, respectively. The concentrations of the radical scavengers were $0.20 \mathrm{mM}$ [27]; light irradiance was $1 \mathrm{~mW} \mathrm{~cm}^{-2}$.

In the presence of scavengers, the photocatalytic activity (A) of the samples examined was evaluated as the relative alteration of phenol concentration during the reaction period (eqn (4)):

$$
A=\left(C_{0}-C_{8.5}\right) / C_{0}
$$

where $C_{0}$ is the initial phenol concentration (ppm) and $C_{8.5}$ denotes the phenol concentration (ppm) after the reaction (reaction time of $8.5 \mathrm{hrs}$ ).

\section{Results}

\subsection{XRD, SEM and EDX characterization}

XRD patterns of the three as-synthesized strontium bismuthate samples are illustrated in Figure 2, which demonstrates that the samples correspond to the $\mathrm{Sr}_{2} \mathrm{Bi}_{2} \mathrm{O}_{5}, \mathrm{Sr}_{3} \mathrm{Bi}_{2} \mathrm{O}_{6}$, and $\mathrm{Sr}_{6} \mathrm{Bi}_{2} \mathrm{O}_{11}$ phases [28-30]. Moreover, the synthesis conditions of Table 1 were suitable in obtaining highly crystalline homogeneous phases of strontium bismuthates with $\mathrm{SrO}$ content greater than 50 at.\% in the cation sublattice. Cell parameters of the as-prepared samples are listed in Table 2. All strontium bismuthate samples pretreated at $350{ }^{\circ} \mathrm{C}$ for $6 \mathrm{hrs}$ possessed comparable and relatively small specific surface areas (Table 2), which accord with low surface areas of compounds typically synthesized by solid-state reactions. This allows us to compare the photocatalytic activities for the same quantity of the three bismuthates used in photocatalytic tests. 


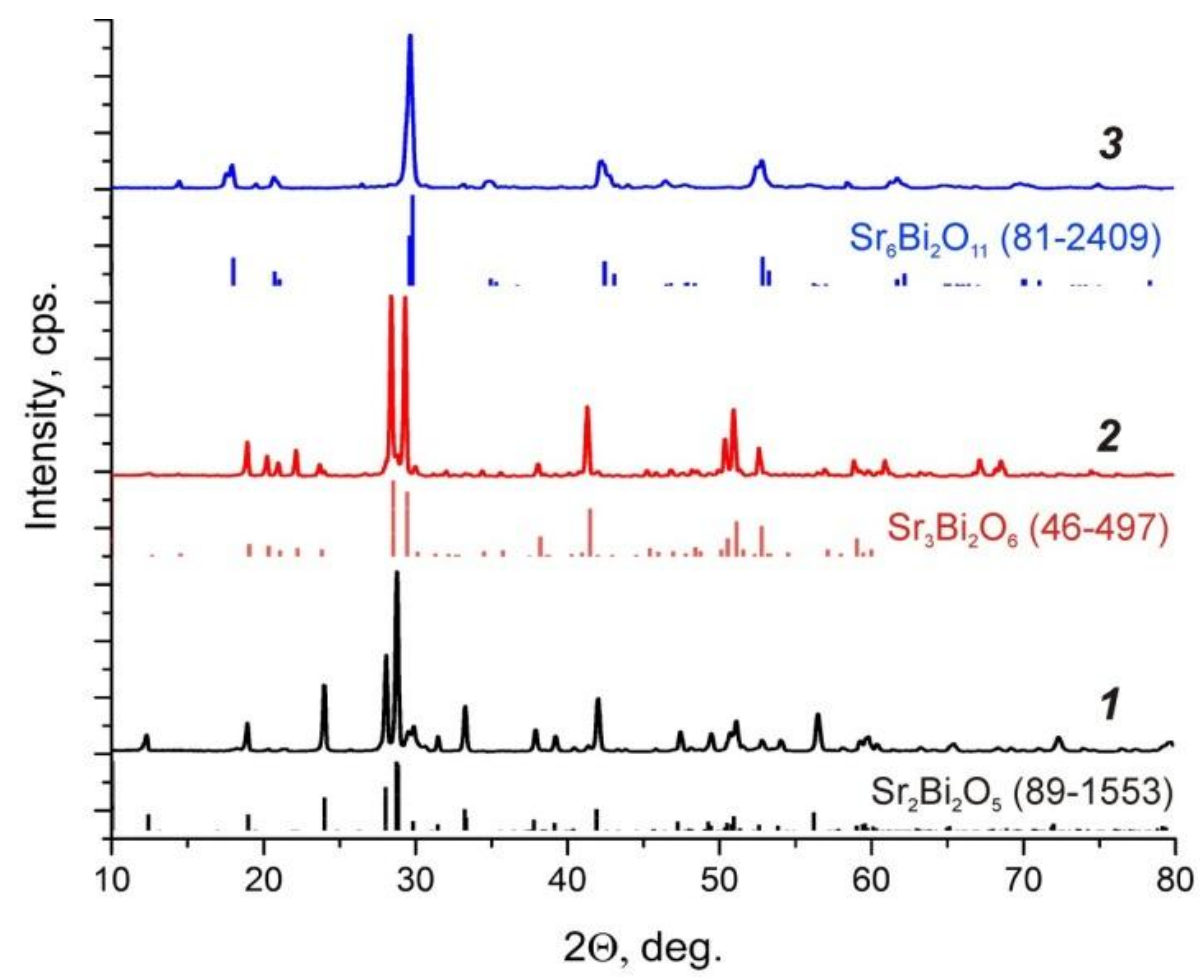

Figure 2. X-Ray Diffraction (XRD) patterns of synthesized strontium bismuthates: (1) $\mathrm{Sr}_{2} \mathrm{Bi}_{2} \mathrm{O}_{5},(2) \mathrm{Sr}_{3} \mathrm{Bi}_{2} \mathrm{O}_{6}$, and (3) $\mathrm{Sr}_{6} \mathrm{Bi}_{2} \mathrm{O}_{11}$. XRD results identified $\mathrm{Sr}_{2} \mathrm{Bi}_{2} \mathrm{O}_{5}$ (PDF 89-1553), $\mathrm{Sr}_{3} \mathrm{Bi}_{2} \mathrm{O}_{6}$ (PDF 46-497), and $\mathrm{Sr}_{6} \mathrm{Bi}_{2} \mathrm{O}_{11}$ (PDF 812409) phases as presented.

Table 2. Cell parameters and specific surface area of the as-prepared strontium bismuthates.

\begin{tabular}{|r|c|c|c|}
\hline \multicolumn{1}{|c|}{ Parameter } & \multicolumn{3}{|c|}{ Sample } \\
\hline Phase & $\mathrm{Sr}_{2} \mathrm{Bi}_{2} \mathrm{O}_{5}$ & $\mathrm{Sr}_{3} \mathrm{Bi}_{2} \mathrm{O}_{6}$ & $\mathrm{Sr}_{6} \mathrm{Bi}_{2} \mathrm{O}_{11}$ \\
\hline Crystal lattice & $\begin{array}{c}\text { Base-centered } \\
\text { orthorhombic }\end{array}$ & $\begin{array}{c}\text { Rhombohedrally-centered } \\
\text { trigonal }\end{array}$ & $\begin{array}{c}\text { body-centered } \\
\text { tetragonal }\end{array}$ \\
\hline Space group & Cmcm & $R 3 m$ & $I 4 / m m m$ \\
\hline Cell parameters, $\AA$ & 3.8261 & 12.526 & $6.0058(3)$ \\
$\mathrm{b}, \AA$ & - & 18.331 & - \\
$\mathrm{c}, \AA$ & 14.3066 & 2490.82 & $8.3718(5)$ \\
\hline${\text { Cell volume, } \AA^{3}}_{\mathrm{S}_{\mathrm{BET}}, \mathrm{m}^{2} \mathrm{~g}^{-1}}^{6.1715}$ & 337.82 & 1.11 & 301.97 \\
\hline
\end{tabular}

All as-synthesized strontium bismuthates adopted the crystal lattice of the «coordinate+graded» translational type. The $\mathrm{Sr}_{2} \mathrm{Bi}_{2} \mathrm{O}_{5}$ sample possesses the crystal lattice of the non-symmetric space group belonging to the lower symmetry class $m m m$, while the $\mathrm{Sr}_{3} \mathrm{Bi}_{2} \mathrm{O}_{6}$ sample adopted the crystal lattice of the symmorphic space group that belongs to the middle class $3 m$ syngony. Just like the sample $\mathrm{Sr}_{3} \mathrm{Bi}_{2} \mathrm{O}_{6}$, the $\mathrm{Sr}_{6} \mathrm{Bi}_{2} \mathrm{O}_{11}$ sample adopted the crystal lattice of the symmophoric space group. The 
relevant spatial diagrams for all strontium bismuthates examined herein are reported in Figure S2, which shows that the samples $\mathrm{Sr}_{2} \mathrm{Bi}_{2} \mathrm{O}_{5}$ and $\mathrm{Sr}_{6} \mathrm{Bi}_{2} \mathrm{O}_{11}$ are characterized by a similar atoms packing in the crystal lattice and the orientation of the crystal lattice in space, whereas $\operatorname{Sr}_{3} \mathrm{Bi}_{2} \mathrm{O}_{6}$ differs significantly from them. This explains why the unit cell volume of $\mathrm{Sr}_{3} \mathrm{Bi}_{2} \mathrm{O}_{6}$ is many times greater than those of $\mathrm{Sr}_{2} \mathrm{Bi}_{2} \mathrm{O}_{5}$ and $\mathrm{Sr}_{3} \mathrm{Bi}_{2} \mathrm{O}_{6}$.

Figure 3 presents the images of the strontium bismuthate synthesized particles obtained by scanning electron microscopy (SEM), which show that the particles composition defines not only their crystal structures but also the peculiarities of the surface morphology. Evidently, particles of the $\mathrm{Sr}_{2} \mathrm{Bi}_{2} \mathrm{O}_{5}$ and $\mathrm{Sr}_{6} \mathrm{Bi}_{2} \mathrm{O}_{11}$ phases (Figures 3a and $3 \mathbf{b}$ ) show similar aspects: sizes of the particles are several tens of microns without visible pores or other features that may increase the specific surface area. Although $\mathrm{Sr}_{3} \mathrm{Bi}_{2} \mathrm{O}_{6}$ particles are of similar sizes (i.e., several tens of micrometers), they do display voids and pores on the surface (Figure 3c) that explain the slightly greater specific surface area in comparison to the others.
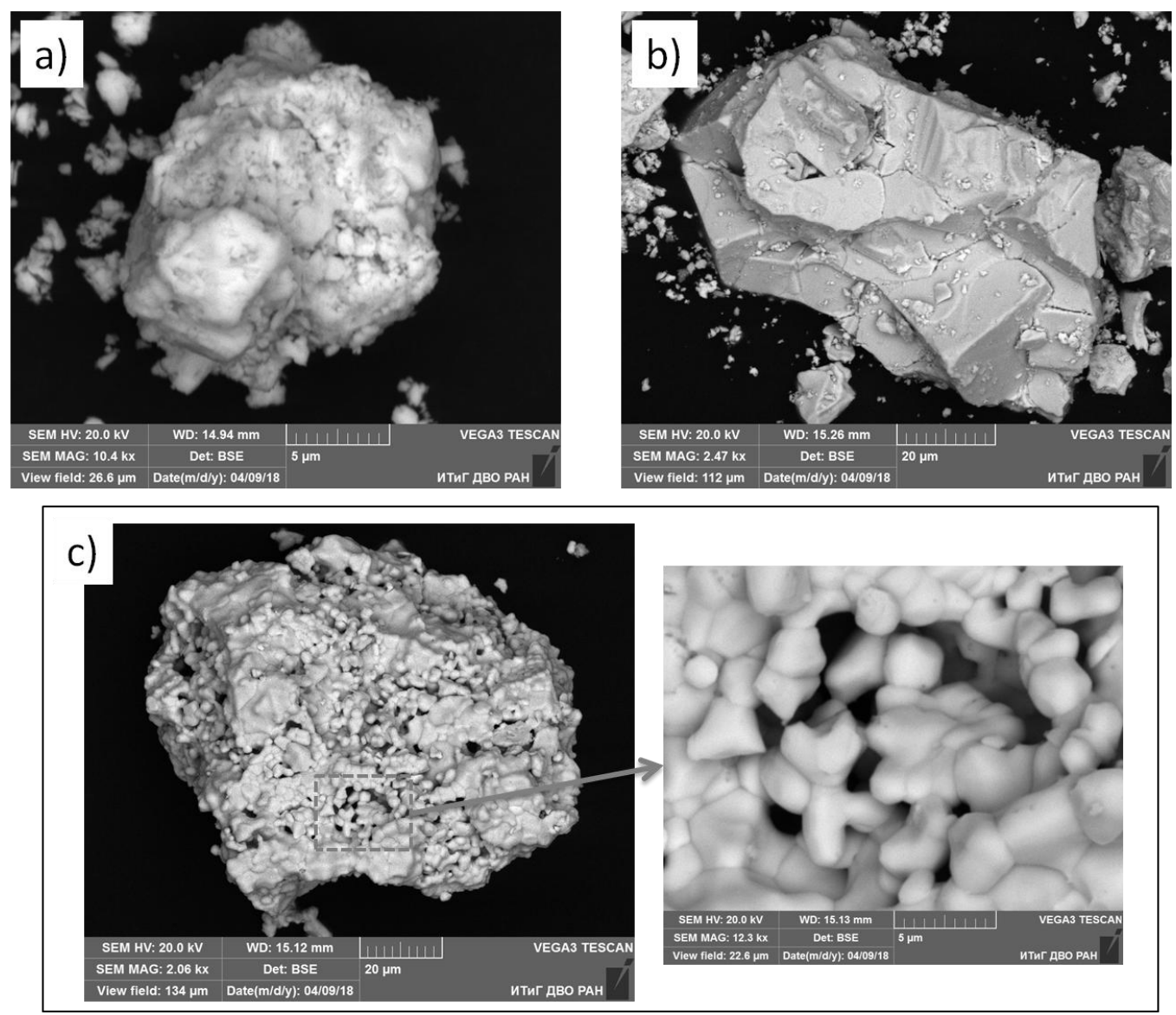

Figure 1. $\mathrm{SEM}$ images of strontium bismuthate synthesized particles (a) $\mathrm{Sr}_{2} \mathrm{Bi}_{2} \mathrm{O}_{5}$, (b) $\mathrm{Sr}_{6} \mathrm{Bi}_{2} \mathrm{O}_{11}$, and (c) $\mathrm{Sr}_{3} \mathrm{Bi}_{2} \mathrm{O}_{6}$. 
The EDX spectra obtained for each of the as-synthesized strontium bismuthate samples are reported in Figures S3-S5, which show the ratios of strontium to bismuth measured by the EDX method that correspond to the stoichiometric composition of the samples: the measured $\mathrm{Sr} / \mathrm{Bi}$ ratios are for the $\mathrm{Sr}_{2} \mathrm{Bi}_{2} \mathrm{O}_{5}$ sample, 0.94 (13.0 at.\% $\div 13.8$ at.\%); for the $\mathrm{Sr}_{3} \mathrm{Bi}_{2} \mathrm{O}_{6}$ sample, 1.42; and for the $\mathrm{Sr}_{6} \mathrm{Bi}_{2} \mathrm{O}_{11}$ sample, 2.82 .

\subsection{Raman spectral analysis}

The Raman spectra of all the as-synthesized strontium bismuthates are displayed in Figure 4. The Raman spectrum of $\mathrm{Bi}_{2} \mathrm{O}_{3}$ investigated by Betsch and White [31] and by Narang and coworkers [32] indicates that bismuth does not form a simple structure; new phases containing bismuth are formed. It is well known that bismuth ions can form $\mathrm{BiO}_{3}$ pyramidal and $\mathrm{BiO}_{6}$ octahedral units. The Raman bands of bismuth oxides can be classified into for main groups: (1) modes at frequencies lower $100 \mathrm{~cm}^{-1}$ belong to lattice vibrations mostly due to $\mathrm{Bi}-\mathrm{Bi}$ stretches and bendings; (2) below $200 \mathrm{~cm}^{-1}$, the Raman $\mathrm{Bi}-\mathrm{O}$ stretching modes are due to displacements of the bismuth metal-ion vibrations; (3) in the $300-600 \mathrm{~cm}^{-1}$ spectral region, bridging anion modes are mainly due to the displacement of the oxygen atom with respect to the $\mathrm{Bi}$ atom causing $\mathrm{Bi}-\mathrm{O}$ elongation; and (4) $\mathrm{Bi}-\mathrm{O}^{-}$non-bridging anion modes at $600-700 \mathrm{~cm}^{-1}[33,34]$. Concomitantly, $\mathrm{SrO}^{-}$vibrations are also present in the $130-140 \mathrm{~cm}^{-1}$, $280-295 \mathrm{~cm}^{-1}$, and $620-660 \mathrm{~cm}^{-1}$ spectral regions for all samples investigated [35-37].

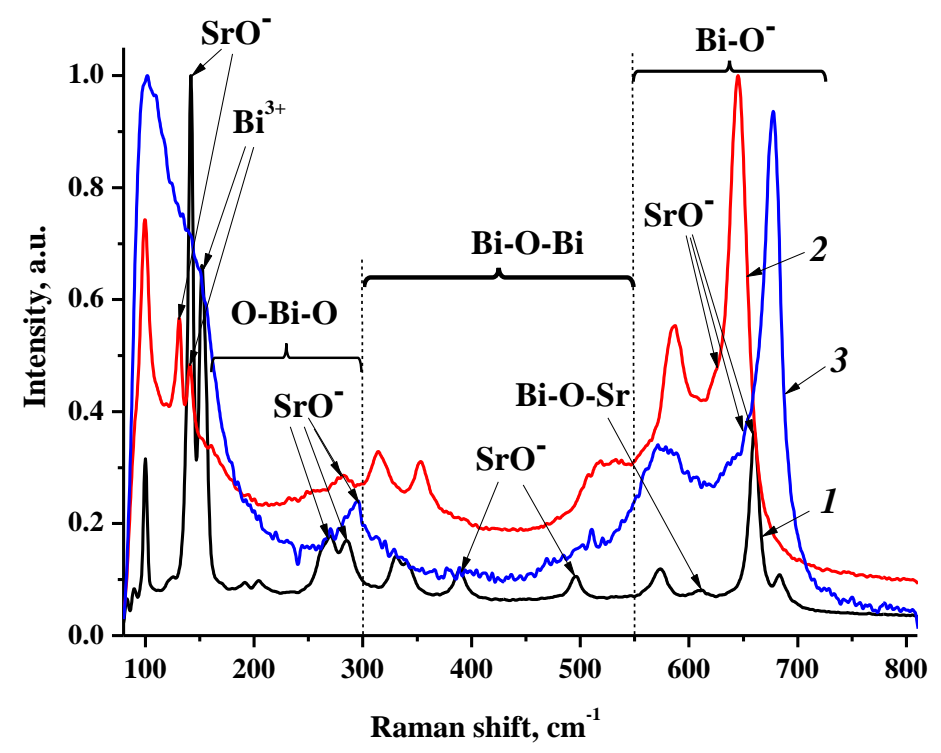

Figure 4. Raman spectra of synthesized strontium bismuthate samples: (1) black spectrum, $\mathrm{Sr}_{2} \mathrm{Bi}_{2} \mathrm{O}_{5},(2)$ red spectrum, $\mathrm{Sr}_{3} \mathrm{Bi}_{2} \mathrm{O}_{6}$, and (3) blue spectrum, $\mathrm{Sr}_{6} \mathrm{Bi}_{2} \mathrm{O}_{11}$. 
Vibrational modes are more representative and more pronounced in the Raman spectrum of the $\mathrm{Sr}_{2} \mathrm{Bi}_{2} \mathrm{O}_{5}$ sample (additional bands at $269 \mathrm{~cm}^{-1}, 390 \mathrm{~cm}^{-1}$, and $496 \mathrm{~cm}^{-1}$ ); even the band at $610 \mathrm{~cm}^{-1}$ due to $\mathrm{Bi}-\mathrm{O}-\mathrm{Sr}$ vibrations is observed. Relevant band assignments for the main vibrational modes observed in the Raman spectra are reported in Figure 4; more detailed information on the interpretation of the Raman data is given in Table $\mathbf{S 1}$.

A good look of the Raman spectra indicates increased broadening of the peaks in the order: $\mathrm{Sr}_{2} \mathrm{Bi}_{2} \mathrm{O}_{5}<\mathrm{Sr}_{3} \mathrm{Bi}_{2} \mathrm{O}_{6}<\mathrm{Sr}_{6} \mathrm{Bi}_{2} \mathrm{O}_{11}$, likely due to some structural disorder; curiously, this order also shows an increase in the number of oxygen atoms in the structure. The stretching anion motion, i.e., the vibrations of bridging oxygens in an angularly constrained $\mathrm{Bi}-\mathrm{O}-\mathrm{Bi}$ configuration $\left(525 \mathrm{~cm}^{-1}, 300-355\right.$ $\mathrm{cm}^{-1}$ ) destabilizes the structural order. Moreover, by increasing the $\mathrm{SrO}$ content, a conversion of $\mathrm{BiO}_{6}$ units into $\mathrm{BiO}_{3}$ units might be expected thereby producing non-bridging oxygen atoms as observed in some types of binary glasses $[38,39]$. Indeed, $\mathrm{Bi}-\mathrm{O}-\mathrm{Bi}$ bridging anion modes in $\mathrm{BiO}_{6}$ units practically disappeared; the $\mathrm{Bi}-\mathrm{O}^{-}$non-bridging anion modes in $\mathrm{BiO}_{3}$ units became the most intense features in the Raman spectrum of the $\mathrm{Sr}_{6} \mathrm{BiO}_{11}$ sample. The presence of $\mathrm{BiO}_{6}$ octahedral units in $\mathrm{Sr}_{2} \mathrm{Bi}_{2} \mathrm{O}_{5}$ and $\mathrm{Sr}_{3} \mathrm{Bi}_{2} \mathrm{O}_{6}$ indicates that the coordination number of the $\mathrm{Sr}$ cations is higher than that of the bismuthate $\mathrm{Sr}_{6} \mathrm{Bi}_{2} \mathrm{O}_{11}$ sample.

\subsection{XPS characterization}

The elemental compositions of the surface of the three bismuthates were determined by the XPS method and are reported in

Table S2. XPS spectra of the $\mathrm{Sr}_{3 \mathrm{~d}}, \mathrm{Bi}_{4 \mathrm{f}}$, and $\mathrm{O}_{1 \mathrm{~s}}$ regions are displayed in Figure 5. Analysis of these XPS spectra reveals the presence of natural carbon contamination on the samples' surface: the $\mathrm{C}_{1 \mathrm{~s}}$ peak (Figure 5A) at a binding energy (BE) of $284.8 \mathrm{eV}$ corresponds to the $\mathrm{C}-\mathrm{C}$ bond, while the peak at $\sim 289 \mathrm{eV}$ suggests that $\mathrm{CO}_{2}$ molecules are chemisorbed on the surface of all as-synthesized samples of strontium bismuthate due to the high affinity of strontium ions for $\mathrm{CO}_{2}$ molecules. Deconvolution of the $\mathrm{Sr}_{3 \mathrm{~d}}$ spectra (Figure 5B) confirms the presence of surface strontium atoms bound with $\mathrm{CO}_{2}$ molecules. At the same time, the $\mathrm{Bi}_{4 \mathrm{f}}$ XPS spectra (Figure 5C) exhibit only one peak that corresponds to the $\mathrm{Bi}-\mathrm{O}$ bond. Figure 5D shows the $\mathrm{O}_{1 \mathrm{~s}}$ XPS spectra and their deconvolution results for all three strontium bismuthate samples. The $\mathrm{O}_{1 \text { s }}$ peak at $\mathrm{BE} \sim 531.6 \mathrm{eV}$ is associated with the $\mathrm{O}-\mathrm{C}=\mathrm{O}$ bond of chemisorbed $\mathrm{CO}_{2}$ molecules. Two other peaks at lower BEs are connected with oxygen atoms in different charge states. The peak at $529.5 \mathrm{eV}$ is due to oxygen ions, $\mathrm{O}^{2-}$, in the lattice sites of the strontium bismuthates, while the peak at $530.9 \mathrm{eV}$ is attributed to the interstitial oxygen species, $\mathrm{O}^{-}$. 

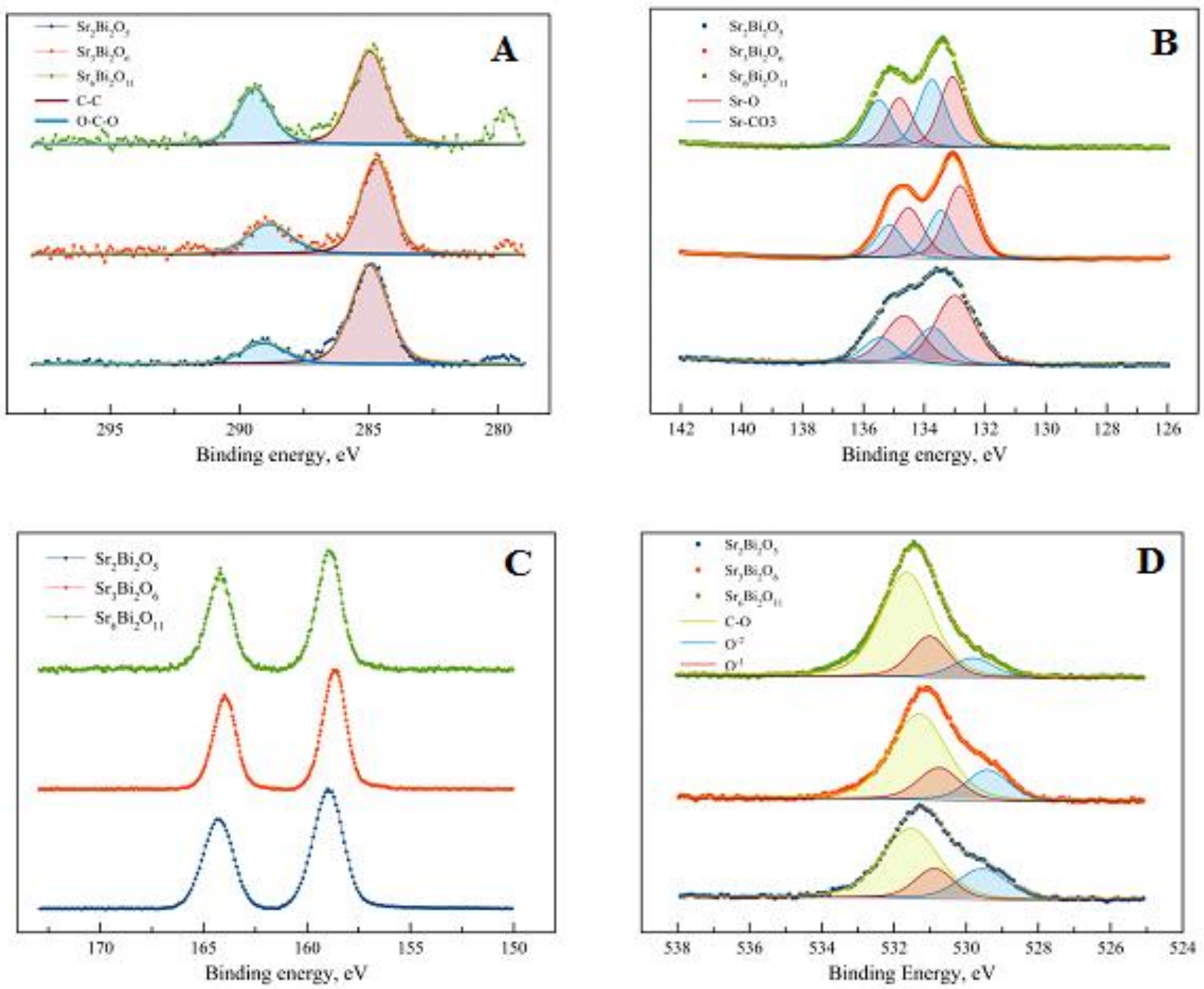

Figure 5. XPS spectra and the deconvolution results for all synthesized strontium bismuthate samples in $\mathrm{C} 1 \mathrm{~s}$ (A), $\mathrm{Sr} 3 \mathrm{~d}\left(\mathrm{~B}, \mathrm{Bi} 4 \mathrm{f}(\mathrm{C})\right.$, and $\mathrm{O} 1 \mathrm{~s}(\mathrm{D})$ regions. Spectra are shown in green, red, and blue for $\mathrm{Sr}_{2} \mathrm{Bi}_{2} \mathrm{O}_{5}, \mathrm{Sr}_{3} \mathrm{Bi}_{2} \mathrm{O}_{6}$, and $\mathrm{Sr}_{6} \mathrm{Bi}_{2} \mathrm{O}_{11}$, respectively.

Table 3 summarizes the elemental compositions of the three bismuthates but exclude the contribution of adsorbed carbon dioxide. These data make it possible to determine the stoichiometry of the surface compositions, which are in complete accord with the bulk compositions of all three bismuthate samples. For instance, the contribution of interstitial oxygen increases from sample to sample with the $\mathrm{SrO}$ content increasing in the order: $\mathrm{Sr}_{2} \mathrm{Bi}_{2} \mathrm{O}_{5} ; \mathrm{Sr}_{3} \mathrm{Bi}_{2} \mathrm{O}_{6} ; \mathrm{Sr}_{6} \mathrm{Bi}_{2} \mathrm{O}_{11}$. According to the Raman data, the structure disorder is also enhanced in the same order. 
Table 3. Elemental composition data, values of the valence band top $\left(\mathrm{E}_{\mathrm{VB}}\right)$ and bandgap energies $\left(\mathrm{E}_{\mathrm{g}}\right)$ for the three strontium bismuthates investigated.

\begin{tabular}{|lc|c|c|c|}
\hline Properties & & $\mathbf{S r}_{2} \mathbf{B i}_{\mathbf{2}} \mathbf{O}_{\mathbf{5}}$ & $\mathbf{S r}_{\mathbf{3}} \mathbf{B i}_{\mathbf{2}} \mathbf{O}_{\mathbf{6}}$ & $\mathbf{S r}_{\mathbf{6}} \mathbf{B i}_{\mathbf{2}} \mathbf{O}_{\mathbf{1 1}}$ \\
\hline Element content, (at.\%) & & & & \\
& $\mathrm{Sr}$ & 21.3 & 26.9 & 31.6 \\
& $\mathrm{Bi}$ & 23.2 & 18.4 & 10.5 \\
& $\mathrm{O}$ & 55.5 & 54.7 & 57.9 \\
Including & & & & \\
& $\mathrm{O}^{2-}$ & 31.0 & 26.9 & 20.0 \\
& $\mathrm{O}^{-}$ & 24.5 & 27.8 & 37.9 \\
\hline $\mathrm{Sr}: \mathrm{Bi}: \mathrm{O}$ & & $2.0: 2.2: 5.2$ & $3.0: 2.1: 6.1$ & $6.0: 2.0: 11.0$ \\
\hline $\mathrm{E}_{\mathrm{VB}}{ }^{,}(\mathrm{eV})$ & 1.6 & 1.7 & 2.2 \\
\hline $\mathrm{E}_{\mathrm{g}},{ }^{b}(\mathrm{eV})$ & & 3.17 & 3.40 & 2.61 \\
\hline
\end{tabular}

${ }^{a}$ From XPS spectra of the valence band top; energy values are given versus the NHE scale.

${ }^{b}$ Bandgaps from Tauc plots, see text.

The energies of the top level of the valence band for the three bismuthate samples were obtained from the low-energy edges of the XPS spectra (Figure 6) of the $\mathrm{O}_{2 \mathrm{p}}$ binding energy states (see Table 3). These energies vary with the composition of the sample and slightly decrease with increase in $\mathrm{SrO}$ content in the cation sublattice of the samples.

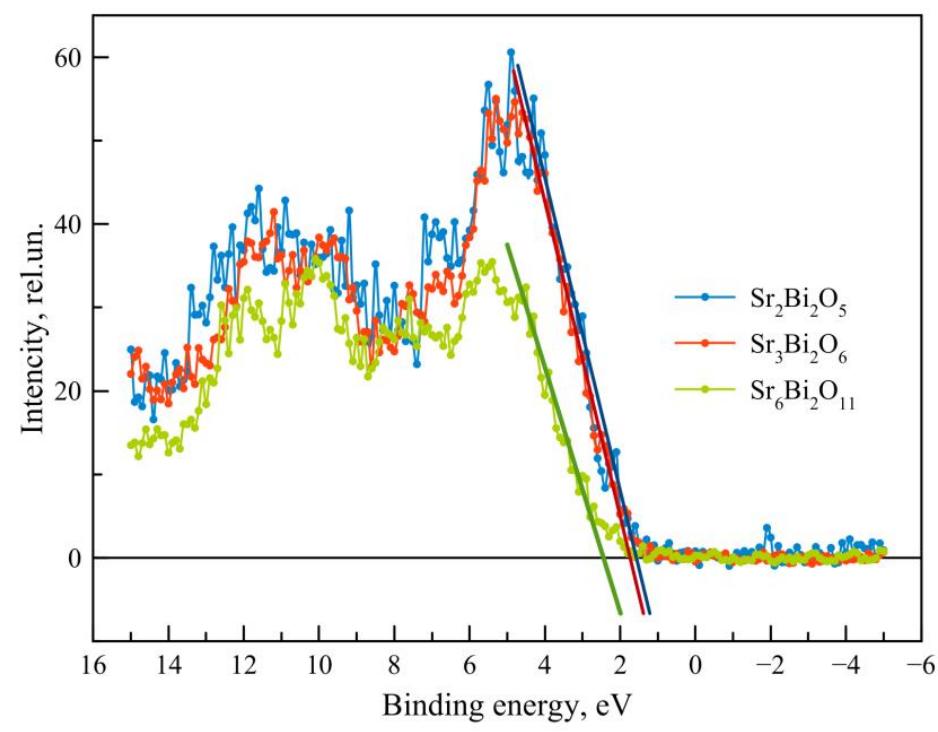

Figure 6. XPS spectra of the top level of the valence band for the three strontium bismuthate samples. The horizontal black line is the baseline of the XPS signal, whereas the straight lines (blue, red, and green) are the linear extrapolation of the low-energy edge of the XPS spectra of $\mathrm{Sr}_{2} \mathrm{Bi}_{2} \mathrm{O}_{5}, \mathrm{Sr}_{3} \mathrm{Bi}_{2} \mathrm{O}_{6}$, and $\mathrm{Sr}_{6} \mathrm{Bi}_{2} \mathrm{O}_{11}$, respectively. The binding energy scale is presented relative to the NHE scale. 


\subsection{Diffuse reflectance spectroscopy}

All the as-synthesized samples of strontium bismuthate display different colors as illustrated in Figure S1. The increasing absorption of the samples in the series $\mathrm{Sr}_{3} \mathrm{Bi}_{2} \mathrm{O}_{6}, \mathrm{Sr}_{2} \mathrm{Bi}_{2} \mathrm{O}_{5}, \mathrm{Sr}_{6} \mathrm{Bi}_{2} \mathrm{O}_{11}$ (Figure 7) is in line with the color changes observed in Figure S1.

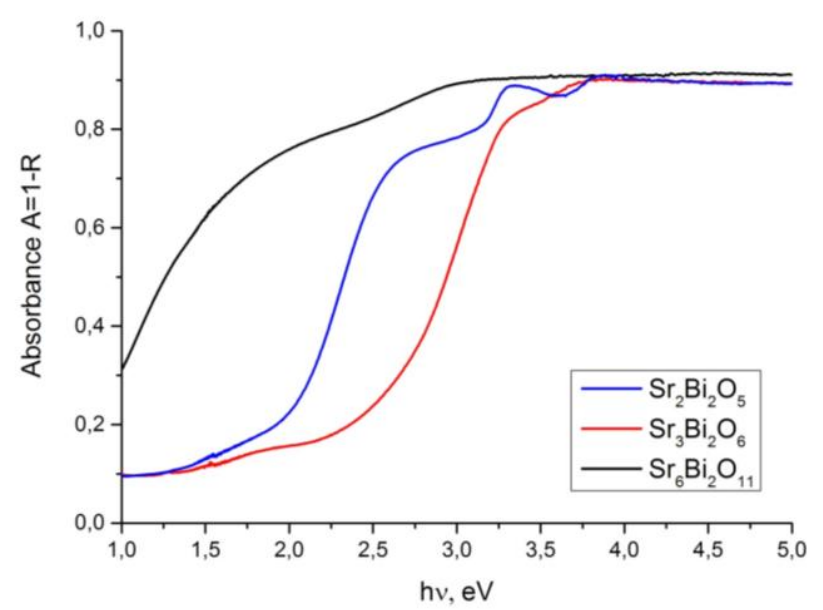

Figure 7. Diffuse reflectance spectrum, reported as the absorption spectrum, of all the as-synthesized strontium bismuthate samples.

It is seen from Figure 7 that the manifestation of the absorption of the strontium bismuthates in the visible spectral range strongly depends on their chemical formula; the visually estimated absorption edge of the samples red-shifts from $\mathrm{Sr}_{3} \mathrm{Bi}_{2} \mathrm{O}_{6}$ (blue spectrum) to $\mathrm{Sr}_{6} \mathrm{Bi}_{2} \mathrm{O}_{11}$ (red spectrum). Note that the DR spectrum of $\mathrm{Sr}_{2} \mathrm{Bi}_{2} \mathrm{O}_{5}$ (Figure 7) is similar to that reported earlier [19, 20] in spectral similarities that appear both in the position of the absorption threshold around $2.5 \mathrm{eV}(500 \mathrm{~nm})$ and in the peculiarities at $3.1-3.6 \mathrm{eV}(400-350 \mathrm{~nm})$.

The bandgap energies $E_{g}$ of the strontium bismuthates (Table 3) were estimated from the DR spectra using the Tauc equation for direct allowed band-to-band optical transitions modified by substitution of the linear absorption coefficient in the Kubelka-Munk function (for details see Supporting Information, Figure S6). The bandgap energy estimates (Table 3) also demonstrate the dependence of the strontium bismuthates' absorption thresholds from their chemical compositions. The $\mathrm{E}_{\mathrm{g}}$ value obtained in this study $\left(3.17 \mathrm{eV}\right.$ for $\left.\mathrm{Sr}_{2} \mathrm{Bi}_{2} \mathrm{O}_{5}\right)$ is in a good agreement with the bandgap energy $(3.2 \mathrm{eV})$ reported previously [20].

\subsection{EIS characterization}

The frequency and temperature dependencies of the real part of the specific conductivity for all the as-synthesized strontium bismuthates are illustrated in Figure 8. All strontium bismuthates are characterized by both positive and negative conductivity at certain temperatures and external electric 
fields. For example, the strontium bismuthate $\mathrm{Sr}_{2} \mathrm{Bi}_{2} \mathrm{O}_{5}$ shows increased conductivity with increase of temperature and with decrease of the frequency of the external electric field (from upper left corner to lower right-hand corner of the conduction field; see Figure 8a). Considering this trend, there is a rapid increase in conductivity within the range of $22.5 \mathrm{MHz}$, which is observed during all the temperature ranges examined. The black line displayed in Figure 8a presents an isoline equal to zero conductivity. Generally, this line has a horizontal direction for the strontium bismuthate $\mathrm{Sr}_{2} \mathrm{Bi}_{2} \mathrm{O}_{5}$.

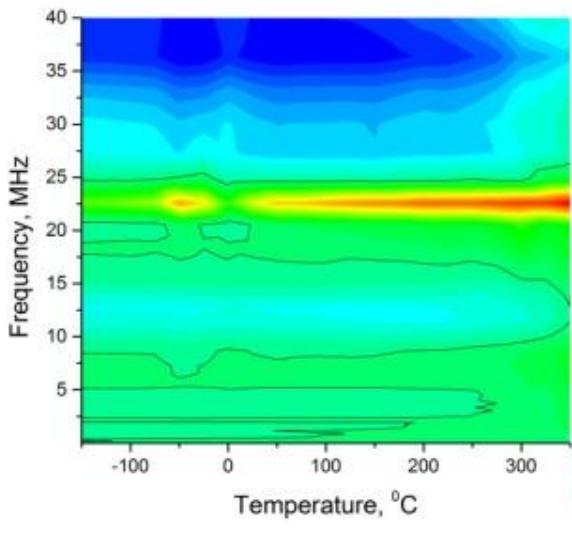

(a)

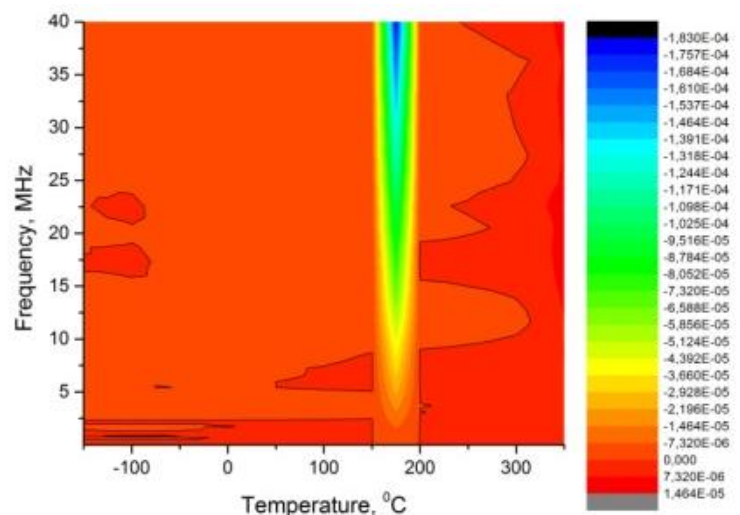

(b)
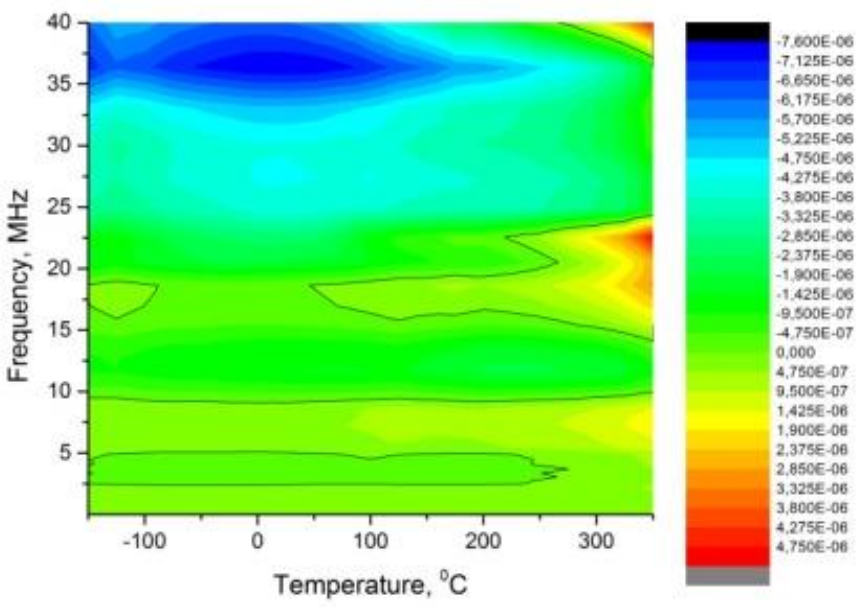

(c)

Figure 8. Frequency-temperature dependency of the real part of specific conductivity of strontium bismuthates: a - $\mathrm{Sr}_{2} \mathrm{Bi}_{2} \mathrm{O}_{5} ; \mathrm{b}-\mathrm{Sr}_{3} \mathrm{Bi}_{2} \mathrm{O}_{6} ; \mathrm{C}-\mathrm{Sr}_{6} \mathrm{Bi}_{2} \mathrm{O}_{11}$. Black line - isoline of zero conductivity. Conductivity scale is presented in $\mathrm{S} / \mathrm{cm}^{2}$.

The strontium bismuthate $\mathrm{Sr}_{3} \mathrm{Bi}_{2} \mathrm{O}_{6}$ also displays increased conductivity with temperature increases and with decreases of the frequency of the external eleectric field (from upper left corner to lower right-hand corner of the conductivity field shown in Figure 8b). Along the line of the previous case, an increase in conductivity is traced within the frequency range of $22.5 \mathrm{MHz}$; the black line in Figure 8b presents an isoline equal to zero conductivity. It further shows that for the strontium 
bismuthate $\mathrm{Sr}_{3} \mathrm{Bi}_{2} \mathrm{O}_{6}$ this isoline has both horizontal and vertical components. A distinctive feature of $\mathrm{Sr}_{3} \mathrm{Bi}_{2} \mathrm{O}_{6}$ is the presence of a temperature range of rapid conductivity decrease located within 100 to $150{ }^{\circ} \mathrm{C}$. The decrease of conductivity is relatively small in the low-frequency range of the external electric field. However, as the frequency of the external electric field increases, the decrease in conductivity becomes more significant.

For strontium bismuthate $\mathrm{Sr}_{6} \mathrm{Bi}_{2} \mathrm{O}_{11}$, the situation corresponds to the case of $\mathrm{Sr}_{2} \mathrm{Bi}_{2} \mathrm{O}_{5}$. The tendency toward an increase of conductivity as the temperature is increased and the frequency of the external electric field is decreased (from upper left corner to lower right-hand corner of the conduction field shown in Figure 8c) is clearly delineated. There is also a local increase in conductivity within the range of 17.5 and $22.5 \mathrm{MHz}$; in this case, the zero conductivity isoline is generally oriented horizontally.

To the extent that the conductivity of the strontium bismuthate samples investigated is a thermally-activated process, it allows us to estimate the corresponding activation energies using the Arrhenius approach from the conductivity data of Figure 8. The real part of the specific conductivity of the various strontium bismuthates given in Arrhenius coordinates is illustrated in Figure 9. The data were obtained at a frequency of $22.579 \mathrm{MHz}$. The so-estimated activation energies $\left(\mathrm{E}_{\mathrm{a}}\right)$ are $43 \mathrm{meV}$ for $\mathrm{Sr}_{2} \mathrm{Bi}_{2} \mathrm{O}_{5}, 977 \mathrm{meV}$ for $\mathrm{Sr}_{3} \mathrm{Bi}_{2} \mathrm{O}_{6}$, and $391 \mathrm{meV}$ for $\mathrm{Sr}_{6} \mathrm{Bi}_{2} \mathrm{O}_{11}$.

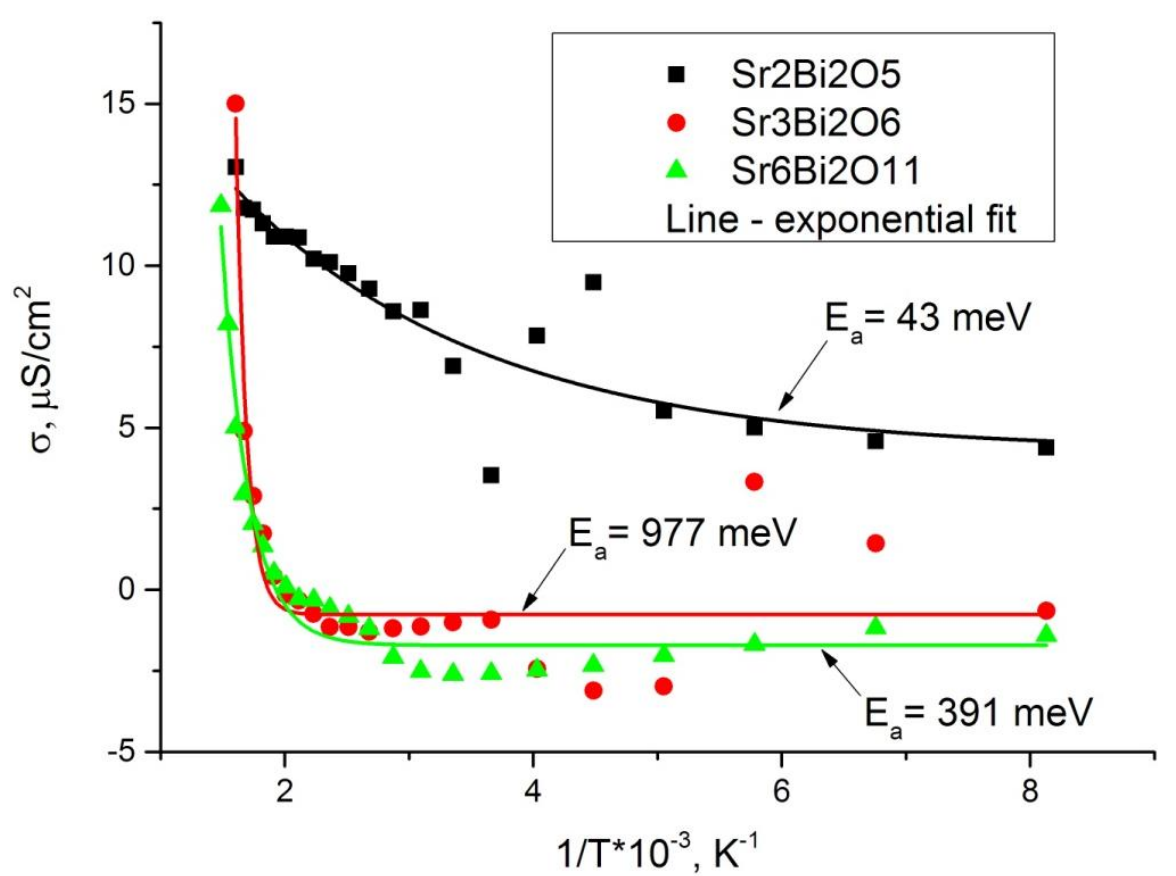

Figure 9. Real part of the specific conductivity of strontium bismuthates in Arrhenius coordinates. 


\subsection{Photocatalytic and related properties}

\subsubsection{Photocatalytic degradation of acetaldehyde in the gas phase}

The relative efficiencies of the removal of acetaldehyde in the gas phase are portrayed in Figure 10, which shows that only the $\mathrm{Sr}_{6} \mathrm{Bi}_{2} \mathrm{O}_{11}$ sample displays detectable photoactivity of ca. $0.2 \mu$ mol of acetaldehyde decomposed during $1 \mathrm{hr}$ of irradiation, while the other two bismuthates were relatively photoinactive. We hasten to point out that the flow reactor used in the ISO test is such that the photocatalytic reaction occurs only during a single pass of the acetaldehyde substrate for it to come in contact with the photocatalyst's surface. Nonetheless, it is encouraging that the $\operatorname{Sr}_{6} \mathrm{Bi}_{2} \mathrm{O}_{11}$ bismuthate manifested photocatalytic activity despite this unfortunate aspect of the test.

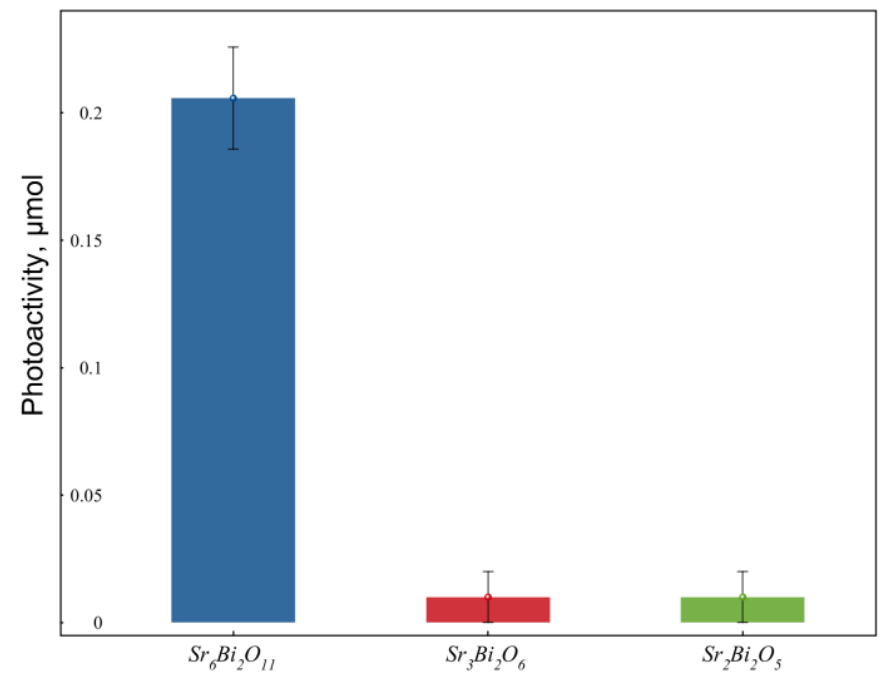

Figure 10. Photoactivity of various strontium bismuthate samples in the acetaldehyde photocatalytic test.

\subsubsection{Photocatalytic degradation of phenol in aqueous media}

Unlike the removal of acetaldehyde, the photocatalyzed degradation of phenol carried out in aqueous media used a batch-type reactor. All the samples manifested some degree of photocatalytic activity under otherwise identical experimental conditions (Figure 11). Expressing photoactivity in terms of reaction rates, we found that the photoactivity of $\mathrm{Sr}_{6} \mathrm{Bi}_{2} \mathrm{O}_{11}$ was $20 \%$ greater $(k=1.02 \pm 0.11$ $\mathrm{ppm} \mathrm{hr}^{-1}$ ) than the corresponding photoactivity of P25 titania (Evonik) for which $k=0.82 \pm 0.09 \mathrm{ppm}$ $\mathrm{hr}^{-1}$. The photoactivities of the other two strontium bismuthates were $0.22 \pm 0.06 \mathrm{ppm} \mathrm{hr}^{-1}$ and $0.06 \pm$ $0.05 \mathrm{ppm} \mathrm{hr}{ }^{-1}$ for $\mathrm{Sr}_{3} \mathrm{Bi}_{2} \mathrm{O}_{6}$ and $\mathrm{Sr}_{2} \mathrm{Bi}_{2} \mathrm{O}_{5}$, respectively, from which we conclude that under the conditions used, the bismuthate $\mathrm{Sr}_{2} \mathrm{Bi}_{2} \mathrm{O}_{5}$ is photocatalytically inactive. 


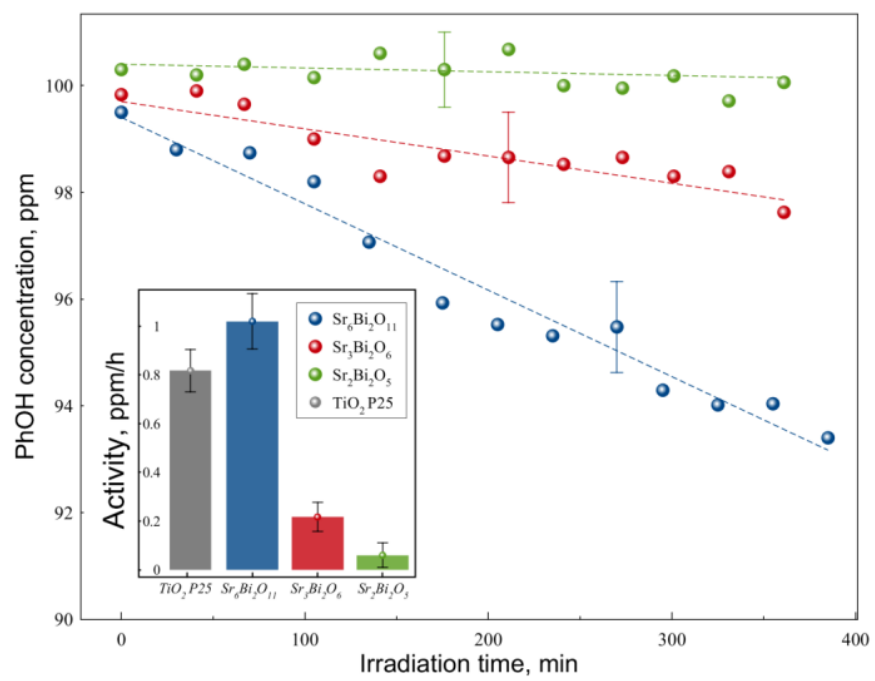

Figure 11. Changes in the concentration of phenol in aqueous media in the presence of various strontium bismuthate samples. The insert reports the rate of phenol decomposition by the various strontium bismuthate samples (photoactivity).

The fact that the most efficient sample was $\mathrm{Sr}_{6} \mathrm{Bi}_{2} \mathrm{O}_{11}$ in both tests infers that the same or similar mechanisms are involved for both gas and liquid phases. In order to investigate this issue further, we next conducted the same experiments, albeit in the presence of suitable radical scavengers.

\subsubsection{Photodegradaiton of phenol in the presence of radical scavengers}

The photocatalyzed decomposition of phenol in aqueous media in the presence of the radical scavengers (i) isopranol (IPA), (ii) p-benzoquinone (p-BQ), and (iii) ammonium oxalate (AO) was carried out so as to determine the effect(s) of these scavengers on the photocatalytic activity of the strontium bismuthates. To the extent that the bismuthate $\mathrm{Sr}_{6} \mathrm{Bi}_{2} \mathrm{O}_{11}$ showed the greatest photoactivity in the removal of acetaldehyde, it was the first bismuthate tested with the radical scavengers (Figure 12c). It is evident that isopropanol had no effect on the photodegradation of phenol, contrary to the presence of p-benzoquinone and ammonium oxalate both of which inhibited the process of decomposition. We infer that $\mathrm{Sr}_{6} \mathrm{Bi}_{2} \mathrm{O}_{11}$ decomposes the phenol via formation of superoxide radical anions on the photocatalyst surface (reductive half-reaction; $\mathrm{O}_{2}+\mathrm{e}_{\mathrm{cb}}^{-} \rightarrow \mathrm{O}_{2}^{-\bullet}$ ), thereby allowing the valence band photoholes (oxidative half-reaction) from the photocatalyst to degrade phenol oxidatively. The behavior of the IPA scavenger, known to scavenge hydroxyl radicals, suggests that these radicals played no role in the phenolic decomposition process under the prevalent conditions used. 

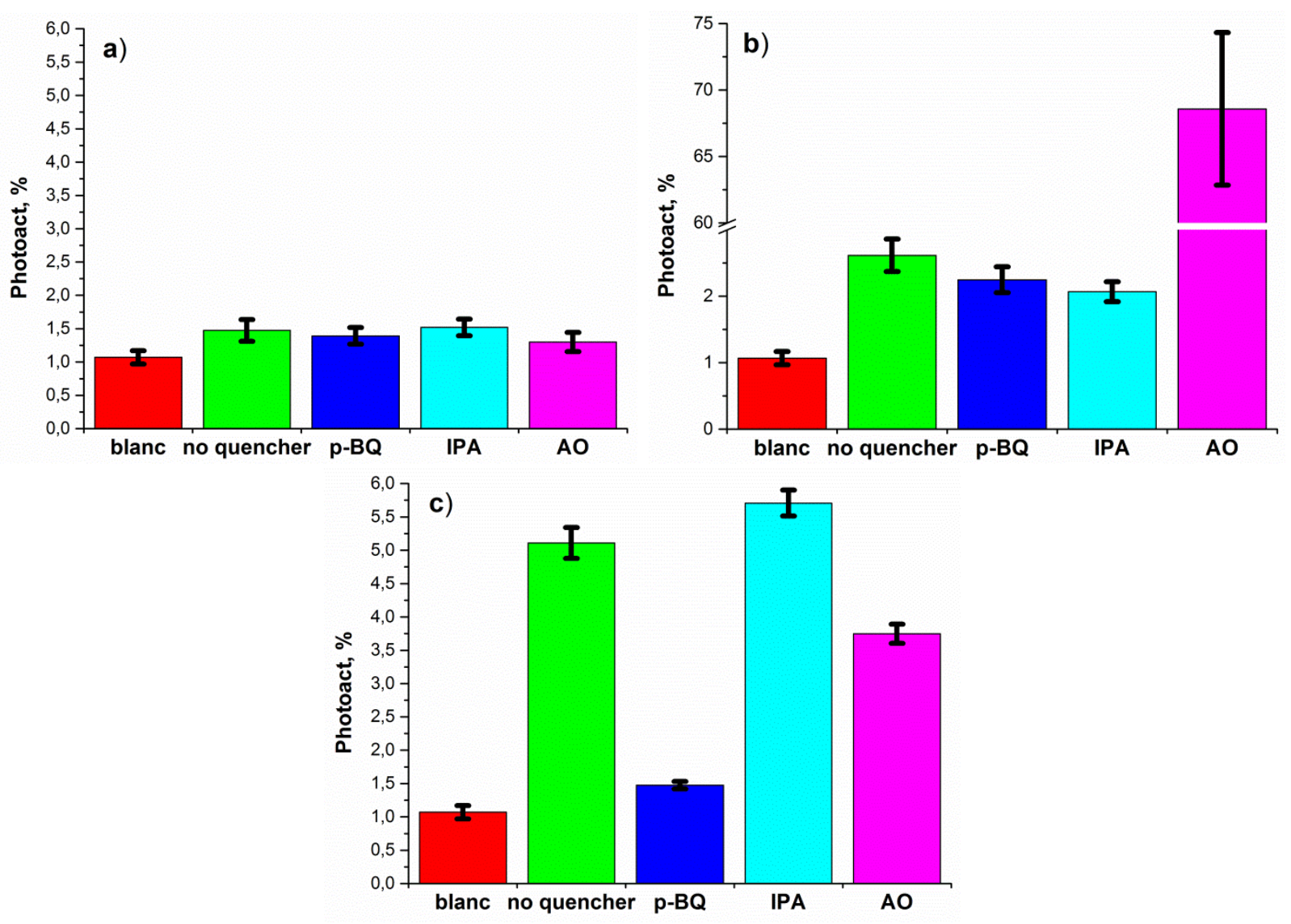

Figure 12. Phenol concentration changes in aqueous media under irradiation in the presence of selected radical scavengers and strontium bismuthates of various compositions: (a) $\mathrm{Sr}_{2} \mathrm{Bi}_{2} \mathrm{O}_{5}$, (b) $\mathrm{Sr}_{3} \mathrm{Bi}_{2} \mathrm{O}_{6}$, and (c) $\mathrm{Sr}_{6} \mathrm{Bi}_{2} \mathrm{O}_{11}$; blanc refers to photolysis of phenol with neither the presence of the photocatalyst nor the presence of the selected radicals scavengers; no quencher signifies only the presence of the photocatalyst in the aqueous media, while $\mathrm{p}-\mathrm{BQ}, \mathrm{IPA}$, and $\mathrm{AO}$ refer to the photodecomposition of phenol in the aqueous media in the presence of the photocatalyst and the scavengers.

A certain photocatalytic activity was shown by the strontium bismuthate $\mathrm{Sr}_{3} \mathrm{Bi}_{2} \mathrm{O}_{6}$ in the phenol decomposition process as illustrated in Figure $\mathbf{1 2 b}$, which demonstrates how the selected radical scavengers affected the phenol decomposition in the presence of the $\mathrm{Sr}_{3} \mathrm{Bi}_{2} \mathrm{O}_{6}$ sample. The presence of p-benzoquinone and isopropanol had little impact on the phenol decomposition process. By contrast, addition of ammonium oxalate (scavenger of photoholes), the extent of phenol decomposition was many times greater (ca. 30 times greater).

The previous test data for the decomposition of acetaldehyde with the strontium bismuthate $\mathrm{Sr}_{2} \mathrm{Bi}_{2} \mathrm{O}_{5}$ showed this oxide to be photocatalytically inactive. Nonetheless, the possible photocatalytic activity of this bismuthate might be exposed in the presence of one of the radical scavengers, as happened with the $\mathrm{Sr}_{3} \mathrm{Bi}_{2} \mathrm{O}_{6}$ sample. Figure 12a shows how the radical scavengers affect the phenol decomposition process by irradiation of the phenolic suspension in the presence of the strontium 
bismuthate $\mathrm{S}_{2} \mathrm{Bi}_{2} \mathrm{O}_{5}$ sample. Clearly, none of the radical scavengers affected the phenol decomposition; in the present instance, the $\mathrm{Sr}_{2} \mathrm{Bi}_{2} \mathrm{O}_{5}$ bismuthate displayed no photocatalytic activity.

\subsection{UV-induced coloration of the bismuthate samples}

The formation of photocatalytic active surface centers include the trapping of photogenerated carrier of a given sign by pre-existing chemically inactive surface defects; the subsequent decay of these active states usually occur via recombination of a trapped carrier with a free photocarrier of the opposite sign (see: active state of a surface photocatalytic center in ref. [40]). Typically, so-called color centers responsible for stable photoinduced coloration of wide band gap solids are created in the same way in the bulk and at the surface of solid particles. In the latter case, color centers are considered as active states of surface photocatalytic centers. Various relations between the paths and effectiveness of color centers and formation of photocatalytic centers have been established for a representative set of metal oxides and alkali halides [41, 42]. Consequently, it was imperative that the photocoloration of the newly synthesized strontium bismuthates also be examined in some detail.

The considerable growth of the absorption of the $\mathrm{Sr}_{2} \mathrm{Bi}_{2} \mathrm{O}_{5}$ and $\mathrm{Sr}_{3} \mathrm{Bi}_{2} \mathrm{O}_{6}$ bismuthates in their extrinsic absorption region and in the near-fundamental absorption edge from irradiation of these systems by UV light $(\lambda=365 \mathrm{~nm}, \mathrm{E}(\mathrm{hv})=3.4 \mathrm{eV})$ under ambient conditions was monitored by diffuse reflectance spectroscopy (Figures 13a, 13b). The photoinduced coloration of these two samples was stable and annealed noticeably at elevated temperatures $\left(\mathrm{T}>250-400{ }^{\circ} \mathrm{C}\right)$. By contrast, no coloration was displayed by the $\mathrm{Sr}_{6} \mathrm{Bi}_{2} \mathrm{O}_{11}$ bismuthate (Figure 13c).

It will be emphasized that the bismuthates $\mathrm{Sr}_{2} \mathrm{Bi}_{2} \mathrm{O}_{5}$ and $\mathrm{Sr}_{3} \mathrm{Bi}_{2} \mathrm{O}_{6}$ that exhibited relatively wide bandgaps (Table 3) and were initially somewhat weakly-colored are shown to be photosensitive, while the heavily colored $\mathrm{Sr}_{6} \mathrm{Bi}_{2} \mathrm{O}_{11}$ system (Figure $\mathrm{S} 1$ ) with the smallest bandgap energy shows no photocoloration. The same peculiarities were displayed by the lightly (yellow) and heavily multi-doped $\mathrm{TiO}_{2}$ (red and brown) ceramics as reported elsewhere [43].

The UV-induced absorption spectra $\Delta \mathrm{A}(\mathrm{h} v)$ are complex and can be presented as the sum of five overlapping bands for $\mathrm{Sr}_{2} \mathrm{Bi}_{2} \mathrm{O}_{5}$ (Figure 14a) and by three overlapping bands for $\mathrm{Sr}_{6} \mathrm{Bi}_{2} \mathrm{O}_{11}$ (Figure 14b) of the Gaussian-shaped single absorption bands with positions at maxima $E_{m}$ and half-width at half-maximum (HWHM): $\mathrm{E}_{\mathrm{m}}=1.08 \mathrm{eV}, \mathrm{HWHM}=0.45 \pm 0.02 \mathrm{eV} ; \mathrm{E}_{\mathrm{m}}=1.91 \mathrm{eV}, \mathrm{HWHM}=0.44 \pm$ $0.02 \mathrm{eV} ; \mathrm{E}_{\mathrm{m}}=2.14 \mathrm{eV}, \mathrm{HWHM}=0.24 \pm 0.05 \mathrm{eV} ; \mathrm{E}_{\mathrm{m}}=2.88 \mathrm{eV}, \mathrm{HWHM}=0.19 \pm 0.02 \mathrm{eV} ;$ and $\mathrm{E}_{\mathrm{m}}=$ $3.11 \mathrm{eV}, \mathrm{HWHM}=0.11 \pm 0.01 \mathrm{eV}$ for the $\mathrm{Sr}_{2} \mathrm{Bi}_{2} \mathrm{O}_{5}$ system, whereas for the $\mathrm{Sr}_{3} \mathrm{Bi}_{2} \mathrm{O}_{6}$ bismuthate the parameters are $\mathrm{E}_{\mathrm{m}}=1.93 \mathrm{eV}, \mathrm{HWHM}=0.34 \pm 0.05 \mathrm{eV} ; \mathrm{E}_{\mathrm{m}}=2.43 \mathrm{eV}, \mathrm{HWHM}=0.28 \pm 0.07 \mathrm{eV}$; and 
$\mathrm{E}_{\mathrm{m}}=2.83 \mathrm{eV}, \mathrm{HWHM}=0.19 \pm 0.01 \mathrm{eV}$. Note that both the position of the UV-induced bands (at $\mathrm{E}$ $(h v) \leq E_{g}$ ) and their hall-widths (a few tens of $\mathrm{eV}$ ) are typical of color centers in solids (see, for example, refs. $[41,43,44])$.
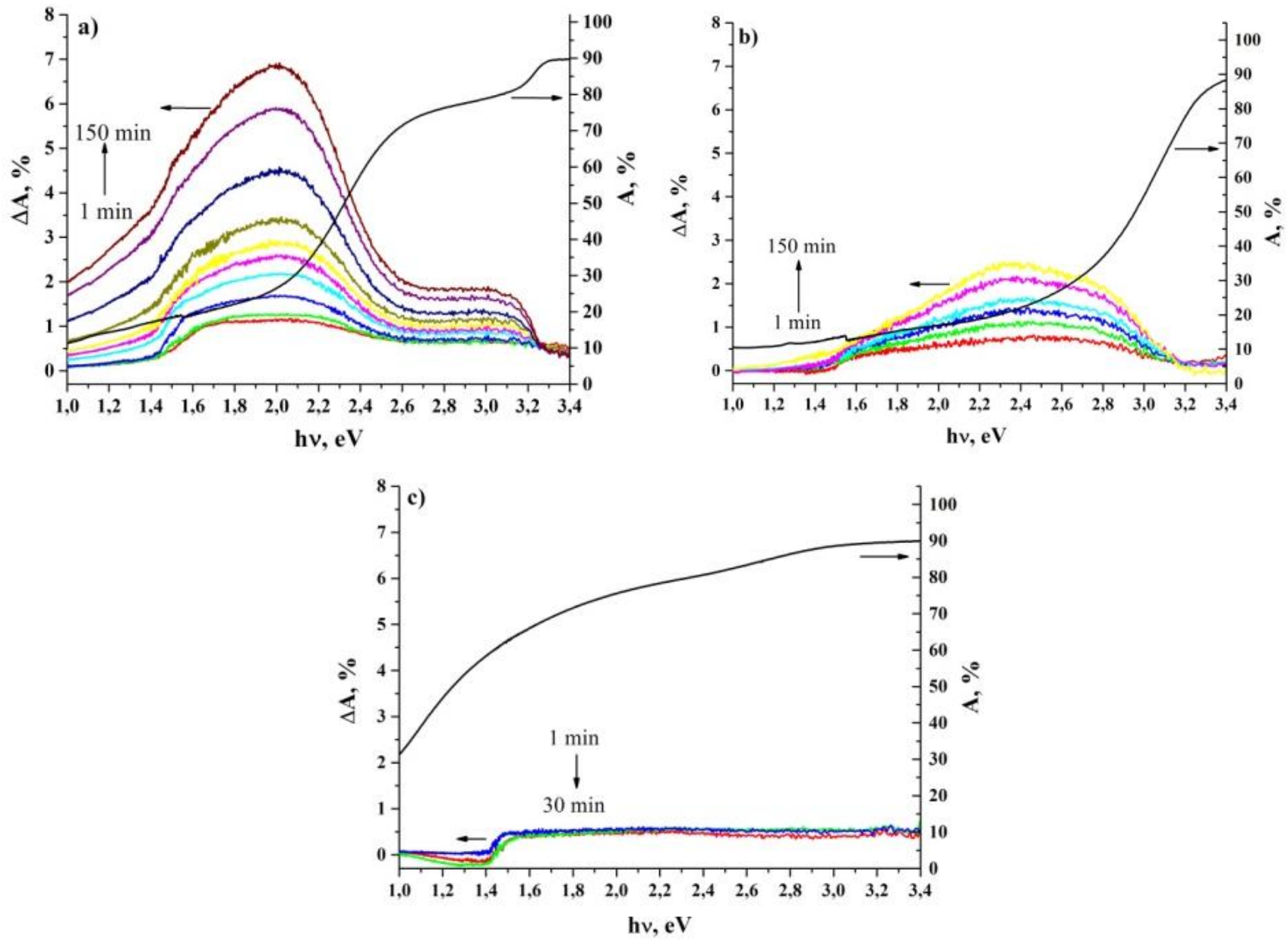

Figure 13. Difference absorption spectra $\Delta A=A_{\circ}-A(t)$ (left ordinate) and absorbance spectra $A=1-R_{0}$ (right ordinate) of (a) $\mathrm{Sr}_{2} \mathrm{Bi}_{2} \mathrm{O}_{5}$, (b) $\mathrm{Sr}_{3} \mathrm{Bi}_{2} \mathrm{O}_{6}$, and (c) $\mathrm{Sr}_{6} \mathrm{Bi}_{2} \mathrm{O}_{11}$. Here $\mathrm{A}_{\circ}$ refer to the absorption of the initial state of the strontium bismuthate samples and $A(t)$ is the absorption of these samples after being irradiated with UV light $(\lambda=$ $365 \mathrm{~nm}$, irradiance, $15 \mathrm{~mW} \mathrm{~cm}^{-2}$; irradiation time, up to $150 \mathrm{~min}$. under ambient conditions in air).

Since the UV-induced complex bands for both $\mathrm{Sr}_{2} \mathrm{Bi}_{2} \mathrm{O}_{5}$ and $\mathrm{Sr}_{3} \mathrm{Bi}_{2} \mathrm{O}_{6}$ bismuthates can be presented as the sum of a few Gaussian-shaped bands, it is possible to assign the different Gaussian bands to different color centers. This assumption is consistent with the kinetics of photocoloration of the strontium bismuthates (Figure 15) which can be fitted by eqn. (5).

$$
\Delta \mathrm{A}(t)=\mathrm{A}_{1}\left(1-e^{-t / \tau_{1}}\right)+\mathrm{A}_{2}\left(1-e^{-t / \tau_{2}}\right)
$$


where $\mathrm{A}_{1}, \mathrm{~A}_{2}, \tau_{1}$ and $\tau_{2}$ are constants that have meaning as the ultimate coloration level (A) and characteristic coloration time $(\tau)$ for the partial kinetics of coloration of both $(1)$ and $(2)$ in Figure 15.
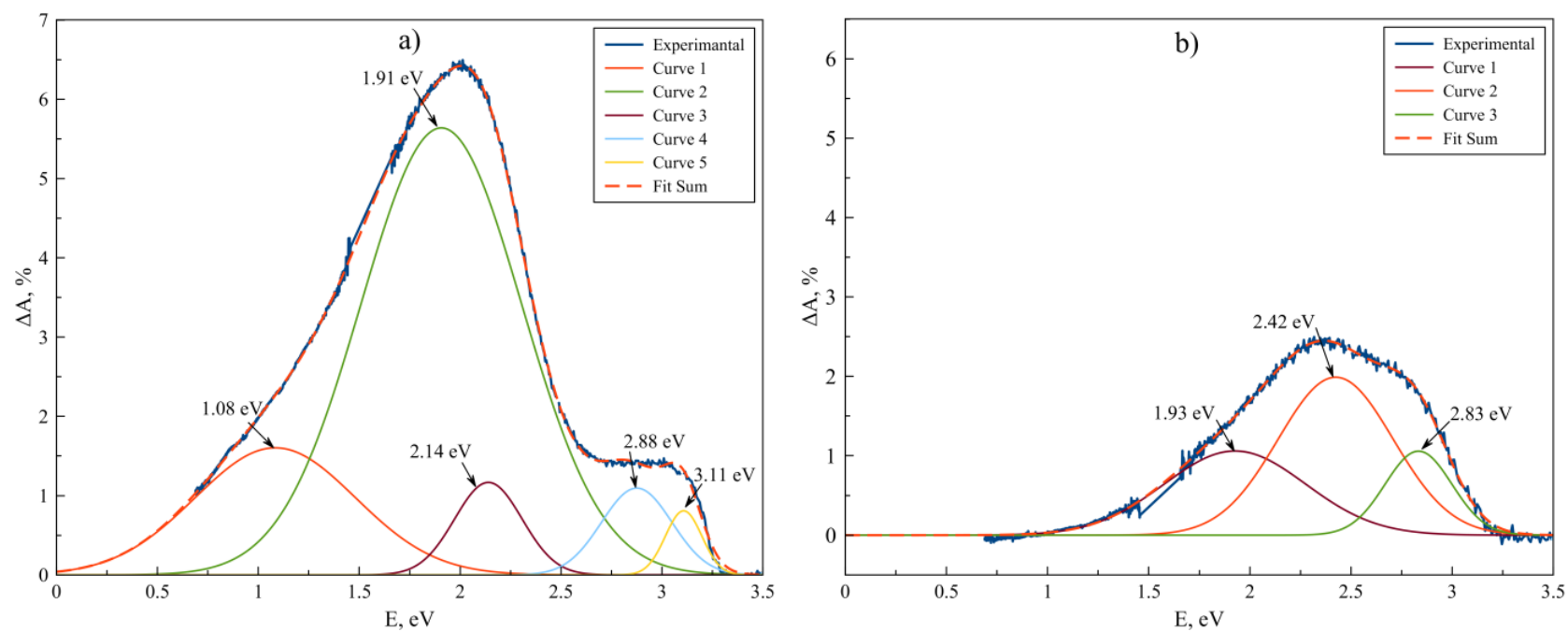

Figure 14. Difference absorption spectra $\Delta A=A_{o}-A(t)$ of (a) $\mathrm{Sr}_{2} \mathrm{Bi}_{2} \mathrm{O}_{5}$ and (b) $\mathrm{Sr}_{3} \mathrm{Bi}_{2} \mathrm{O}_{6}$. Here $\mathrm{A}_{\circ}$ are the absorption of the initial state of the strontium bismuthate samples and $A(t)$ is the absorption of the samples after being irradiated by UV light $\left(\lambda=365 \mathrm{~nm}\right.$; irradiance, $\left.15 \mathrm{~mW} \mathrm{~cm}^{-2}\right)$ for $150 \mathrm{~min}$.

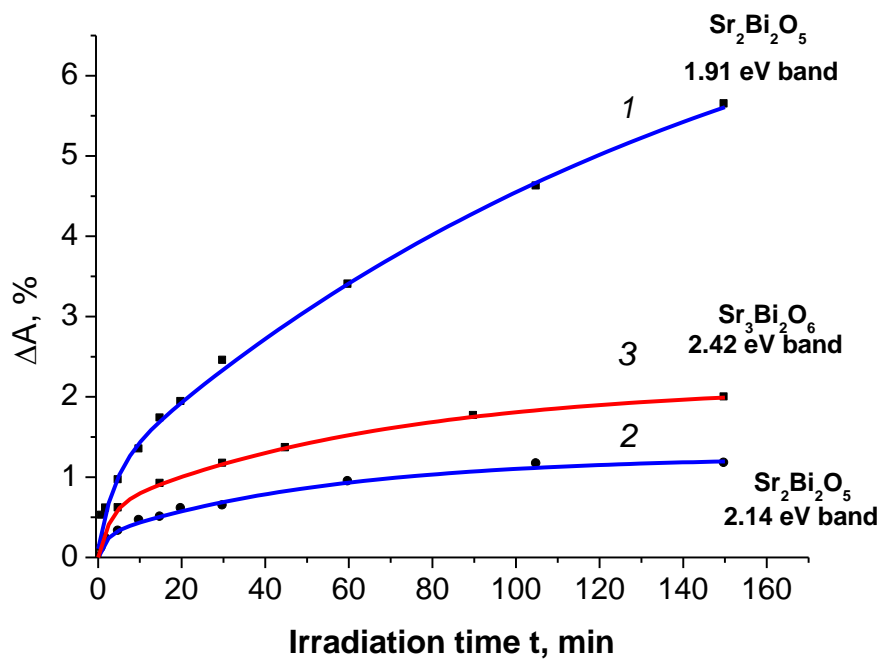

Figure 15. Kinetics of the UV-induced coloration of $\mathrm{Sr}_{2} \mathrm{Bi}_{2} \mathrm{O}_{5}$ (1 and 2, points) and $\mathrm{Sr}_{3} \mathrm{Bi}_{2} \mathrm{O}_{6}(3$, points). The ordinates of the points denote the heights of the Gaussian-shaped bands at $E(h v)=1.91 \mathrm{eV}$ and $2.14 \mathrm{eV}(1$ and 2), and at $E(h v)=2.42 \mathrm{eV}(3)$ obtained by resolution of the experimental spectra recorded after a set of fixed exposition times (abscissa) into Gaussian bands. The solid lines represent the approximations of the kinetics as per eqn. (5) - see text.

The bi-exponential kinetics eqn. (5) for the UV coloration of powdered Al-doped $\mathrm{TiO}_{2}$ were reported earlier, where it was shown that the partial kinetics of coloration resulted from a simple model 
based on a treatment of trapping and de-trapping of photogenerated carriers by pre-existing point defects in the solid particles [44]. It should be emphasized that the characteristic times of coloration $\tau_{1}$ and $\tau_{2}$ evaluated from the approximation eqn (5) are different for different Gaussian-shaped bands. For instance, $\tau_{1}=150 \pm 40 \mathrm{~min}$ and $\tau_{2}=3.8 \pm 1.4 \mathrm{~min}$ for the band at $1.98 \mathrm{eV}$, while $\tau_{1}=55 \pm 10 \mathrm{~min}$ and $\tau_{2}=1.8 \pm 0.8 \mathrm{~min}$ for the band at $2.14 \mathrm{eV}$. The same is true for the remaining subbands (Figure 13a, 13b and Figure 14). The coloration kinetic parameters for the sets of Gaussian-shaped subbands, together with some comments regarding the mechanism of UV coloration and bi-exponential kinetics (eqn. (5)) are presented elsewhere (see Supporting Information). From that discussion, we get that the complex shape of the UV-induced spectra of $\mathrm{Sr}_{2} \mathrm{Bi}_{2} \mathrm{O}_{5}$ and $\mathrm{Sr}_{3} \mathrm{Bi}_{2} \mathrm{O}_{6}$ is due to different color centers rather than to different optical transitions of the single color centers.

Judging by the maximal amplitudes of $\Delta \mathrm{A}$ at $\mathrm{E}(\mathrm{h} v)$ near $2.0 \mathrm{eV}$ for both well-colored strontium bismuthates (Figure 13), the effectiveness of photocoloration of $\mathrm{Sr}_{2} \mathrm{Bi}_{2} \mathrm{O}_{5}$ is approximately threefold greater than that of $\mathrm{Sr}_{3} \mathrm{Bi}_{2} \mathrm{O}_{6}$. Similarly, the ultimate level of $\mathrm{UV}$ coloration $\left(\Delta \mathrm{A}(\mathrm{t}=\propto)=\mathrm{A}_{1}+\mathrm{A}_{2}\right.$ (eqn (5)) for the highest Gaussian-shaped bands are $8.3 \pm 2.5 \%$ at $1.91 \mathrm{eV}\left(\mathrm{Sr}_{2} \mathrm{Bi}_{2} \mathrm{O}_{5}\right)$ and $2.16 \pm 0.05 \%$ at $2.42 \mathrm{eV}\left(\mathrm{Sr}_{3} \mathrm{Bi}_{2} \mathrm{O}_{6}\right)$ (Figure 15; see also the discussion on the kinetics of UV coloration of $\mathrm{Sr}_{2} \mathrm{Bi}_{2} \mathrm{O}_{5}$ and $\mathrm{Sr}_{3} \mathrm{Bi}_{2} \mathrm{O}_{6}$ in the Supporting Information, and Table S3). Thus, on the presumption that the greater $\Delta \mathrm{A}(\mathrm{t}=\propto)$ (or $\Delta \mathrm{A}$ at fixed irradiation time) is, the greater is the concentration of induced color centers regardless of the chemical composition of the samples; the order of strontium bismuthates with increasing UV-induced coloration is: $\mathrm{Sr}_{6} \mathrm{Bi}_{2} \mathrm{O}_{11} ; \mathrm{Sr}_{3} \mathrm{Bi}_{2} \mathrm{O}_{6} ; \mathrm{Sr}_{2} \mathrm{Bi}_{2} \mathrm{O}_{5}$. The photocatalytic activity of the strontium bismuthates in the photodegradation of phenol (Figure 11) decreases in the same order. Assuming that the extent of UV coloration of the strontium bismuthates correlates with their photocatalytic power, it follows that the greater is the efficiency of photocoloration, the lower is the photocatalytic activity of the oxide.

\section{Discussion}

\subsection{Characterization of the bismuthate samples}

It was mentioned above (Figure 13) that the influence of UV irradiation on strontium bismuthates of a certain composition $\left(\mathrm{Sr}_{2} \mathrm{Bi}_{2} \mathrm{O}_{5}\right.$ and $\left.\mathrm{Sr}_{3} \mathrm{Bi}_{2} \mathrm{O}_{6}\right)$ results in the formation of absorption bands within the visible spectral region. Considering this effect from the point of semiconductor band theory, it can be assumed that there are defective levels within the semiconductor's forbidden bandgap, which are filled with charge carriers photogenerated under UV-light exposure. 
Crystalline solids always contain point defects in their lattice. Some of the most common defects in such crystalline solids are the Schottky and Frenkel defects. The Schottky defect refers to a vacancy in the crystal lattice. A distinctive feature of Schottky defects is that they are formed in pairs (so as to fulfill the condition of neutrality of the crystal lattice). By comparison, the Frenkel defects represent a pair of vacancies and interstitial atoms. Schottky defects are more easily formed in more highly-packed crystal lattices, whereas in crystals with large interatomic gaps, the Frenkel defects are more likely to be formed. Strontium bismuthates examined in the presented study display a large volume of the unit cell. Consequently, it may be inferred that the basic mechanism of defect formation will likely occur via a Frenkel mechanism.

There is also an empirical rule, according to which atoms of the lightest element will shift to the interstitial position. In the case of strontium bismuthates, oxygen is the lightest element. Consequently, it is expected that in the strontium bismuthates a large number of anti-Frenkel's defects should form such as, for example, "vacancy in the anionic sublattice + interstitial oxygen".

The XPS data of Table 3 show that all the as-synthesized strontium bismuthates contain a large number of oxygen atoms in the $\mathrm{O}^{-}$state. Consequently, it may be concluded that the oxygen (i.e., the interstitial oxygen) leaving its position in the crystal lattice will lead to the formation of Frenkel defects.

The equilibrium concentration of Fenkel defects $(n)$ is related to the energy required for moving an atom from the lattice site to the interstice $(\Delta \mathrm{E})$ by the known correlation (eqn (6)):

$$
n \approx \sqrt{N N^{\top}} e^{-\frac{\Delta E}{2 k T}}
$$

where $\mathrm{N}$ and $\mathrm{N}^{`}$ denote the concentration of the lattice sites and interstitial positions, respectively; $k$ is Boltzmann's constant, and $\mathrm{T}$ is temperature.

If we now consider as the equilibrium concentration of Frenkel defects the specific number of oxygen atoms in the $\mathrm{O}^{-}$state per unit cell of each of the synthesized strontium bismuthates; as the concentration of sites, the number of atoms in the unit cell of each of their synthesized strontium bismuthates; as the concentration of interstitial positions, the number of oxygen atoms in the unit cell of each of the synthesized strontium bismuthates (we assume that Frenkel defects are formed only by small displacements of the oxygen atoms) then we can estimate the energy $\Delta \mathrm{E}$ for each of the synthesized strontium bismuthates (Table 4) by transforming the above eqn. (6) into eqn (7):

$$
\Delta E=2 k T \ln \frac{\sqrt{N N}}{n}
$$


Perusal of Table 4 shows that the energy of defect formation decreases from $55.06 \mathrm{meV}$ for $\mathrm{Sr}_{2} \mathrm{Bi}_{2} \mathrm{O}_{5}$ to $35.43 \mathrm{meV}$ for $\mathrm{Sr}_{6} \mathrm{Bi}_{2} \mathrm{O}_{11}$ as the number of oxygen atoms in the unit cell increases. It should also be noted that for all the cases considered, the energy of formation of defects of the type described is very small and comparable to the thermal energy. This means that the number of oxygen atoms in the $\mathrm{O}^{-}$state (" $n$ " in the terminology of Table 4 investigated during the experiments reflects the steady-state dynamic equillibrium between the oxygens and the interstitial states. Thus, formation of defects of this type is not the result of the selected method to obtain such samples, but is determined by the crystal lattice of the as-prepared strontium bismuthates.

Table 4. Energy of formation of Frenkel defects for the three as-synthesized strontium bismuthate samples.

\begin{tabular}{|c|c|c|c|}
\hline \multirow{2}{*}{ Criteria } & \multicolumn{3}{|c|}{ Sample } \\
\cline { 2 - 4 } & $\mathbf{S r}_{\mathbf{2}} \mathbf{B i}_{\mathbf{2}} \mathbf{O}_{\mathbf{5}}$ & $\mathbf{S r}_{\mathbf{3}} \mathbf{B i}_{\mathbf{2}} \mathbf{O}_{\mathbf{6}}$ & $\mathbf{S r}_{\mathbf{6}} \mathbf{B i}_{\mathbf{2}} \mathbf{O}_{\mathbf{1 1}}$ \\
\hline$n$ & 2.29 & 3.1 & 7.24 \\
\hline$N$ & 9 & 11 & 19 \\
\hline$N$ & 5 & 6 & 11 \\
\hline \multirow{2}{*}{$\mathrm{E}, \mathrm{meV}$} & 55.06 & 49.36 & 35.43 \\
\hline
\end{tabular}

We noted above that irradiation of the strontium bismuthates $\mathrm{Sr}_{2} \mathrm{Bi}_{2} \mathrm{O}_{5}$ and $\mathrm{Sr}_{3} \mathrm{Bi}_{2} \mathrm{O}_{6}$ causes the formation of complex absorption bands, which can be represented as the sum of several Gaussians (see Figure 13). Also all components of these complex absorption bands exhibit a certain saturation characteristic (Figure S7). In case where all the components are saturated, simple calculations yield absorption bands that may look like those illustrated in Figure 16 recalling, however, that formation of such absorption bands for one of the strontium bismuthates was not observed.

Frenkel defects suggest that in the course of photoexcitation the photoelectron can be captured by a vacancy (with formation of an $\boldsymbol{F}$-center) or by aninterstitial oxygen (with transition of such oxygen to the $\mathrm{O}^{2-}$ state). In this case, formation of $\boldsymbol{F}$-centers is related to the formation of absorption bands in the visible region, in contrast to the capture of electrons by interstitial oxygens (Figure 17). 


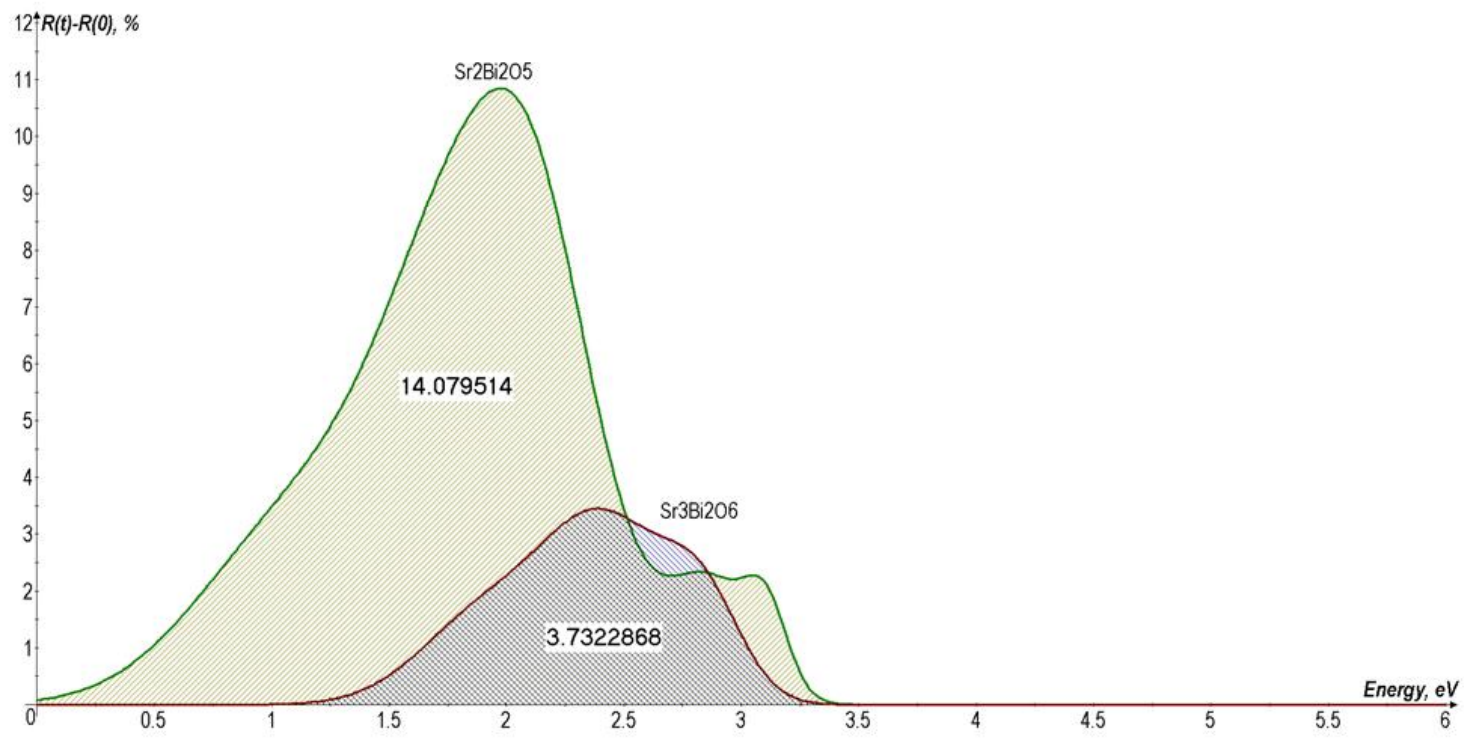

Figure 16. Results of the simulation of absorption bands for the $\mathrm{Sr}_{2} \mathrm{Bi}_{2} \mathrm{O}_{5}$ and $\mathrm{Sr}_{3} \mathrm{Bi}_{2} \mathrm{O}_{6}$ bismuthate samples.

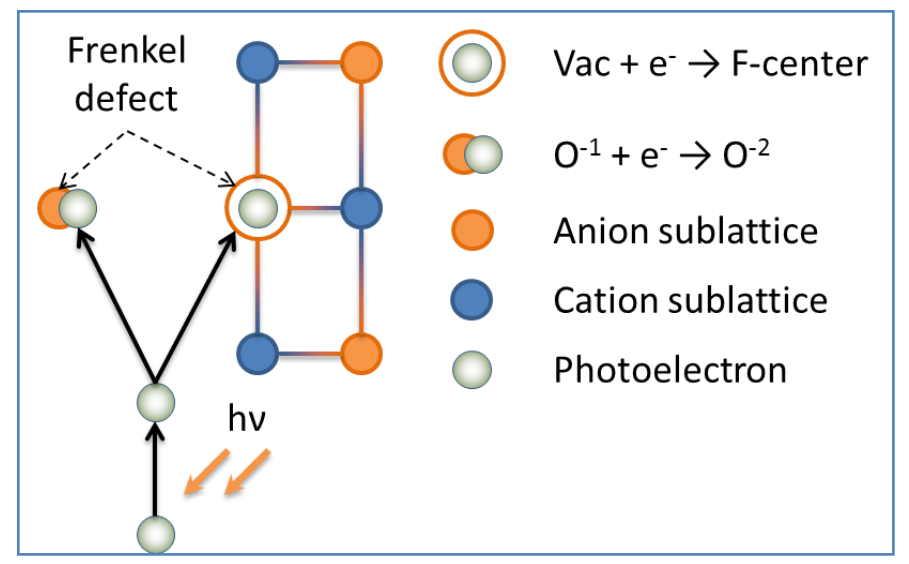

Figure 17. Scheme depicting the formation of a Frenkel defect and its capture by photoelectrons.

If this hypothesis correctly reflected the photodegradation processes, then the difference in photocatalytic activity of the various strontium bismuthates in the decomposition of phenol reaction can be explained.

A typical photocatalytic experiment might use $300 \mathrm{mg}$ of a strontium bismuthate sample to decompose a substrate. In that case, taking into account the number of Frenkel defects in a unit cell for each of the as-synthesized strontium bismuthates, it can be shown that the total number of defects in such a 300-mg sample is $6.5 \times 10^{19}$ for $\mathrm{Sr}_{2} \mathrm{Bi}_{2} \mathrm{O}_{5}, 6.4 \times 10^{19}$ for $\mathrm{Sr}_{3} \mathrm{Bi}_{2} \mathrm{O}_{6}$, and 6.1 x $10^{19}$ for $\mathrm{Sr}_{6} \mathrm{Bi}_{2} \mathrm{O}_{11}$. In a typical photocatalytic experiment, $300 \mathrm{~mL}$ of an aqueous phenolic solution might contain $100 \mathrm{ppm}$ of phenol; the total number of phenol molecules is then $1.0 \times 10^{21}$. 
The strontium bismuthate $\mathrm{Sr}_{2} \mathrm{Bi}_{2} \mathrm{O}_{5}$ showed no photocatalytic activity. In this case, all the photoelectrons formed during irradiation are captured by the vacancies with formation of $\boldsymbol{F}$-centers that would display the absorption band shown in Figure 16. Simple calculations demonstrate that, in this case, to form an absorption band with unit area would involve $0.5 \times 10^{19} \boldsymbol{F}$ centers. So, in this case, the decomposition of phenol does not occur because all the photoelectrons are localized in the oxygen vacancies (Figure 18).

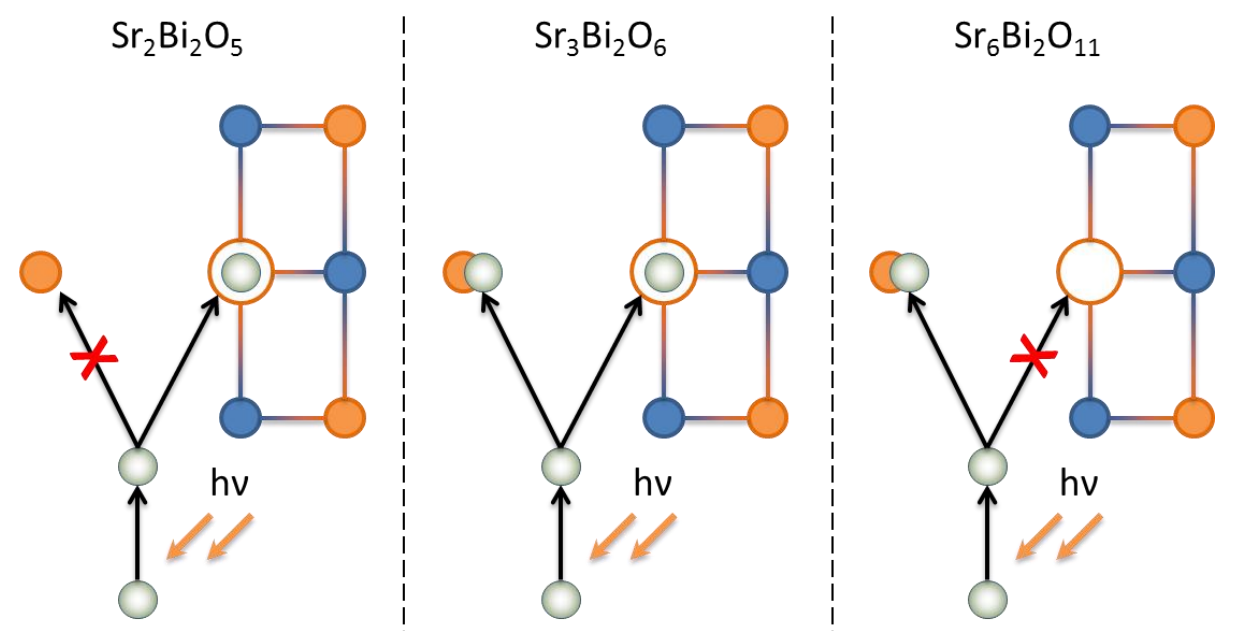

Figure 18. Possible mechanisms for the capture of photoelectons in the crystal lattice point defects of the three strontium bismuthates; gray balls are the electrons; the lone orange ball denotes an interstitial oxygen, whereas the empty ball refers to an oxygen vacancy. The $\mathrm{Sr}_{2} \mathrm{Bi}_{2} \mathrm{O}_{5}$ bismuthate yields only $\boldsymbol{F}$ centers upon capture of electrons by the vacancies; the $\mathrm{Sr}_{3} \mathrm{Bi}_{2} \mathrm{O}_{6}$ sample yields both $\boldsymbol{F}$ centers and interstitially captured electrons, whereas in the $\mathrm{Sr}_{6} \mathrm{Bi}_{2} \mathrm{O}_{11}$ system electrons are captured by the interstitial oxygens, but no $\boldsymbol{F}$ centers are formed.

The strontium bismuth $\mathrm{Sr}_{6} \mathrm{Bi}_{2} \mathrm{O}_{11}$ sample turned out to be the most active photocatalyst among the ones investigated in the present study. The phenol decomposition rate was $1.02 \mathrm{ppm} \mathrm{hr}^{-1}$, which means that during the $6.5 \mathrm{hrs}$ of the experiment, $6.7 \times 10^{19}$ molecules of phenol were destroyed. Hence, more than one phenol molecule was destroyed by each point defect during the experiment, indicating that the turnover number was greater than unity (i.e., TON >1). Apparently, the high photocatalytic activity and the absence of $\boldsymbol{F}$-centers in such a system infer that in this case only the electrons captured by the interstitial oxygens are involved in the phenol decomposition (Figure 18).

The strontium bismuthate $\mathrm{Sr}_{3} \mathrm{Bi}_{2} \mathrm{O}_{6}$ occupies an intermediate position between the three analyzed bismuthates. On the one hand, an induced absorption band is formed (presumably due to formation of $\boldsymbol{F}$-centers) as in $\mathrm{Sr}_{2} \mathrm{Bi}_{2} \mathrm{O}_{5}$. On the other hand, the former exhibits some photocatalytic activity in the phenol decomposition reaction (presumably due to photoelectrons captured by interstitial oxygens) as in $\operatorname{Sr}_{6} \mathrm{Bi}_{2} \mathrm{O}_{11}$. In this case, electrons can be localized both at interstitial oxygens (and participate in phenol decomposition) and in vacancies with formation of $\boldsymbol{F}$-centers (Figure 18). 


\subsection{Proposed photocatalytic mechanisms}

The XPS and DRS spectroscopic methods afforded the determination of the energy of the highest level of the valence band and the bandgap of all the as-synthesized strontium bismuthates (Table 3). Also determined were the levels of point defects within the bandgap in the anion sublattice of strontium bismuthates $\mathrm{Sr}_{2} \mathrm{Bi}_{2} \mathrm{O}_{5}$ and $\mathrm{Sr}_{3} \mathrm{Bi}_{2} \mathrm{O}$. These experimental data make it possible to construct the band structure of strontium bismuthates of various compositions (Figure 19), which will be used to infer a scheme to rationalize the photocatalytic processes occurring in each of the synthesized strontium bismuthates. The most photoactive of the bismuthates was $\mathrm{Sr}_{6} \mathrm{Bi}_{2} \mathrm{O}_{11}$ with a bandgap width of $2.61 \mathrm{eV}$, with an energy of the top of the valence band of $+2.22 \mathrm{eV}$ and an energy of the bottom of the conduction band of $-0.39 \mathrm{eV}$ (Figure 19).

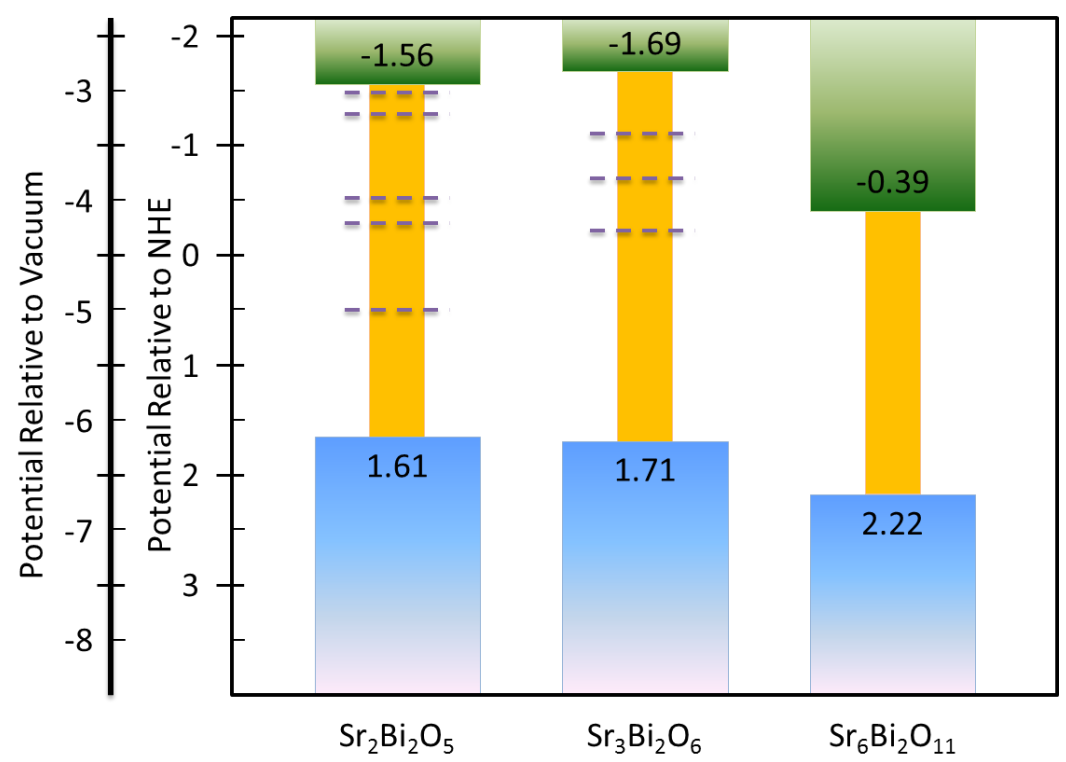

Figure 19. Band structure of strontium bismuthates of various compositions.

Let us now consider the processes that take place with the conduction band photoelectrons that will constitute the half-reaction for the oxidative degradation of substrates. The potential needed to form the superoxide radical anion by electron capture $\left(\mathrm{O}_{2}+\mathrm{e}^{-} \rightarrow \mathrm{O}_{2}^{-{ }^{-}}\right)$is $-0.33 \mathrm{eV}$. Since photoelectrons in the conduction band of $\mathrm{Sr}_{6} \mathrm{Bi}_{2} \mathrm{O}_{11}$ turn out to be highly electronegative, formation of $\mathrm{O}_{2}^{-\bullet}$ radical anions take place on the surface of the photocatalyst, as evidenced by the data obtained in the experiments with selected radical scavengers (Figure 12) where it was shown that $\mathrm{O}_{2}{ }^{-\bullet}$ species are the main active species that impact the photocatalytic activity of $\mathrm{Sr}_{6} \mathrm{Bi}_{2} \mathrm{O}_{11}$. 
Insofar as the processes involving the valence band photoholes and the half-reaction components are concerned, the potential for the formation of hydroxyl radicals, ${ }^{\circ} \mathrm{OH}$, by capture of a photohole is $+2.27 \mathrm{eV}[45]$ and $+2.38 \mathrm{eV}$ for the water molecule; however, these potentials are greater than the energy of the of the valence band photoholes so that the reactions $\mathrm{OH}^{-}+\mathrm{h}^{+} \rightarrow{ }^{\circ} \mathrm{OH}$ and $\mathrm{H}_{2} \mathrm{O}+$ $\mathrm{h}^{+} \rightarrow{ }^{\bullet} \mathrm{OH}+\mathrm{H}^{+}$will not occur on the surface of the bismuthates. Recent studies [46] have shown that the one-electron oxidation potential of phenol, which corresponds to the reaction of direct transfer of a photohole from the photocatalyst surface to the phenol molecule, is $+1.90 \mathrm{eV}$. From an energy point of view, this process is the only one possible as confirmed by the data obtained in the experiment with selected radical scavengers (Figure 12), in which the photoholes are the second active species to impact the photocatalytic activity of $\mathrm{Sr}_{6} \mathrm{Bi}_{2} \mathrm{O}_{11}$. Figure 20 illustrates the scheme for the photocatalytic processes that involve the strontium bismuthate $\mathrm{Sr}_{6} \mathrm{Bi}_{2} \mathrm{O}_{11}$; shown are the superoxide radical anions initiating the oxidative decomposition of phenol to water and carbon dioxide through the para- and ortho-benzoquinone intermediates. These same intermediates also form in the first stage of the oxidative half-reaction [47].
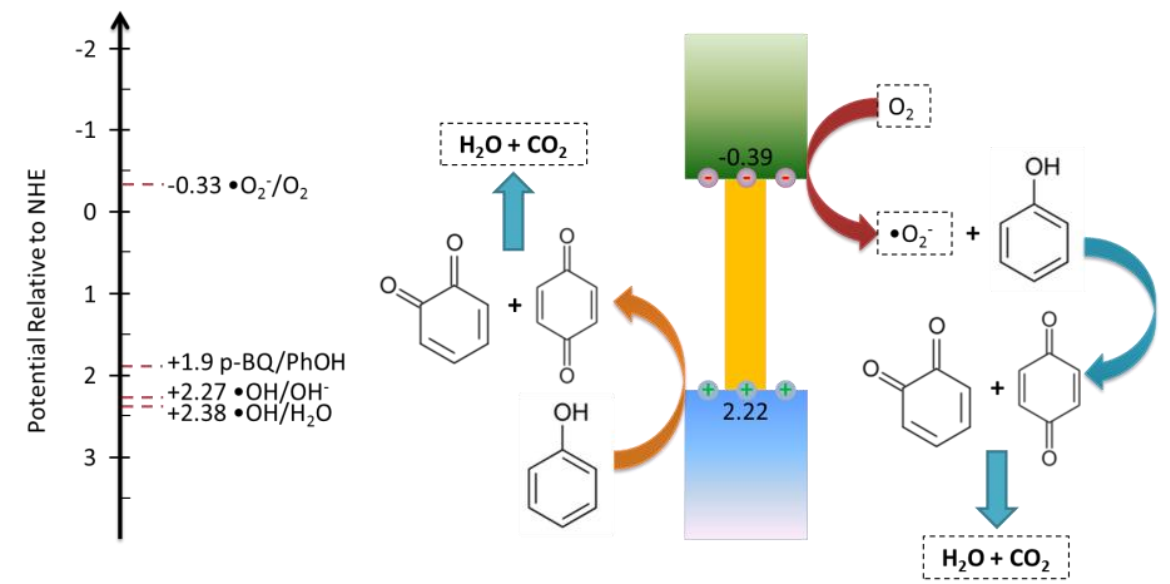

Figure 20. Scheme illustrating the photocatalytic processes that involve the strontium bismuthate $\mathrm{Sr}_{6} \mathrm{Bi}_{2} \mathrm{O}_{11}$.

Strontium bismuthate $\mathrm{Sr}_{3} \mathrm{Bi}_{2} \mathrm{O}_{6}$ differs significantly from the $\mathrm{Sr}_{6} \mathrm{Bi}_{2} \mathrm{O}_{11}$ bismuthate in composition and energetics. It has a wider bandgap width of $3.4 \mathrm{eV}$, and the energies of the top of the valence band and the bottom of the conduction band are also significantly shifted upward on the NHE scale: $+1.71 \mathrm{eV}$ and $-1.96 \mathrm{eV}$, respectively. Let us first consider the processes taking place with the participation of photoelectrons in this bismuthate. First of all, one important difference to be noted in the $\mathrm{Sr}_{3} \mathrm{Bi}_{2} \mathrm{O}_{6}$ composition from the one considered earlier is that during the photoactivation, not only the conduction band is filled with photoelectrons, but the defect levels designated as 1, 2 and 3 (Figure 21) within the bandgap also capture the photoelectrons. The latter trapped/localized photoelectrons 
cannot be involved in further photocatalytic processes. As in the previous case, formation of the superoxide radical anions occurs with the participation of photoelectrons in the conduction band. Based on a suitable arrangement of the levels, the oxidative half-reaction via these reactive oxygen species is likely a very significant path to the ultimate photodegradation of substrates. However, $\operatorname{the} \mathrm{Sr}_{3} \mathrm{Bi}_{2} \mathrm{O}_{6}$ system demonstrated a rather low photocatalytic activity compared to $\operatorname{Sr}_{6} \mathrm{Bi}_{2} \mathrm{O}_{11}$. The limiting factor is likely to be the channel of the reductive half-reaction involving the photoelectrons as these are trapped by the defects within the bandgap.
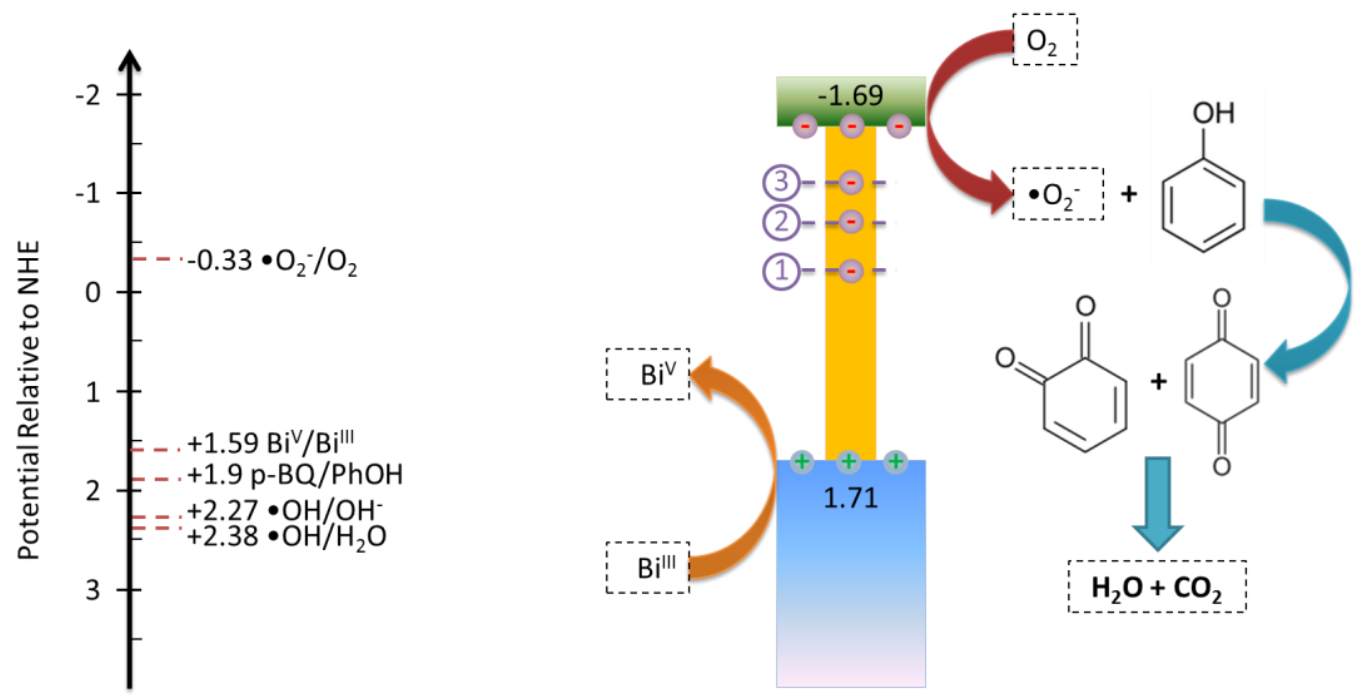

Figure 21. Scheme depicting the photocatalytic process with the strontium bismuthate $\mathrm{Sr}_{3} \mathrm{Bi}_{2} \mathrm{O}_{6}$.

In this regard, as seen in the energy scheme of Figure 21, the oxidative half-reaction cannot occur in any of the mechanisms discussed above, i.e., formation of ${ }^{\circ} \mathrm{OH}$ radicals from $\mathrm{OH}^{-}$ions or from $\mathrm{H}_{2} \mathrm{O}$, as well as direct transfer of photoholes to phenol are non-players. Therefore, the observed weak photocatalytic activity of this bismuthate is mostly due to a weaker reduction half-reaction, which dampens somewhat the phenol decomposition rate by superoxide radical anions. Photoholes are known [48] to change the oxidation state of bismuth atoms, in addition to which such a process prevents the formation of hydroxyl radicals as reported for fairly similar structures [49]. Moreover, the reduction half-reaction is limited by the number of bismuth atoms, which can be converted from the trivalent to the pentavalent state, an occurrence not possible in the strontium bismuthate $\operatorname{Sr}_{6} \mathrm{Bi}_{2} \mathrm{O}_{11}$, as bismuth is already in the pentavalent form.

It was shown earlier that addition of the ammonium oxalate hole scavenger increases significantly the photocatalytic activity of $\mathrm{Sr}_{3} \mathrm{Bi}_{2} \mathrm{O}_{6}$; an explanation for this observation is embodied in the mechanistic of photostimulated processes depicted in Figure 22 wherein the oxidative half-reaction 
is kept unchanged. However, addition of ammonium oxalate significantly affects the processes of the oxidative half-reaction. The redox potential of ammonium oxalate is $+1.15 \mathrm{eV}$ [50]. This means that the oxidative decomposition of ammonium oxalate will be the predominant process rather than the $\mathrm{Bi}^{\mathrm{III}}$ $\rightarrow \mathrm{Bi}^{\mathrm{V}}$ process for which the redox potential is $+1.59 \mathrm{eV}$, and as such the photocatalytic activity of $\mathrm{Sr}_{3} \mathrm{Bi}_{2} \mathrm{O}_{6}$ is diminished.
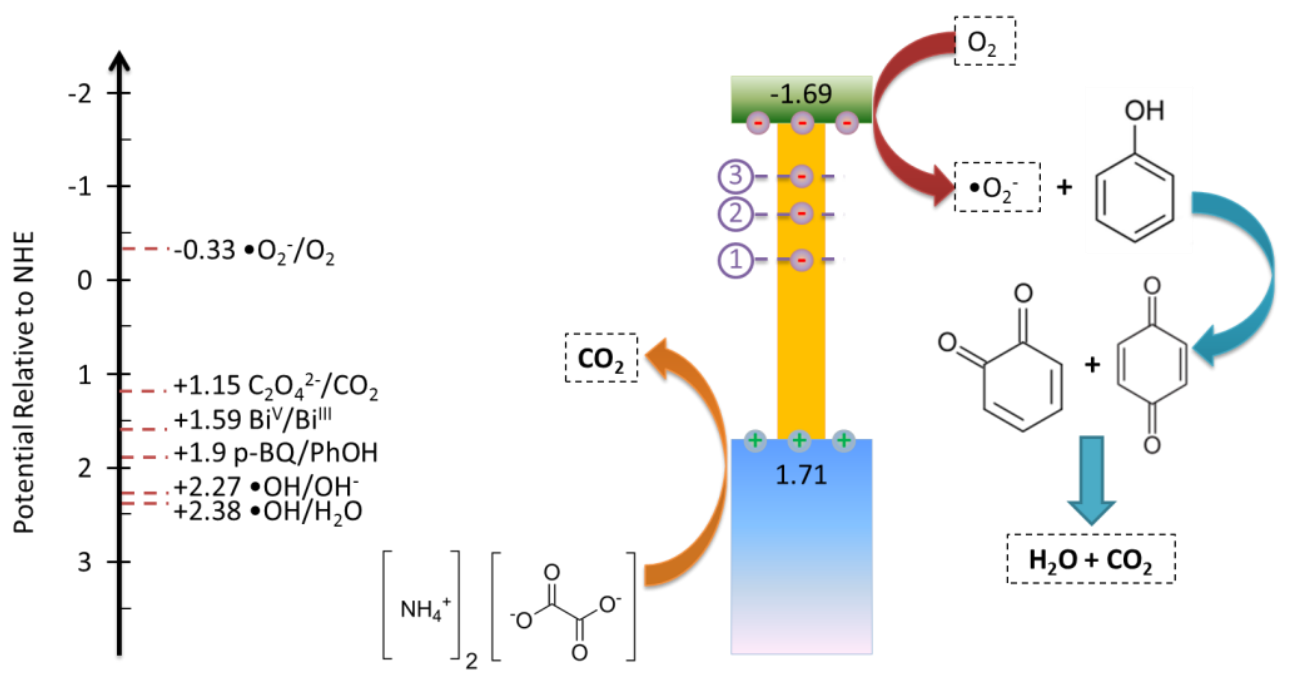

Figure 22. Scheme illustrating the photocatalytic process involving the strontium bismuthate $\mathrm{Sr}_{3} \mathrm{Bi}_{2} \mathrm{O}_{6}$ and the sacrificial agent ammonium oxalate.

The strontium bismuthate $\mathrm{Sr}_{2} \mathrm{Bi}_{2} \mathrm{O}_{5}$ is similar in the width of the bandgap as well as in the relative potentials of the valence and conduction bands with those of $\mathrm{Sr}_{3} \mathrm{Bi}_{2} \mathrm{O}_{6}$ : the bandgap energy is $3.17 \mathrm{eV}$, while the energies of the top of the valence band and the bottom of the conduction band are, respectively, $+1.61 \mathrm{eV}$ and $-1.56 \mathrm{eV}$. However, the $\mathrm{Sr}_{2} \mathrm{Bi}_{2} \mathrm{O}_{5}$ sample embodies a larger number of defect levels (oxygen vacancies) within the bandgap, and which apparently act as very effective recombination centers thereby diminishing the formation of such active species as the superoxide radical anions (Figure 23). This explains the lack of photocatalytic activity of the $\mathrm{Sr}_{2} \mathrm{Bi}_{2} \mathrm{O}_{5}$ bismuthate both in the absence and presence of sacrificial electron donors (hole scavengers). 

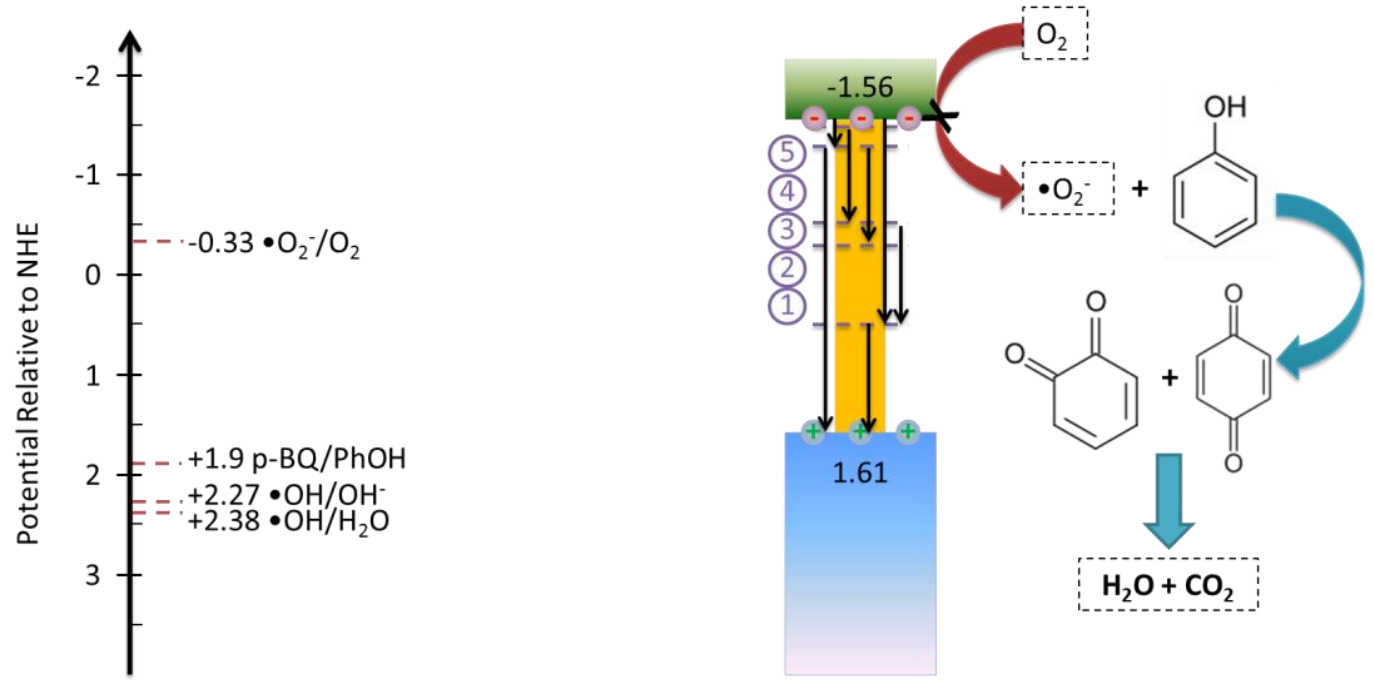

Figure 23. Flow diagram of the photocatalytic processes involving the strontium bismuthate $\mathrm{Sr}_{2} \mathrm{Bi}_{2} \mathrm{O}_{5}$.

\section{Concluding remarks}

The present studies allow us to make some thought-provoking inferences. First, two novel visible-light-active photocatalysts were prepared by a solid-state synthesis methodology; these are two strontium bismuthate systems located in the phase diagram to the right of $50 \mathrm{~mol} \%$, i.e., strontium bismuthates where the number of strontium atoms exceeds the number of bismuth atoms in the cation sublattice; they have been characterized employing a variety of spectroscopic techniques (XRD, XPS, DR, Raman, DSEM, and EIS). Second, both of these display photocatalytic activity toward the photodegradation of substrates in the gas phase (acetaldehyde) and in aqueous media (phenol), with the $\mathrm{Sr}_{6} \mathrm{Bi}_{2} \mathrm{O}_{11}$ phase exhibiting a significantly greater photoactivity than the $\mathrm{Sr}_{3} \mathrm{Bi}_{2} \mathrm{O}_{6}$ phase; for comparison, the bismuthate $\mathrm{Sr}_{2} \mathrm{Bi}_{2} \mathrm{O}_{5}$ was also re-examined. Detailed photocatalytic mechanisms have been proposed to explain how the composition and structure of the three strontium bismuthates affect their photocatalytic activity. Third, the role of point defects in the crystal lattice of these bismuthates of various structures is described for processes in which the photocatalytic activity might be inhibited. The inferences reported in this regard were aided by examining such photophysical properties of the bismuthates as the UV-induced coloration that provided information regarding defect levels within their respective bandgaps that acted as electron traps and thus affected their photocatalytic performance.

\section{Acknowledgements}

The research was graciously funded by a grant from the Russian Science Foundation (project No. 17-73-00007). P.D. Murzin, A.V. Rudakova and V.K. Ryabchuk are grateful to financial support by the Mega-grant of the Government of the Russian Federation within the Project "Establishment of the 
Laboratory "Photoactive Nanocomposite Materials" No. 14.Z50.31.0016. The authors strongly express their gratitude to the staff of the Khabarovsk Innovation and Analytical Center of the Yu. A. Kosygin Institute of Tectonics and Geophysics FEB RAS, and the Resource Centres of the Research Park at the Saint-Petersburg State University (i) Centre for Diagnostics of Functional Materials for Medicine, Pharmacology and Nanoelectronics, (ii) Centre for Physical Methods of Surface Investigation, (iii) Centre for Optical and Laser Materials Research, and (iv) Nanophotonics Centre for their valuable assistance in carrying out the research and in providing the needed equipment. One of us (NS) is grateful to Prof. Angelo Albini for his continued hospitality in the PhotoGreen Laboratory at the University of Pavia, Italy.

\section{References}

[1]. L.V. Bora, R.K. Mewada, Visible/solar light active photocatalysts for organic effluent treatment: Fundamentals, mechanisms and parametric review, Renew. Sustain. Energy Rev., 76 (2017) 1393-1421.

[2]. X. Wang, F. Wang, Y. Sang, H. Liu, Full-spectrum solar-light-activated photocatalysts for lightchemical energy conversion, Adv. Energy Mater., 7 (2017) 1700473 (15 pages); doi: 10.1002/aenm.201700473.

[3]. A. Truppi, F. Petronella, T. Placido, M. Striccoli, A. Agostiano, M.-L. Curri, R. Comparelli, Visible-light-active $\mathrm{TiO}_{2}$-based hybrid nanocatalysts for environmental applications, Catalysts, 7 (2017) 100 (33 pages); doi:10.3390/catal7040100.

[4]. M. Humayun, F. Raziq, A. Khan, W. Luo, Design of novel visible light active photocatalyst materials: Surface modified $\mathrm{TiO}_{2}$, Adv. Mater., 28 (2016) 5425-5446; doi.org/10.1080/ 17518253.2018 .1440324$.

[5]. K. Qi, B. Cheng, J. Yu, W. Ho, Review on the improvement of the photocatalytic and antibacterial activities of ZnO, J. Alloys Comp., 727 (2017) 792-820.

[6]. S. Chen, T. Takata, K. Domen. Particulate photocatalysts for overall water splitting, Nature Rev., 2 (2017) 17050 (17 pages)..

[7]. A. Lais, M.A. Gondal, M.A. Dastageer, Semiconducting oxide photocatalysts for reduction of $\mathrm{CO}_{2}$ to methanol, Environ. Chem. Letters, 16 (2018) 183-210; doi:10.1007/s10311-017-0673-8.

[8]. J. Wen, J. Xie, X. Chen, X. Li, A review on $\mathrm{g}-\mathrm{C}_{3} \mathrm{~N}_{4}$-based photocatalysts, Appl. Surf. Sci. B, 391 (2018) 72-123; DOI:10.1016/j.apsusc.2016.07.030.

[9]. X. Li, J. Yu, S. Wageh, A. Al-Ghamdi, J. Xie, Graphene in photocatalysis. A review, Small, 12 (2016) 6640-6696.

[10]. A. Nikokavoura, Ch. Trapalis. Graphene and $\mathrm{g}-\mathrm{C} 3 \mathrm{~N}_{4}$ based photocatalysts for $\mathrm{NO}_{\mathrm{x}}$ removal: A review, Appl. Surf. Sci., 430 (2018) 18-52.

[11]. R. He, S. Cao, P. Zhou, J. Yu. Recent advances in visible light Bi-based photocatalysts. Chinese J. Catal., 35 (2014) 989-1007.

[12]. D. Shtarev, V. Ryabchuk, K. Makarevich, A. Shtareva, A. Blokh, I. Astapov, N. Serpone, Calcium Bismuthate Nanoparticulates with Orthorhombic and Rhombohedral Crystalline Lattices: Effects of Composition and Structure on Photoactivity, ChemistrySelect, 2 (2017) 9851-9863. 
[13]. Y. Wang, Y. He, T. Li, J. Cai, M. Luo, L. Zhao, Photocatalytic degradation of methylene blue on $\mathrm{CaBi}_{6} \mathrm{O}_{10} / \mathrm{Bi}_{2} \mathrm{O}_{3}$ composites under visible light, Chem. Engin. J., 189-190 (2012) 473-481.

[14]. Y. Wang, Y. He, T. Li, J. Cai, M. Luo, L. Zhao, Novel $\mathrm{CaBi}_{6} \mathrm{O}_{10}$ photocatalyst for methylene blue degradation under visible light irradiation, Catal. Commun., 18 (2012) 161-164.

[15]. T. Montalvo-Herrera, D. Sanchez-Martinez, L.M. Torres-Martinez, Sonochemical synthesis of $\mathrm{CaBi}_{10}$ nanoplates: photocatalytic degradation of organic pollutants (ciprofloxacin and methylene blue) and oxidizing species study $\left(\mathrm{h}^{+},{ }^{\circ} \mathrm{OH}, \mathrm{H}_{2} \mathrm{O}_{2}\right.$ and $\left.\mathrm{O}_{2}^{-{ }^{-}}\right)$, J. Chem. Technol. Biotechnol., 92 (2017) 1496-1502.

[16]. Z. Liu, X. Wang, Q. Cai, C. Ma, Z. Tong, $\mathrm{CaBi}_{6} \mathrm{O}_{10}$ : a novel promising photoanode for photoelectrochemical water oxidation, J. Mater. Chem. A, 5 (2017) 8545-8554.

[17]. Y.-C. Yang, X. Wang, J. Qu, Preparation and photocatalytic degradation of malachite green by photocatalyst $\mathrm{SrBi}_{4} \mathrm{O}_{7}$ under visible light irradiation, Appl. Mechan. Mater., 522-524 (2014) 411-415.

[18]. W. Zhou, X. Yu, Use of $\mathrm{Sr}_{2} \mathrm{Bi}_{2} \mathrm{O}_{5}$ as photocatalyst for the degradation of acid red G, Desalin. Water Treatm., 30 (2011) 295-299.

[19]. Z. Shan, Y. Xia, Y. Yang, H. Ding, F. Huang, Preparation and photocatalytic activity of novel efficient photocatalyst $\mathrm{Sr}_{2} \mathrm{Bi}_{2} \mathrm{O}_{5}$, Mater. Letters, 63 (2009) 75-77.

[20]. Y. Obukuro, S. Matsushima, K. Obata, T. Suzuki, M. Arai, E. Asato, Y. Okuyama, N. Matsunaga, G. Sakai, Effects of $\mathrm{La}$ doping on structural, optical, electronic properties of $\mathrm{Sr}_{2} \mathrm{Bi}_{2} \mathrm{O}_{5}$ photocatalyst, J. Alloys Comp., 658 (2016) 139-146; doi:10.1016/j.jallcom.2015.10.199.

[21]. X. Hu, C. Hu, J. Qu, Photocatalytic decomposition of acetaldehyde and Escherichia coli using $\mathrm{NiO} / \mathrm{SrBi}_{2} \mathrm{O}_{4}$ under visible light irradiation, Appl. Catal. B:Environ., 69 (2006) 17-23.

[22]. C. Hu, X. Hu, J. Guo, J. Qu, Efficient destruction of pathogenic bacteria with $\mathrm{NiO} / \mathrm{SrBi}_{2} \mathrm{O}_{4}$ under visible light irradiation. Environ. Sci. Technol., 40 (2006) 5508-5513.

[23]. D.S. Shtarev, A.I. Blokh, E.O. Nashchochin, A.V. Shtareva, The dependence of the conduction band edge of the alkali earth metal bismuthates on their composition, Optic. Quant. Electron., 50 (2018) 228; doi:10.1007/s11082-018-1498-9

[24]. B, Hallstedt, L, J. Gauckler, Revision of the thermodynamic descriptions of the $\mathrm{Cu}-\mathrm{O}, \mathrm{Ag}-\mathrm{O}$, $\mathrm{Ag}-\mathrm{Cu}-\mathrm{O}, \mathrm{Bi}-\mathrm{Sr}-\mathrm{O}, \mathrm{Bi}-\mathrm{Ca}-\mathrm{O}, \mathrm{Bi}-\mathrm{Cu}-\mathrm{O}, \mathrm{Sr}-\mathrm{Cu}-\mathrm{O}, \mathrm{Ca}-\mathrm{Cu}-\mathrm{O}$ and $\mathrm{Sr}-\mathrm{Ca}-\mathrm{Cu}-\mathrm{O}$ systems. Computer Coupling of Phase Diagrams and Thermochem., 27 (2003) 177-191.

[25]. NIST X-ray Photoelectron Spectroscopy Database: see http://srdata.nist.gov/

[26]. ISO 22197-2: "Test method for air-purification performance of semiconducting photocatalytic materials, removal of acetaldehyde".

[27]. D. S. Shtarev, A. V. Shtareva, A. I. Blokh, P. S. Goncharova, K. S. Makarevich, On the question of the optimal concentration of benzoquinone when it is used as a radical scavenger, Appl. Phys. A, 123 (2017) 602.

[28]. R.S. Roth, C.J. Rawn, B.P. Burton, F. Beech. Phase equilibria and crystal chemistry in portions of the system $\mathrm{SrO}^{\prime} \mathrm{CaO}-\mathrm{Bi}_{2} \mathrm{Os}-\mathrm{CuO}$, Part II - The System $\mathrm{SrO}-\mathrm{Bi}_{2} \mathrm{O}_{3}-\mathrm{CuO}$, J. Res. Natl. Inst. Stand. Technol., 95 (1990) 291-335.

[29]. W. Wong-Ng, H. F. McMurdie, B. Paretzkin, M. A. Kuchinski, A. L. Dragoo, Standard X-ray diffraction powder patterns of fourteen ceramic phases, Powder Diffraction, 3 (1988) 246- 254. 
[30]. M. Portilla, Oxygen and the formation of new ordered perovskite-based structures in the Bi-Sr-O system, J. Solid State Chem., 105 (1993) 371-377.

[31]. R. J. Betsch, W. B. White, Vibrational spectra of bismuth oxide and the sillenite-structure bismuth oxide derivatives, Spectrochim. Acta Part A: Molec. Spectros., 34 (1978) 505-514

[32]. S.N. Narang, N.D. Patel, V.B. Kartha, Infrared and Raman spectral studies $\alpha-\mathrm{Bi}_{2} \mathrm{O}_{3}$, J. Molec. Struct., 327 (1994) 221-235.

[33]. R. V. Kumar, A. Edukondalu, B. Srinivas, G. Sriramulu, M. G. Krishna, K. S. Kumar, FTIR and Raman studies on $25 \mathrm{Bi}_{2} \mathrm{O}_{3}-(75-\mathrm{x}) \mathrm{B}_{2} \mathrm{O}_{3}-\mathrm{xBaO}$ glasses, AIP Conference Proceedings, 1665 (1995) 070038.

[34]. A. A. Kharlamov, R. M. Almeida, J. Heo, Vibrational spectra and structure of heavy metal oxide glasses, J. Non-Crystal. Solids, 202 (1996) 233-240.

[35]. K. H. Rieder, B. A. Weinstein, M. Cardona, H. Bilz, Measurement and comparative analysis of the second-order Raman spectra of the alkaline-earth oxides with a $\mathrm{NaCl}$ structure, Phys. Rev. $B, 8$ (1973) 4780-4786.

[36]. C. Gautam, A. K. Yadav, V. K. Mishra, K. Vikram, Synthesis, IR and Raman spectroscopic studies of $(\mathrm{Ba}, \mathrm{Sr}) \mathrm{TiO}_{3}$ borosilicate glasses with addition of $\mathrm{La}_{2} \mathrm{O}_{3}$, Open J. Inorg. Non-met. Mat., 2 (2012) 47-54.

[37]. A. Dutta, P. K. Mukhopadhyay, T. P. Sinha, S. Shannigrahi, A. K. Himanshu, P. Sen, S. K. Bandyopadhyay, $\mathrm{Sr}_{2} \mathrm{SmNbO}_{6}$ perovskite: Synthesis, characterization and density functional theory calculations, Mat. Chem. Phys., 179 (2016) 55-64.

[38]. S. Hazra, S. Mandal, A. Ghosh, Properties of unconventional lithium bismuthate glasses, Phys. Rev. B, 56 (1997) 8021-8025.

[39]. S. Hazra, A. Ghosh, Structure and properties of nonconventional glasses in the binary bismuth cuprate system, Phys. Rev., 51 (1995) 851-857.

[40]. S.E. Braslavsky, A.M. Braun, A.E. Cassano, A.V. Emeline, M.I. Litter, L. Palmisano, V.N. Parmon, N. Serpone, Glossary of terms used in photocatalysis and radiation catalysis (IUPAC Recommendations 2011), Pure Appl. Chem., 83 (2011) 931 - 1014

[41]. A.V. Emeline, G.V. Kataeva, V.K. Ryabchuk, N. Serpone, Photostimulated generation of defects and surface reactions on a series of wide band-gap metal-oxide solids, J. Phys. Chem. B., 103 (1999) 9190-9199.

[42]. V.K. Ryabchuk, Photophysical processes related to photoadsorption and photocatalysis on wide band gap solids: A review, Int. J. Photoenergy, 6 (2004) 95-113.

[43]. V. N. Kuznetsov, A. V. Emeline, A. V. Rudakova, M. S. Aleksandrov, N. I. Glazkova, V. A. Lovtcius, G. V. Kataeva, R. V. Mikhaylov, V. K. Ryabchuk, N. Serpone. Visible-NIR light absorption of titania thermochemically fabricated from titanium and its alloys; UV- and visiblelight-induced photochromism of yellow titania, J. Phys. Chem. C, 117 (2013) 25852-25864

[44]. L. Shaitanov, A. Murashkina, A. Rudakova, V. Ryabchuk, A. Emeline, Y. Artemev, G. Kataeva, N. Serpone. UV-induced formation of color centers in dispersed $\mathrm{TiO}_{2}$ particles: Effect of thermal treatment, metal (Al) doping, and adsorption of molecules, J. Photochem. Photobiol. Sci.. 354 (2018) 33-46.

[45]. S. Park J. Park, R. Selvaraj, Y. Kim, Facile microwave-assisted synthesis of $\mathrm{SnS}_{2}$ nanoparticles for visible-light responsive photocatalyst, J. Ind. Engin. Chem., 31 (2015) 269-275. 
[46]. A.S. Pavitt, E. Bylaska, P.G. Tratnyek, Oxidation potentials of phenols and anilines: correlation analysis of electrochemical and theoretical values, Environ. Sci.: Processes Impacts, 19 (2017) 339-349; DOI: 10.1039/C6EM00694A.

[47]. T.A. Enache, A.M. Oliveira-Brett, Phenol and para-substituted phenols electrochemical oxidation pathways, J. Electroanal, Chem,, 655 (2011) 9-16.

[48]. H. Fu, C. Pan, W. Yao, Y. Zhu, Visible-light-induced degradation of rhodamine B by nanosized $\mathrm{Bi}_{2} \mathrm{WO}_{6}$, J. Phys. Chem. B, 109 (2005) 22432- 22439.

[49]. Y.-R. Jiang, S.-Y. Chou, J.-L. Chang, S.-T. Huang, H.-P. Linand, C.-C. Chen, Hydrothermal synthesis of bismuth oxybromide-bismuth oxyiodide composites with high visible light photocatalytic performance for the degradation of CV and phenol, RSC Adv., 5 (2015) 30851.

[50]. B. Sljukic, R. Baron, R. G. Compton, Electrochemical determination of oxalate at pyrolytic graphite electrodes, Electroanalysis, 19 (2007) 918-922; DOI: 10.1002/elan.200703852. 


\section{Strontium Bismuthates - Novel Highly Effective Visible-Light-Active Photocatalysts}

D. S. Shtarev, ${ }^{1,2}$ A. V. Shtareva, ${ }^{1}$ V. K. Ryabchuk, ${ }^{3}$ A. V. Rudakova, ${ }^{3}$ P. D. Murzin, ${ }^{3}$ M. S. Molokeev, ${ }^{2,4,5}$ A. V. Koroleva, ${ }^{3}$ A. I. Blokh, ${ }^{2}$ and N. Serpone ${ }^{6} *$

${ }^{1} Y u$. A. Kosygin Institute of Tectonics and Geophysics, Far Eastern branch of the Russian Academy of Sciences, 65 Kim Yu. Chen Street, Khabarovsk, 680063 Russian Fedferation. shtarev@mail.ru ; avshtareva@mail.ru

${ }^{2}$ Far Eastern State Transport University, 47 Seryshev Street, Khabarovsk, 680021 Russian Federation. msmolokeev@mail.ru ; blokh@rambler.ru

${ }^{3}$ Laboratory of "Photoactive Nanocomposite Materials" and Department of Photonics, V.A. Fock Faculty of Physics, St. Petersburg State University, Ulianovskaya 2, Petergof, Saint-Petersburg, 198904 Russian Federation; v.ryabchuk@spbu.ru ; arudakova@mail.ru ; p.d.murzin@gmail.com ; dalika@inbox.ru

${ }^{4}$ Kirensky Institute of Physics, Akademgorodok 50, bld. 38, Krasnoyarsk, 660036 Russian Federation.

5 Siberian Federal University, 79 Svobodny pr., 660041 Krasnoyarsk, Russian Federation.

${ }^{6}$ PhotoGreen Laboratory, Dipartimento di Chimica, Universita di Pavia, via Taramelli 12, Pavia 27100, Italia. nick.serpone@unipv.it

\section{Supplementary Information}

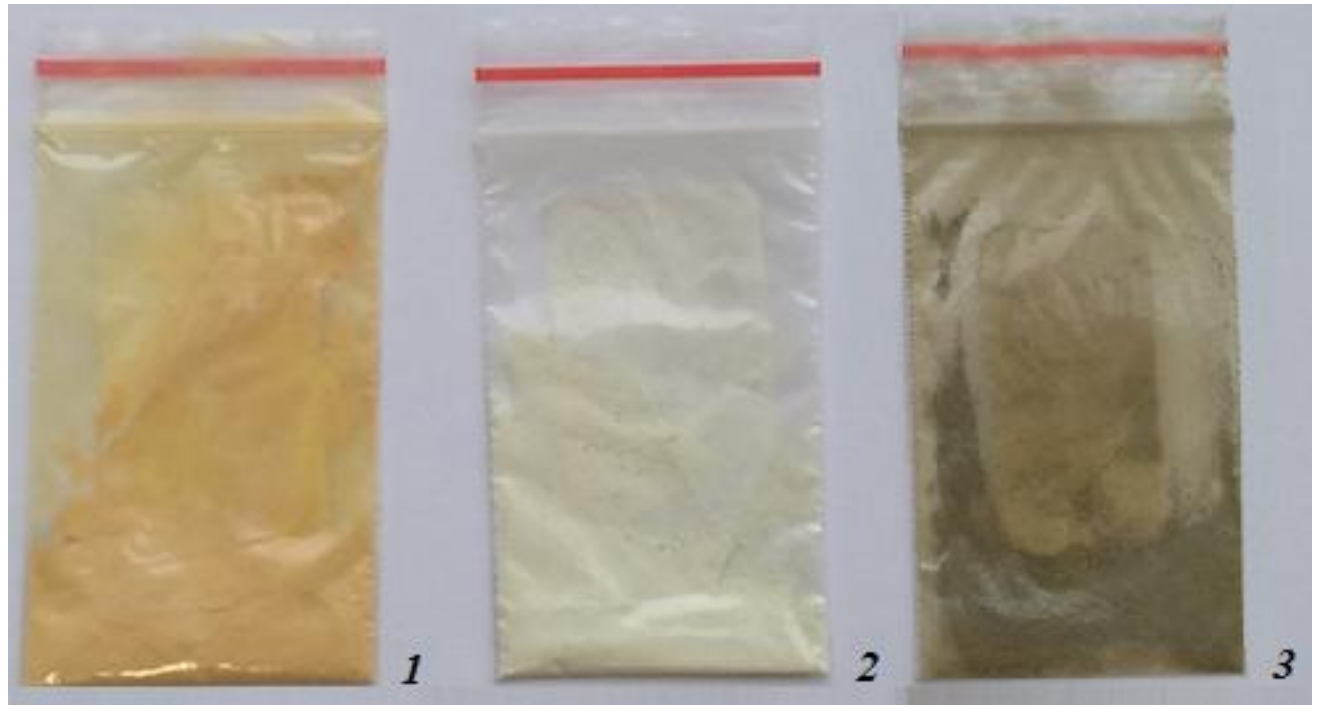

Figure S1. Photographs of strontium bismuthates: $\mathrm{Sr}_{2} \mathrm{Bi}_{2} \mathrm{O}_{5}(1), \mathrm{Sr}_{3} \mathrm{Bi}_{2} \mathrm{O}_{6}$ (2), and $\mathrm{Sr}_{6} \mathrm{Bi}_{2} \mathrm{O}_{11}$ (3). 


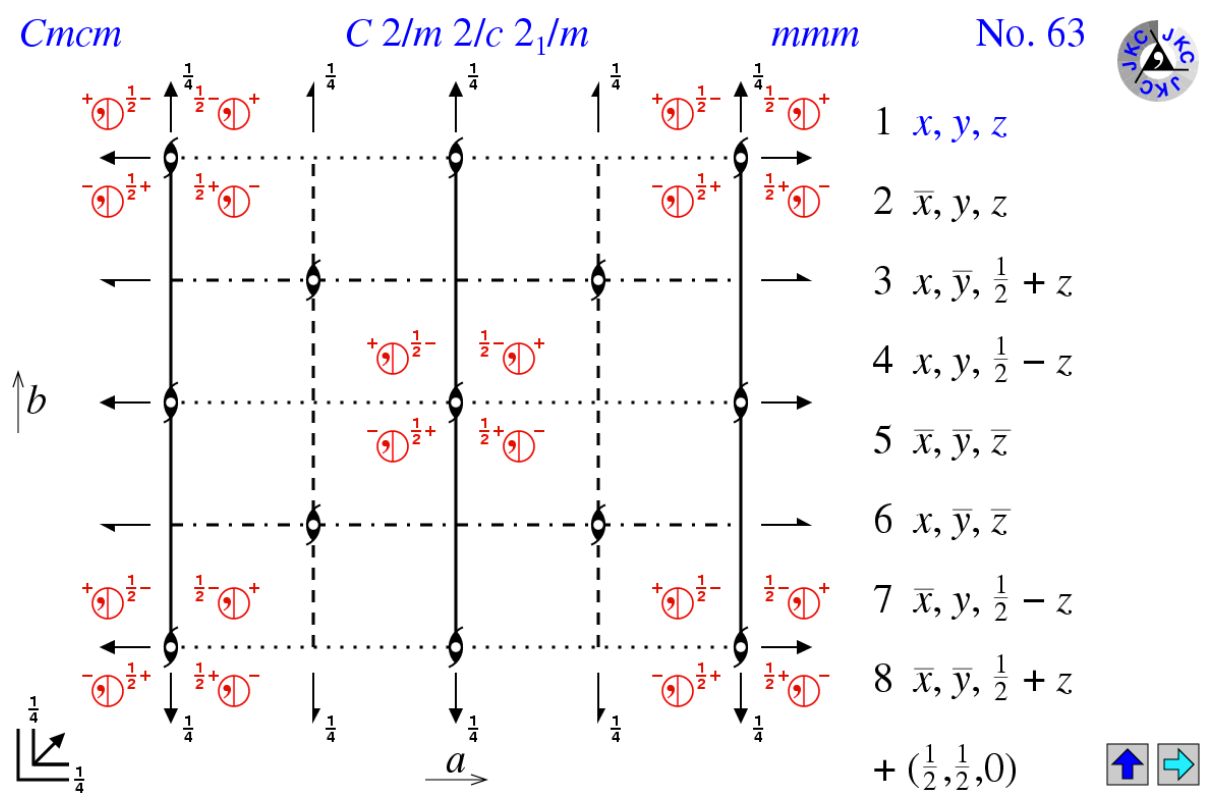

(a)

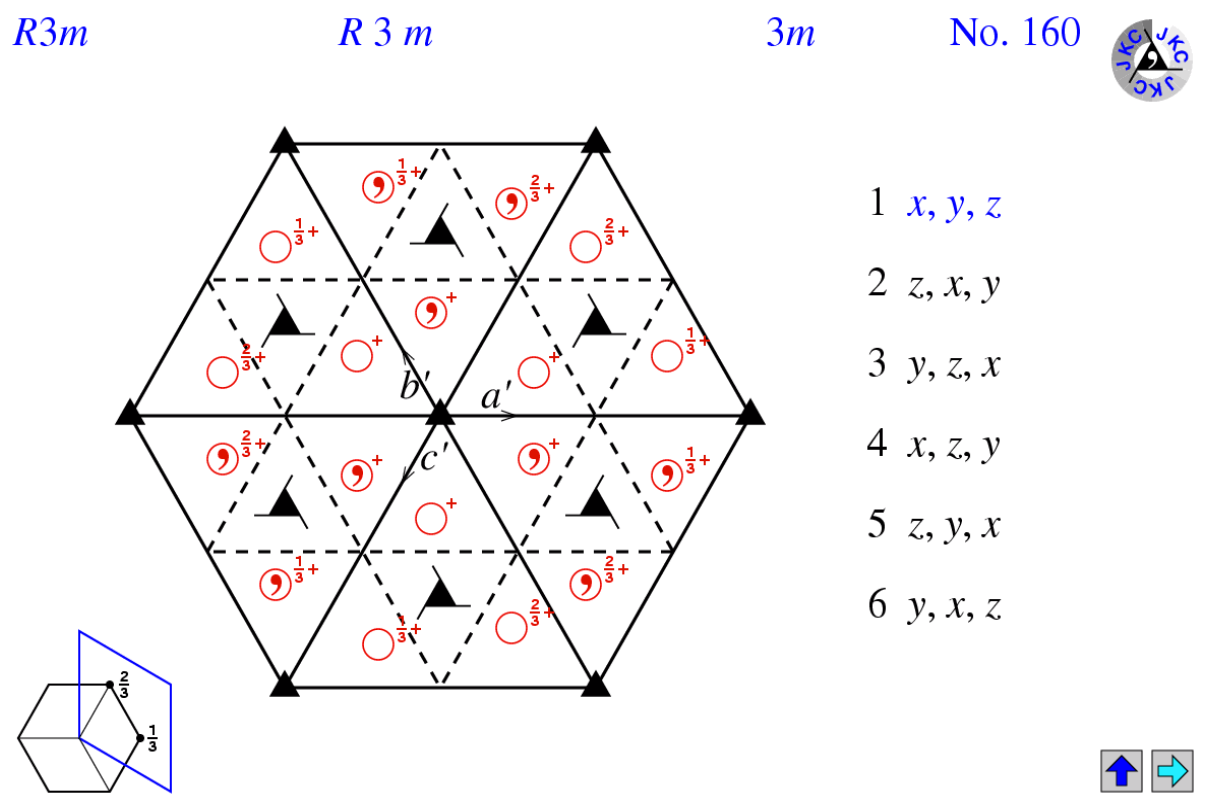

(b) 


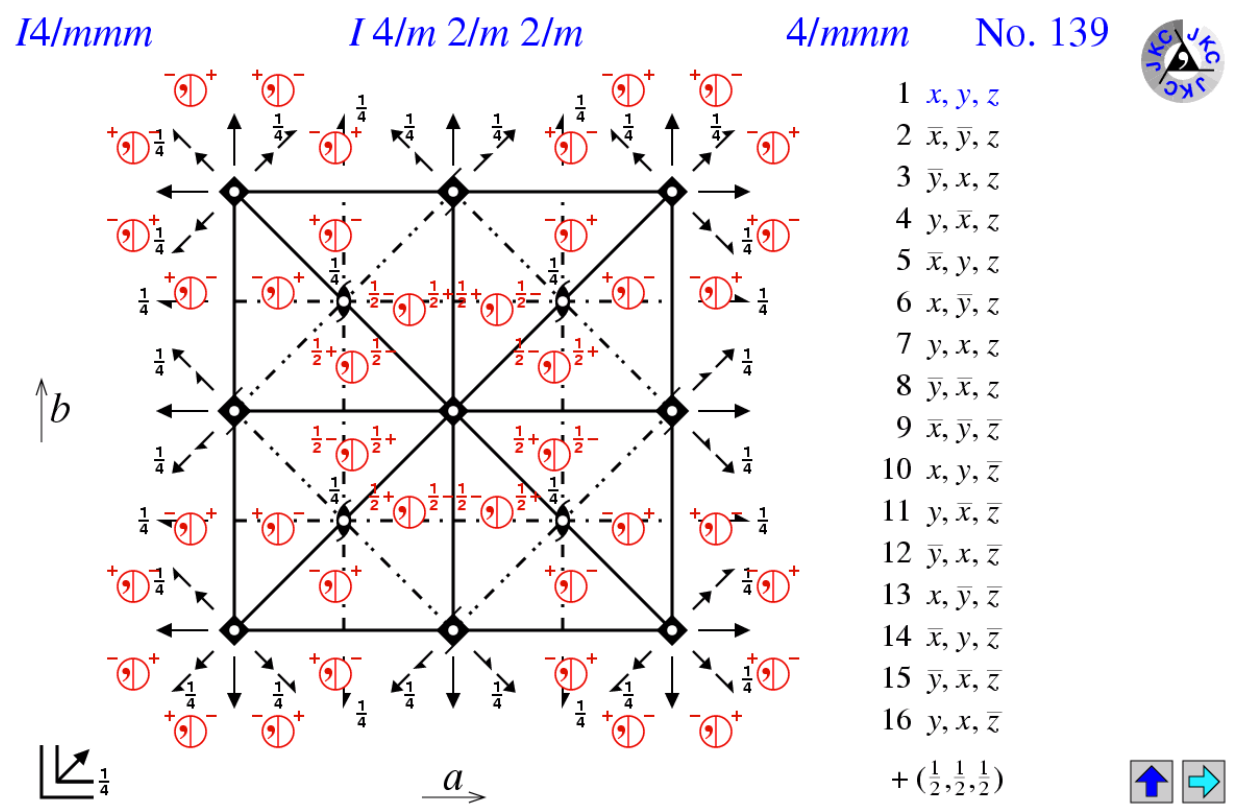

(c)

Figure S2. Space Group Diagrams for studied strontium bismuthates (a) $-\mathrm{Sr}_{2} \mathrm{Bi}_{2} \mathrm{O}_{5}$, (b) $-\mathrm{Sr}_{6} \mathrm{Bi}_{2} \mathrm{O}_{11}$, and (c) $\mathrm{Sr}_{3} \mathrm{Bi}_{2} \mathrm{O}_{6}$
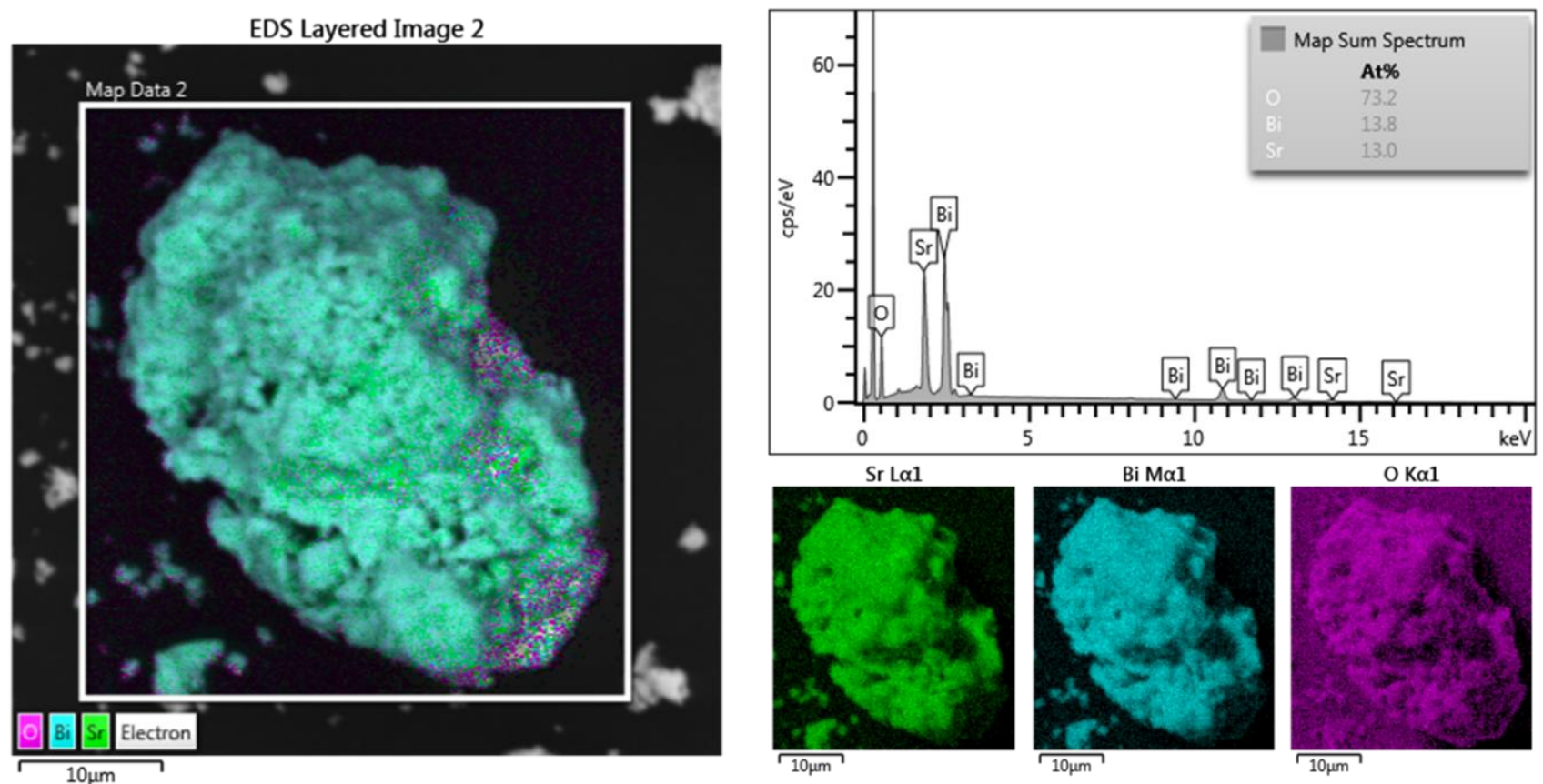

Figure S3. EDX spectrum and mapping by all basic elements of the $\mathrm{Sr}_{2} \mathrm{Bi}_{2} \mathrm{O}_{5}$ particle. 

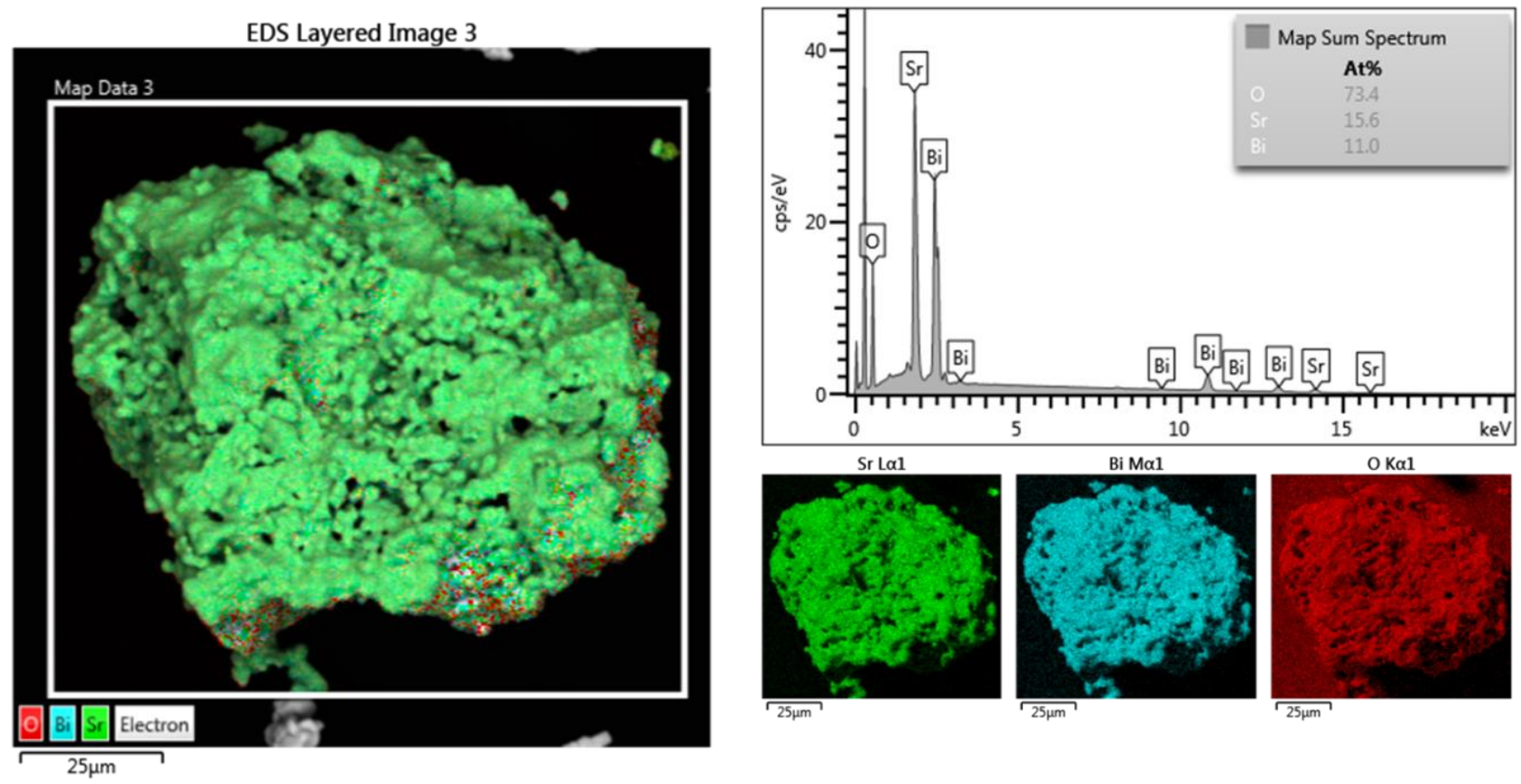

Figure S4. EDX spectrum and mapping by all basic elements of the $\mathrm{Sr}_{3} \mathrm{Bi}_{2} \mathrm{O}_{6}$ particle
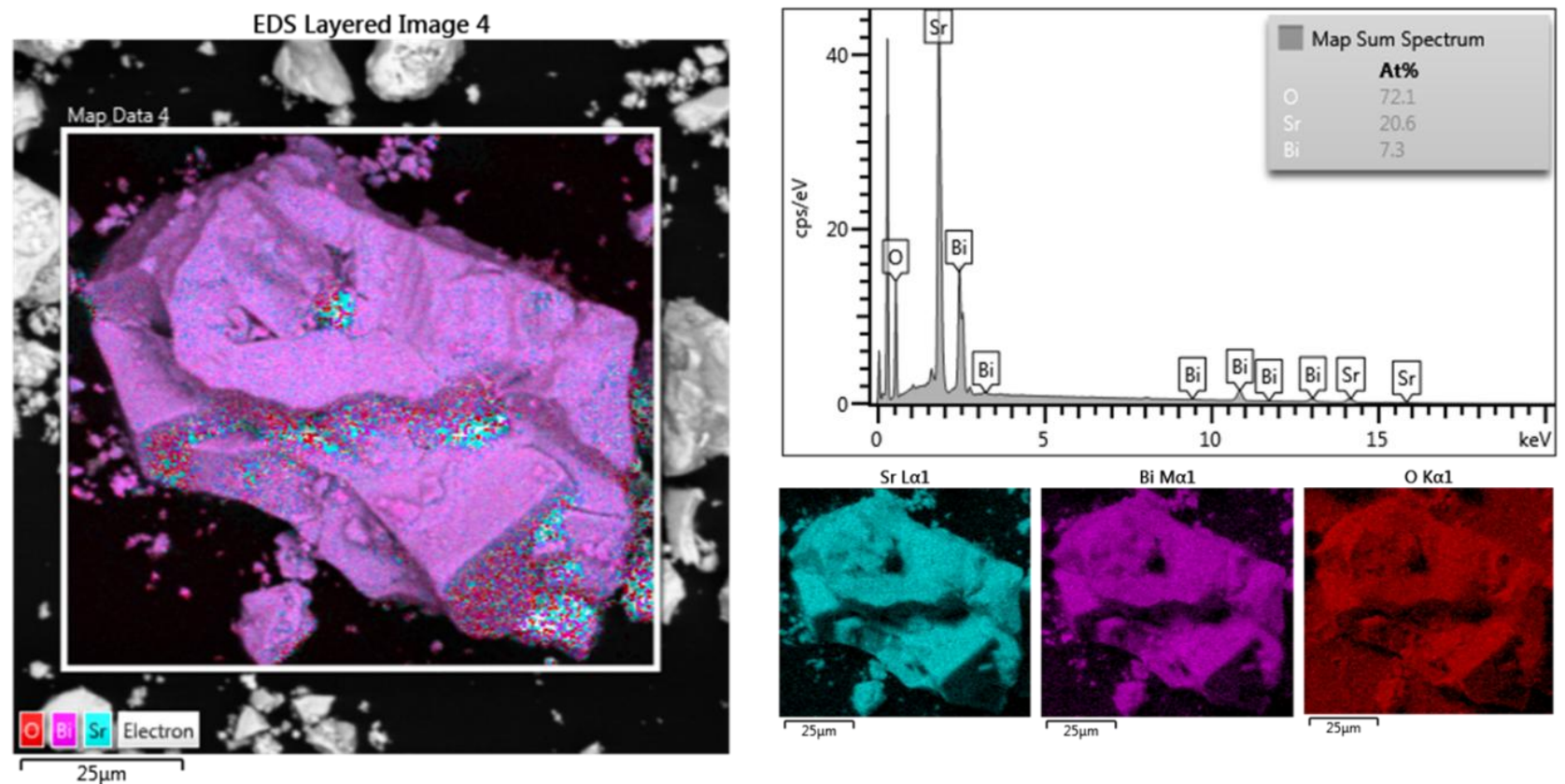

Figure S5. EDX spectrum and mapping by all basic elements of the $\mathrm{Sr}_{6} \mathrm{Bi}_{2} \mathrm{O}_{11}$ particle 
Table S1. The frequencies of Raman modes for all synthesized strontium bismuthates .

\begin{tabular}{|c|c|c|c|c|}
\hline \multirow{2}{*}{ Interpretation } & \multicolumn{3}{|c|}{ Raman shift, $\mathrm{cm}^{-1}$} & \multirow{2}{*}{ Reference } \\
\hline & $\mathrm{Sr}_{2} \mathrm{Bi}_{2} \mathbf{O}_{5}$ & $\mathrm{Sr}_{3} \mathbf{B i}_{2} \mathbf{O}_{6}$ & $\mathrm{Sr}_{6} \mathrm{Bi}_{2} \mathrm{O}_{11}$ & \\
\hline $\mathrm{Bi}_{2} \mathrm{O}_{3}$ lattice vibrations & $100 \mathrm{~m}$ & $100 \mathrm{str}$ & $101 \mathrm{vs}$ & [1] \\
\hline $\mathrm{SrO}^{-}$vibrations & 142 vs & $131 \mathrm{~m}$ & $140 \mathrm{sh}$ & {$[2-4]$} \\
\hline $\begin{array}{l}\mathrm{Bi}^{3+} \text { cation vibrations in } \\
\mathrm{BiO}_{3} \text { and } \mathrm{BiO}_{6}\end{array}$ & $152 \mathrm{~s}$ & $140 \mathrm{w}$ & $151 \mathrm{sh}$ & {$[1,5-7]$} \\
\hline $\begin{array}{c}\mathrm{O}-\mathrm{Bi}-\mathrm{O} \text { vibrations in } \mathrm{BiO}_{3} \\
\text { and } \mathrm{BiO}_{6}\end{array}$ & $\begin{array}{l}191 \mathrm{vW} \\
204 \mathrm{vW}\end{array}$ & - & - & {$[1,5-8]$} \\
\hline $\mathrm{SrO}^{-}$vibrations & $\begin{array}{l}269 \mathrm{w} \\
285 \mathrm{w}\end{array}$ & $\begin{array}{c}- \\
282 \mathrm{vW}\end{array}$ & $\begin{array}{c}- \\
295 \mathrm{w}, \mathrm{br}\end{array}$ & {$[2-4]$} \\
\hline $\begin{array}{l}\mathrm{Bi}-\mathrm{O}-\mathrm{Bi} \text { stretching vibrations } \\
\text { in distorted } \mathrm{BiO}_{6}\end{array}$ & $\begin{array}{l}330 \mathrm{w} \\
341 \mathrm{w}\end{array}$ & $\begin{array}{c}315 \mathrm{w} \\
353 \mathrm{w} \\
525 \mathrm{w}, \text { br }\end{array}$ & $\begin{array}{l}- \\
- \\
-\end{array}$ & {$[5,7-10]$} \\
\hline $\mathrm{SrO}^{-}$vibrations & $\begin{array}{l}390 \mathrm{w} \\
496 \mathrm{w}\end{array}$ & - & - & {$[2-4]$} \\
\hline $\begin{array}{c}{\mathrm{Bi}-\mathrm{O}^{-}}^{-} \text {stretching vibrations } \\
\text { in } \mathrm{BiO}_{6}\end{array}$ & $574 \mathrm{w}$ & $586 \mathrm{~m}$ & 577 w, br & {$[5,7,10]$} \\
\hline $\mathrm{Bi}-\mathrm{O}-\mathrm{Sr}$ in $\mathrm{BiO}$ plane & $610 \mathrm{w}$ & - & - & [11] \\
\hline $\mathrm{SrO}^{-}$vibrations & $661 \mathrm{~m}$ & $622 \mathrm{sh}$ & $653 \mathrm{sh}$ & {$[2-4]$} \\
\hline $\begin{array}{c}\mathrm{Bi}^{-} \mathrm{O}^{-} \text {stretching vibrations } \\
\text { in } \mathrm{BiO}_{3}\end{array}$ & $684 \mathrm{w}$ & $644 \mathrm{vs}$ & $678 \mathrm{vs}$ & {$[5,7,9,10]$} \\
\hline
\end{tabular}

The band intensity (or another spectral characteristics) marks by letters: $\mathrm{s}$ - strong, vs - very strong, $\mathrm{m}$ medium, w - weak, vw - very weak, sh - shoulder, br - broad.

Table S2. XPS data on the element composition of the surface of strontium bismuthate samples (with and without taking into account the surface chemisorbed $\mathrm{CO}_{2}$ molecules)

\begin{tabular}{|l|c|c|c|c|c|c|}
\hline \multirow{2}{*}{ Element } & \multicolumn{2}{|c|}{$\mathbf{S r}_{\mathbf{2}} \mathbf{B i}_{\mathbf{2}} \mathbf{O}_{\mathbf{5}}$} & \multicolumn{2}{c|}{$\mathbf{S r}_{\mathbf{3}} \mathbf{B i}_{2} \mathbf{O}_{\mathbf{6}}$} & \multicolumn{2}{c|}{$\mathbf{S r}_{\mathbf{6}} \mathbf{B i}_{\mathbf{2}} \mathbf{O}_{\mathbf{1 1}}$} \\
\cline { 2 - 7 } & with C & without C & with C & without C & with C & $\begin{array}{l}\text { without } \\
\mathbf{C}\end{array}$ \\
\hline Strontium (Sr3d5), at.\% & 11.42 & 21.3 & 11.51 & 26.9 & 14.77 & 31.6 \\
\hline Bismuth (Bi4f), at.\% & 6.61 & 23.2 & 5.04 & 18.4 & 2.50 & 10.5 \\
\hline Oxygen (O1s), at.\% & 43.02 & 55.5 & 40.35 & 54.7 & 44.92 & 57.9 \\
\hline Carbon (C1s), at.\% & 38.95 & - & 43.10 & - & 37.81 & - \\
\hline
\end{tabular}


The band gap energy $\left(E_{\mathrm{g}}\right)$ of bismuthates has been estimated from DR spectra [12] using Tauc plot (

Figure S) i.e. graphic solution of Tauc equation

$$
\alpha(h v)=\text { const } \frac{\left(h v-E_{g}\right)^{m}}{h v}
$$

For a case of direct allowed band-to-band optical transitions $(\mathrm{m}=1 / 2)$ modified by substitution of linear absorption coefficient $\alpha(h v)$ in eqn. Ошибка! Источник ссылки не найден. on the Kubelka-Munk function:

$$
F(h v)=\frac{\alpha(h v)}{s(h v)}=\frac{[1-R(h v)]^{2}}{2 R(h v)}=\frac{A(h v)^{2}}{2 R(h v)}
$$

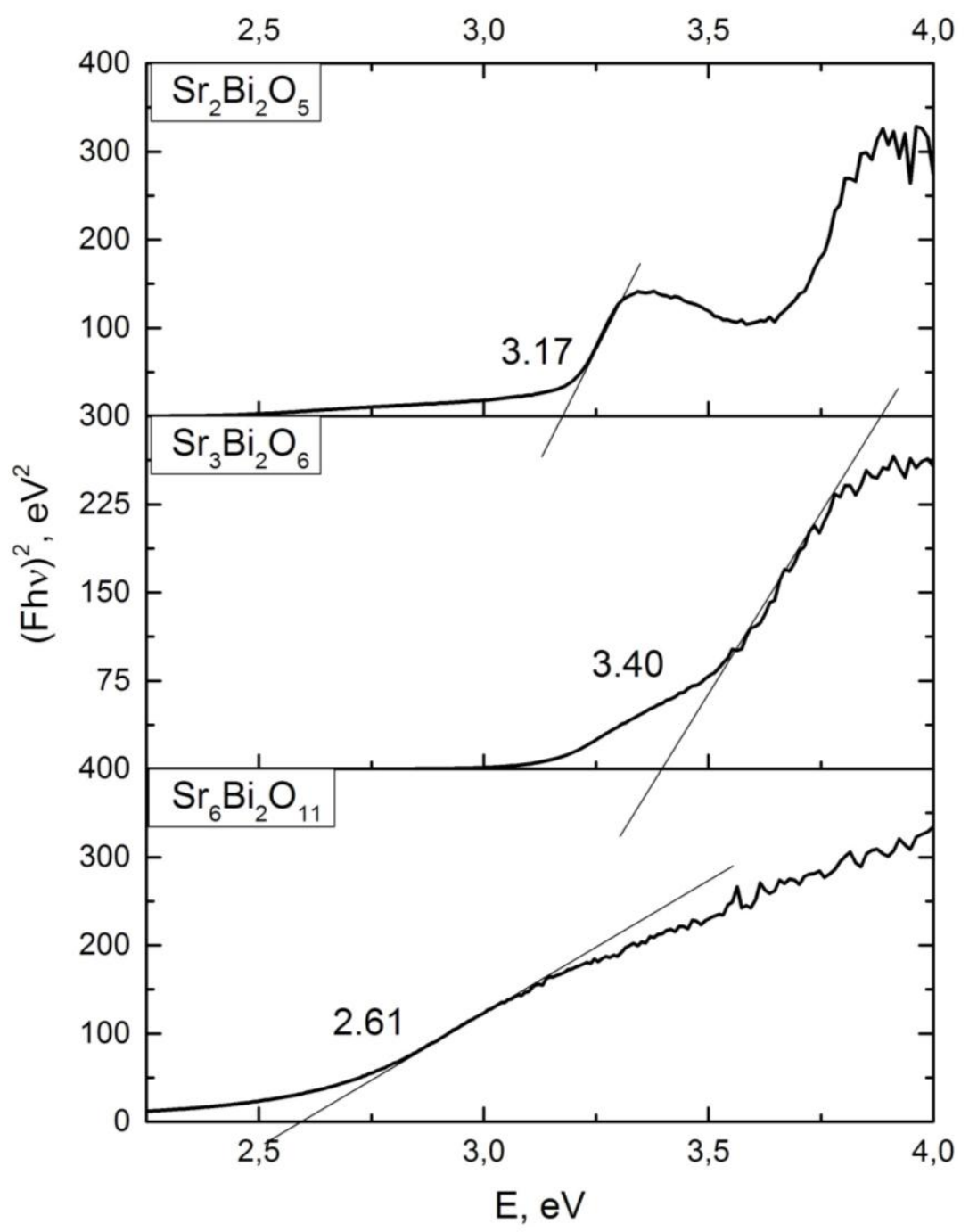


Figure S6. The Tauc plot for all as-prepared samples of the strontium bismuthates

In eqn. Ошибка! Источник ссылки не найден., both $\alpha(h v)$ and $s(h v)$ are linear (Naperian) absorption and liner scattering coefficients, respectively, (commonly accepted unit of measure is $\mathrm{cm}^{-1}$ ), $\mathrm{R}$ and $\mathrm{A}=1-\mathrm{R}$ are the reflectance and absorbance of dispersed samples, respectively, presented in dimensionless units ranging in the $0-1$ interval; the Kubelka-Munk formula transforms $R(h v)$ spectra into $\alpha(h v)$ spectra not exactly, however, as it can be used as a close approximation in the $1>\mathrm{R}>0.2$ range [13] for narrow spectral intervals when the spectral dependence of the scattering coefficient $s(h v)$ can be neglected.

\section{The kinetics of $\mathrm{Sr}_{2} \mathrm{Bi}_{2} \mathrm{O}_{5}$ and $\mathrm{Sr}_{3} \mathrm{Bi}_{2} \mathrm{O}_{6} \mathrm{UV}$ coloration}

Figure $\mathbf{S}$ shows the dependencies of maximal height (points) of Gauss shaped absorption subbands obtained by resolution of experimental spectra of UV-induced color centers into Gauss bands. The set of experimental spectra (Figure 13a, 13b in the Article) were picked up after the set of different exposition times.

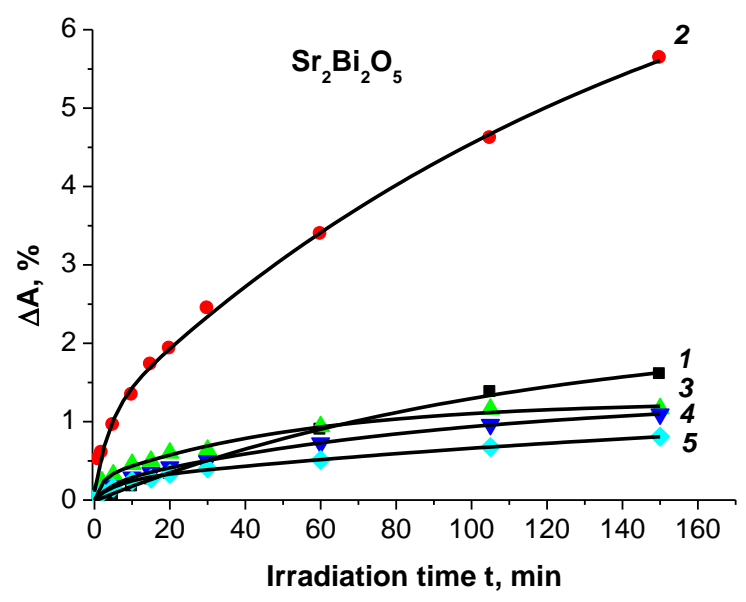

(a)

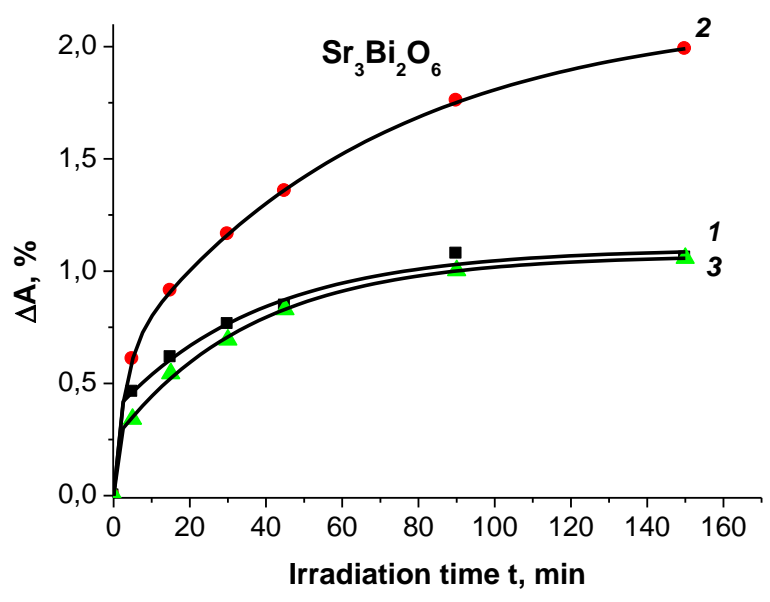

(b)

Figure S7. Kinetics of $\mathrm{Sr}_{2} \mathrm{Bi}_{2} \mathrm{O}_{5}(\mathrm{a})$ and $\mathrm{Sr}_{3} \mathrm{Bi}_{2} \mathrm{O}_{6}$ (b) UV coloration. Ordinates of the points are the heights of the Gaussian-shaped bands at $\mathrm{E}_{\max }: 1.08 \mathrm{eV}(1 \mathrm{in}(\mathrm{a})) ; 1.91 \mathrm{eV}$ (2 in (a)); $2.14 \mathrm{eV}$ (3 in (a)); $2.88 \mathrm{eV}(4 \mathrm{in}(\mathrm{a})) ; 3.11$ $\mathrm{eV}(5 \mathrm{in}(\mathrm{a}))$ and $1.93 \mathrm{eV}(1 \mathrm{in}(\mathrm{b})) ; 2.42 \mathrm{eV}(2 \mathrm{in}(\mathrm{b}))$ and $2.83 \mathrm{eV}(3 \mathrm{in}(\mathrm{b}))$. The solid lines are the approximations of kinetics using eqn. Ошибка! Источник ссылки не найден..

All curves $\Delta \mathrm{A}(\mathrm{t})$ in Figure $\mathbf{S}$ (except for curve $\mathbf{1}$ in (a)) can be fitted more or less tightly by eqn.

Ошибка! Источник ссылки не найден. with four or three variable adjustable parameters from $\mathrm{A}_{1}, \mathrm{~A}_{2}, \tau_{1}$ and $\tau_{2}$ that mean the ultimate coloration level $(\mathrm{A})$ and characteristic coloration times $(\tau)$ for both $(\boldsymbol{1})$ 
and (2) partial kinetics of coloration. The corresponding fitting parameters, correlation coefficients $\mathrm{R}$ and total ultimate coloration levels $\mathrm{A}=\mathrm{A}_{1}+\mathrm{A}_{2}$ are presented in

Table S3.

Table S3. Kinetics parameters of UV-induced Gaussian shaped absorption bands for $\mathrm{Sr}_{2} \mathrm{Bi}_{2} \mathrm{O}_{5}$ and $\mathrm{Sr}_{3} \mathrm{Bi}_{2} \mathrm{O}_{6}$

\begin{tabular}{|c|c|c|c|c|c|c|}
\hline $\begin{array}{c}\text { Sample/Band, } \\
\mathbf{e V}\end{array}$ & $\mathbf{A}_{\mathbf{1}}, \boldsymbol{\%}$ & $\tau_{\mathbf{1}}, \mathbf{m i n}$ & $\mathbf{\mathbf { A } _ { 2 } , \boldsymbol { \% }}$ & $\tau_{\mathbf{2}}, \mathbf{m i n}$ & $\begin{array}{c}\text { Correlation } \\
\text { coefficient/ } \\
\text { Number of } \\
\text { points, } \mathbf{R} / \mathbf{N}\end{array}$ & $\begin{array}{c}\text { Ultimate } \\
\text { coloration } \\
\text { level, } \mathbf{A} \%\end{array}$ \\
\hline $\mathrm{Sr}_{2} \mathrm{Bi}_{2} \mathrm{O}_{5} / 1,08$ & $2.17 \pm 0.09$ & $105 \pm 10$ & $\approx 0$ & - & $0.999 / 11$ & $2.2 \pm 0.1$ \\
\hline $\mathrm{Sr}_{2} \mathrm{Bi}_{2} \mathrm{O}_{5} / 1,91$ & $7.3 \pm 1.1$ & $150 \pm 40$ & $0.9 \pm 0.2$ & $3.8 \pm 1.4$ & $0.998 / 11$ & $8.3 \pm 2.5$ \\
\hline $\mathrm{Sr}_{2} \mathrm{Bi}_{2} \mathrm{O}_{5} / 2.14$ & $1.0 \pm 0.1$ & $54 \pm 10$ & $0.3 \pm 0.1$ & $1.9 \pm 0.8$ & $0.995 / 11$ & $1.3 \pm 0.2$ \\
\hline $\mathrm{Sr}_{2} \mathrm{Bi}_{2} \mathrm{O}_{5} / 2.88$ & $1.1 \pm 0,1$ & $94 \pm 10$ & $0.20 \pm 0.03$ & $4.6 \pm 1.4$ & $0.999 / 11$ & $1.3 \pm 0.1$ \\
\hline $\mathrm{Sr}_{2} \mathrm{Bi}_{2} \mathrm{O}_{5} / 3.11$ & $1.2 \pm 0.4$ & $210 \pm 125$ & $0.23 \pm 0.04$ & $6 \pm 2$ & $0.997 / 11$ & $1.4 \pm 0.4$ \\
\hline $\mathrm{Sr}_{3} \mathrm{Bi}_{2} \mathrm{O}_{6} / 1,93$ & $0.73 \pm 0.06$ & $39 \pm 9$ & $0.37 \pm 0.07$ & 0.05 (fixed) & $0.9956 / 7$ & $1.15 \pm 0.12$ \\
\hline $\mathrm{Sr}_{3} \mathrm{Bi}_{2} \mathrm{O}_{6} / 2.42$ & $1.60 \pm 0.01$ & $67 \pm 2$ & $0.60 \pm 0.02$ & $2.85 \pm 0.019$ & $0.999 / 7$ & $1.02 \pm 0.05$ \\
\hline $\mathrm{Sr}_{3} \mathrm{Bi}_{2} \mathrm{O}_{6} / 2.83$ & $0.83 \pm 0.02$ & $36.6 \pm 2.5$ & $0.24 \pm 0.02$ & 0.05 (fixed) & $0.9992 / 7$ & $1.02 \pm 0.05$ \\
\hline
\end{tabular}

Each of two partial coloration kinetics in eqn. Ошибка! Источник ссылки не найден., i.e. the equation in the form

$$
\Delta \mathrm{A}(t)=A\left(1-e^{-t / \tau}\right)
$$

follows from the simplest mechanism of coloration (see, for example, refs. $[14,15]$ ).

The essential stages of the mechanism of wide band gap semiconductor (SC) UV -coloration includes:

(1) generation of electron-hole $(\mathrm{e}, \mathrm{h})$ pairs via photon absorption in fundamental absorption band;

(2) the trapping of free carriers by proper pre-existing defects $D_{e}$ and $D_{h}$ (with formation color centers of $\mathrm{F}$ type (with trapped electron) or V type (with trapped hole) respectively;

(3) the decay of $\mathrm{F}$ and $\mathrm{V}$ color centers via recombination with photo carriers of opposite sign since thermal decay of deep color centers may be neglected. 
The corresponding set of quasi-chemical equations can be presented as

$$
\begin{array}{cc}
\text { 1. } \mathrm{SC}+\mathrm{h} \nu \rightarrow \mathrm{e}^{-}+\mathrm{h}^{+} \\
\text {2.a. } \mathrm{D}_{\mathrm{e}}+\mathrm{e}^{-} \rightarrow \mathrm{F} & \left(\mathrm{k}_{\mathrm{tr}}\right) \\
\text { 2.b. } \mathrm{D}_{\mathrm{h}}+\mathrm{h}^{+} \rightarrow \mathrm{V} & \left(\mathrm{k}_{\mathrm{tr}}^{*}\right) \\
\text { 3.a. } \mathrm{F}+\mathrm{h}^{+} \rightarrow \mathrm{D}_{\mathrm{e}} & \left(\mathrm{k}_{\mathrm{r}}\right) \\
\text { 3.b. } \mathrm{V}+\mathrm{e}^{-} \rightarrow \mathrm{D}_{\mathrm{h}} & \left(\mathrm{k}_{\mathrm{r}}^{*}\right)
\end{array}
$$

The system of quasi chemical reactions (Eq. Ошибка! Источник ссылки не найден.) should be completed by charge conservation law which for this particular case is presented as:

$$
\left[\mathrm{h}^{+}\right]+[\mathrm{V}]=\left[\mathrm{e}^{-}\right]+[\mathrm{F}]
$$

or after termination of irradiation

$$
[\mathrm{V}]=[\mathrm{F}]
$$

To satisfy the approximation eqn. Ошибка! Источник ссылки не найден. for the kinetics of formation of only one of the color centers (for simplicity and specificity $\boldsymbol{F}$ centers) one should assume that the quasi stationary concentration of photoelectrons $\left(\left[\mathrm{e}^{-}\right]\right)$and photoholes $\left(\left[\mathrm{h}^{+}\right]\right)$remains constant in the course of UV coloration (the latter is possible when appropriate so-called fast recombination centers exist in the solid particle). If so, the mechanism of coloration can then be reduced to the form (eqns. (S7))

$$
\begin{aligned}
& \mathrm{D}_{\mathrm{e}} \rightarrow \mathrm{F} \\
& \mathrm{F}-\mathrm{h}^{+} \rightarrow \mathrm{D}_{\mathrm{e}} \quad \text { (q) }
\end{aligned}
$$

where $\mathrm{p}$ and $\mathrm{q}$ are quasi first-order constants:

$$
\begin{aligned}
& \mathrm{p}=\mathrm{k}_{\mathrm{tr}} \cdot\left[\mathrm{e}^{-}\right] \\
& \mathrm{q}=\mathrm{k}_{\mathrm{r}} \cdot\left[\mathrm{h}^{+}\right]
\end{aligned}
$$

Taking into account that the total concentration of electron traps $\left[\mathrm{N}_{0}\right]=\left[\mathrm{D}_{\mathrm{e}}\right]+[\mathrm{F}]=$ const, the kinetics of coloration $[\mathrm{F}](\mathrm{t})$ at $[\mathrm{F}](0)=0$ may be easily obtained in the form:

where

$$
[\mathrm{F}](t)=\left[\mathrm{N}_{0}\right] \frac{\mathrm{p}}{\mathrm{p}+\mathrm{q}}\left(1-\mathrm{e}^{-\mathrm{t} / \tau}\right)
$$




$$
\tau=\frac{1}{p+q}
$$

So, in terms of the simple mechanism (eqn. Ошибка! Источник ссылки не найден.), the approximation of experimental kinetics of photocolration (eqn. Ошибка! Источник ссылки не найден.) on the assumption that $\Delta \mathrm{A}$ is directly proportional to the concentration of $\mathrm{UV}$-induced color centers can be rationalized as follows: the ultimate coloration level

$$
\Delta \mathrm{A}=k\left[\mathrm{~N}_{0}\right] \frac{\mathrm{p}}{\mathrm{p}+\mathrm{q}}
$$

The characteristic coloration time is given by Eq. Ошибка! Источник ссылки не найден..

Thus, the mechanism treated here describes the existence of saturation of coloration at prolonged irradiation and allows to consider the difference of ultimate coloration levels for different color centers (or different samples) as the result of variation in the concentration of the corresponding pre-existing defects $\left(\mathrm{N}_{0}\right)$ and in the probability of carriers trapping (p) by deep traps and recombination decay of color centers (q). In particular, the absence of coloration (the case of $\mathrm{Sr}_{6} \mathrm{Bi}_{2} \mathrm{O}_{11}$, Figure 13c, Article) can be the result of:

(1) extremely low concentration of deep traps for carriers of a given sign $\left(\left[\mathrm{N}_{0}\right] \approx 0\right)$ or keeping in mind the condition (eqn. Ошибка! Источник ссылки не найден.) the absence of deep traps for carriers of opposite sign;

(2) high rate of decay of a given color centers via recombination with photocarriers of opposite sign: $\mathrm{q} \gg \mathrm{p}$.

Actually, the coloration kinetics for almost all color centers bands is described by the biexponential approximation (eqn. Ошибка! Источник ссылки не найден. in Article). Obviously, the existence of "slow" and "fast" stages of formation of a given color center detected via monitoring of the growth of the corresponding separate absorption band cannot be described by the simple mechanism of eqn. Ошибка! Источник ссылки не найден.. A clarification of this obscurity is beyond the scope of the article. However, without resorting to an ad hoc assumption concerning some special behavior of the photocarriers concentration in the course of irradiation of the strontium bismuthates (eqns. Ошибка! Источник ссылки не найден.) it should be pointed out that the carriers generation is sufficiently inhomogeneous in the case of excitation of a solid particle in its fundamental absorption band when the inverse linear absorption coefficient $1 / \alpha$ is less than the characteristic particle size $\mathrm{d}$ and, in turn, $1 / \alpha$ is larger than the diffusion length $\mathrm{L}$ of the carriers (or the 
depth of the space charge layer) [15]. In this typical case $(1 / \alpha>L)$, the effect of trapping and recombination of photocarriers by surface defects and adsorbed entities changes drastically the rate of formation and ultimate level of the color centers near the surface region with depth close to $\mathrm{L}$, compared with the bulk region with depth close to $1 / \alpha$. Despite the fact that there is no sharp boundary between the two mentioned space regions in illuminated particles, their existence probably manifests itself as apparent "slow" and "fast" stages of photocoloration (eqn. Ошибка! Источник ссылки не найден. in article) similar to the photocoloration kinetics of Al-doped $\mathrm{TiO}_{2}$ [15].

\section{References}

[1]. A. A. Kharlamov, R. M. Almeida, J. Heo, Vibrational spectra and structure of heavy metal oxide glasses, J. Non-Crystal. Solids, 202 (1996) 233-240.

[2]. K. H. Rieder, B. A. Weinstein, M. Cardona, H. Bilz, Measurement and comparative analysis of the second-order Raman spectra of the alkaline-earth oxides with a NaCl structure, Phys. Rev. B, 8 (1973) 4780-4786.

[3]. C. Gautam, A. K. Yadav, V. K. Mishra, K. Vikram, Synthesis, IR and Raman spectroscopic studies of $(\mathrm{Ba}, \mathrm{Sr}) \mathrm{TiO}_{3}$ borosilicate glasses with addition of $\mathrm{La}_{2} \mathrm{O}_{3}$, Open J. Inorg. Non-met. Mat., 2 (2012) 47-54.

[4]. A. Dutta, P. K. Mukhopadhyay, T. P. Sinha, S. Shannigrahi, A. K. Himanshu, P. Sen, S. K. Bandyopadhyay, $\mathrm{Sr}_{2} \mathrm{SmNbO}_{6}$ perovskite: Synthesis, characterization and density functional theory calculations, Mat. Chem. Phys., 179 (2016) 55-64.

[5]. R. J. Betsch, W. B. White, Vibrational spectra of bismuth oxide and the sillenite-structure bismuth oxide derivatives, Spectrochim. Acta Part A: Molec. Spectros., 34 (1978) 505-514

[6]. R. V. Kumar, A. Edukondalu, B. Srinivas, G. Sriramulu, M. G. Krishna, K. S. Kumar, FTIR and Raman studies on $25 \mathrm{Bi}_{2} \mathrm{O}_{3}-(75-\mathrm{x}) \mathrm{B}_{2} \mathrm{O}_{3}-\mathrm{xBaO}$ glasses, AIP Conference Proceedings, 1665 (1995) 070038.

[7]. S.N. Narang, N.D. Patel, V.B. Kartha, Infrared and Raman spectral studies $\alpha-\mathrm{Bi}_{2} \mathrm{O}_{3}$, J. Molec. Struct., 327 (1994) 221-235.

[8]. I. Ardelean, S. Cora, V. Ioncu, Structural investigation of $\mathrm{CuO}-\mathrm{Bi}_{2} \mathrm{O}_{3}-\mathrm{B}_{2} \mathrm{O}_{3}$ glasses by FT-IR, Raman and UV-VIS spectroscopies, J. Optoelectr. Adv. Mater., 8 (2006) 1843-1847.

[9]. S. Hazra, S. Mandal, A. Ghosh, Properties of unconventional lithium bismuthate glasses, Phys. Rev. B, 56 (1997) 8021-8025. 
[10]. F. He, Z. He, J. Xie, Y. Li, IR and Raman spectra properties of $\mathrm{Bi}_{2} \mathrm{O}_{3}-\mathrm{ZnO}-\mathrm{B}_{2} \mathrm{O}_{3}-\mathrm{BaO}$ quaternary glass system, Amer. J. Anal. Chem., 5 (2014) 1142-1150.

[11]. P. C. Thomas, M. K. Kumar, V. U. Nair, Raman spectra of $\mathrm{Bi}-\mathrm{Sr}-\mathrm{Ca}-\mathrm{Cu}-\mathrm{O}$ high temperature superconductors, J. Mater. Sci., 32 (1997) 2171-2175.

[12]. A.B. Murphy, Band-gap determination from diffuse reflectance measurements of semiconductor films, and application to photoelectrochemical water-splitting, Sol. Energy Mater. Sol. Cells, 91 (2007) 1326-1337.

[13]. F. C. Jentoft, Ultraviolet-visible-near infrared spectroscopy in catalysis: Theory, experiment, analysis, and application under reaction conditions. Review article, Adv. Catal., 52 (2009) 129211

[14]. V. N. Kuznetsov, A. V. Emeline, A. V. Rudakova, M. S. Aleksandrov, N. I. Glazkova, V. A. Lovtcius, G. V. Kataeva, R. V. Mikhaylov, V. K. Ryabchuk, N. Serpone. Visible-NIR light absorption of titania thermochemically fabricated from titanium and its alloys; UV- and visiblelight-induced photochromism of yellow titania, J. Phys. Chem. C, 117 (2013) 25852-25864

[15]. L. Shaitanov, A. Murashkina, A. Rudakova, V. Ryabchuk, A. Emeline, Y. Artemev, G. Kataeva, N. Serpone. UV-induced formation of color centers in dispersed $\mathrm{TiO}_{2}$ particles: Effect of thermal treatment, metal (Al) doping, and adsorption of molecules, J. Photochem. Photobiol. Sci.. 354 (2018) 33-46. 